\title{
Beiträge zur Kenntnis der Physiologie und Pathologie der Muskelinnervation.
}

\author{
Von \\ Adalbert Gregor und Paul Schilder. \\ Mit 64 Textfiguren. \\ (Aus der psychiatrischen und Nervenklinik der Universität Leipzig [Direktor: \\ Geh. Rat Prof. Dr. Flechsig].)
}

(Eingegangen am 12. Dezember 1912.)

\section{Untersuchungsmethode.}

Die vorliegenden Untersuchungen werden zu dem Zwecke unternommen, um eine Methode für die Neuropathologie in ausgedehnterem Maße zu verwerten, welche für das Studium der Physiologie der Muskelinnervation sich als außerordentlich fruchtbar erwiesen hat: die Untersuchung der Muskelaktionsströme mit dem Saitengalvanometer. Die Durchführung einer derartigen Untersuchung erschien um so mehr geboten, als alle bisher zum Studium der Muskelfunktion beim Menschen verwendeten Methoden nur auf eine genaue Aufnahme und Registrierung des motorischen Effektes ausgehen, sei es, daß sie die Muskelarbeit bestimmen (Ergographie) oder einen Ausdruck für die Dickenveränderung des Muskels zu gewinnen suchen (Myogramm), die Bewegungsform und ihre zeitlichen Verhältnisse (Isserlin, Pfahl) oder nur letztere bei wiederholter Willküraktionen registrieren (tapping tests). In allen diesen Fällen kann über den Innervationsproze $B$ nur indirekt geurteilt und auf die Erregung des Muskels durch den Nerven nur vermutungsweise geschlossen werden. Bei dem Mangel adaequater Aufnahmen des wesentlichen Vorganges gewann auf diesem Gebiete eine rein symptomatologische Betrachtungsweise Platz und äußerte sich in zum Teil recht unfruchtbaren Aufnahmen von Zitterbewegungen und Haltungsformen. Die mittels des Saitengalvanometers gewonnene Kurve gestattet aber einen direkten Einblick in den Mechanismus der Innervation. Piper hat durch eine Reihe von Versuchen wahrscheinlich gemacht, daß die durch die Aktionsströme hervorgerufenen Schwankungen der Galvanometersaite direkt auf Innervationsimpulse bezogen werden können und $\mathrm{da} \beta$ die natürliche Kontraktion der Muskeln vom Centralnervensystem in der Weise besorgt wird, daß es beim Menschen etwa 50 Impulse pro Sekunde zum Muskel schickt. 
Die bestehende Lücke war für die Kenntnis der normalen Muskelfunktion vielleicht weniger empfindlich, weil mit den noch unbekannten Prozessen ohne weiteres wie mit Konstanten gerechnet werden konnte. Aber schon die Versuche Pipers, welche für die Physiologie nach manchen Richtungen abschließende Erkenntnisse brachten, ergaben, daß dieser Innervationsprozeß sogar beim Normalen nicht unter allen Umständen in unabänderlicher Weise abläuft und unsere Vergleichsversuche an normalen Individuen wiesen neue Differenzen auf.

Auf pathologischem Gebiete sind von der Methode nach zwei Richtungen Aufschlüsse zu erwarten. 1. Sollte sie zunächst da an Stelle der bisherigen Methoden treten, wo diese mangels motorischen Effektes keine Anwendung finden konnten und so die erste Frage, ob überhaupt eine Innervation vorliegt, strittig ist; 2 . ihrem spezifischen Wesen entsprechend bei Störungen der Motilität im weitesten Sinne eventuelle Abweichungen von der normalen Innervation aufdecken und ihre Analyse ermöglichen.

Da bei der Schwierigkeit der Technik die Beurteilung der Resultate eine genaue Kenntnis der Versuchsbedingungen zur Voraussetzung hat, so wollen wir im folgenden eine Darstellung unserer sich an Piper anschließenden Methodik geben und auch die dabei in Betracht zu ziehenden Fehlerquellen erörtern.

Die Ableitung der Muskelströme geschah mittels Tonelektroden, zu denen Glastrichter von $21 / 2 \mathrm{~cm}$ Öffnungsweite dienten. Diese wurden mit Ton, der von physiologischer Kochsalzlösung durchtränkt war, gefüllt, über dem Ton stand eine Schicht konzentrierter Zinksulfatlösung, in welche mit Polklemmen versehene Zinkstäbe tauchten. Derartige Elektroden bewährten sich uns besser als die gleichfalls von Pi per empfohlenen, bei denen das Zinksulfat durch eine Schweinsblase abgeschlossen ist. Die Elektroden wurden auf die gut durchfeuchtete Haut aufgesetzt, und zwar leiteten wir vorwiegend von der Beugemuskulatur des Unterarmes, vom Biceps brachii oder Quadiceps cruris ab.

Wo willkürliche Muskelbewegungen erfolgten, ließen wir teils an einem handlichen, zylinderförmigen Dynamometer drücken, teils am Ergographen arbeiten. Bei einzelnen Kranken kamen wir aber dadurch besser zum Ziele, daß wir sie veranlaßten, die Hand einer zweiten Person zu drücken. In einer Reihe von Versuchen wurde die Leistung durch einen Duboisschen Ergographen aufgenommen. In Fällen, wo es weniger auf die Registrierung der Muskelarbeit als auf die Bewegungsform ankam, ließen wir an einem wenig belasteten Mossoschen Ergographen ziehen und registrierten An- und Abstieg auf einem Kymographion.

Zur Aufnahme der Stromschwankungen diente ein großes Saitengalvanometer von Edelmann. Wir arbeiteten anfangs mit einer 
Platinsaite von 2-3 $\mu$ Dicke und einer Empfindlichkeit von $10^{-4}$ Volt und mit einer ca. $1 \mu$ dicken Quarzsaite und einer Empfindlichkeit von 10-6 Volt. Die Aufnahme der Saitenschwingungen geschah photographisch mittels des von Edelmann für elektrokardiographische Zwecke hergestellten Apparates.

Bei der Würdigung der im folgenden zu beschreibenden Versuche und deren Resultaten sind die beschriebenen Versuchsbedingungen zu berücksichtigen, namentlich möchten wir hervorheben, daß der dabei gewonnene Einblick in das elektromuskuläre Geschehen durch die gewählte Empfindlichkeit des Apparates begrenzt ist. Die von uns ermittelten Einheiten gelten also bloß unter Zugrundelegung dieses Maßes, und es bleibt zunächst fraglich, wie weit eine weitere Analyse möglich ist, ob also die in unseren Kurven registrierten Prozesse einer weiteren Zerlegung zugänglich sind. Diese wäre etwa in dem Sinne zu denken, daß, wo wir einen Stillstand des Galvanometerfadens registrierten, doch noch ein Ablauf von Impulsen stattfand, deren Intensität aber zu gering war, um die Galvanometersaite von der verwendeten Dicke und Spannung in Schwingung zu versetzen.

Damit ist natürlich aber nicht unseren Feststellungen über pathologische Abweichungen der Boden entzogen, da wir ja stets von dem Vergleiche der bei Kranken beobachteten Befunde mit den unter gleichen Versuchsbedingungen bei Normalen erhaltenen Ergebnissen ausgehen. Es kann sich also nicht darum handeln, ob im gegebenen Falle überhaupt eine krankhaft geänderte Innervation vorliegt, sondern ob sie in vollständig erschöpfender Weise durch die Aufnahme dargestellt wird.

$\mathrm{DaB}$ die Untersuchung pathologischen Materiales hier wesentlich größere Schwierigkeiten zu überwinden hat, als bei Gesunden, ergibt sich fürs erste daraus, daß normale Versuchspersonen zunächst als Einheit gelten dürfen und die bei ihnen gewonnenen Resultate eine gegenseitige Kontrolle bilden, während jeder Krankheitsfall als Besonderheit gelten muß, und daß selbst bei klinisch gleicher Krankheit die Intensität des Prozesses eine Identifikation erschwert, selbst wenn man von der zunächst noch fraglichen Annahme ausgeht, daß die Innervationsprozesse bei klinisch gleicher Krankheitsqualität in gleicher Weise betroffen werden. Fürs zweite sind die Variationsmöglichkeiten der Versuche, welche beim Normalen eine Kontrolle der für das einzelne Individuum gewonnenen Resultate gestatten, durch die begrenzte Leistungsfähigkeit der Kranken beschränkt, wodurch die Untersuchung beider Gruppen eine prinzipiell andere wird. Wäbrend wir beim Normalen von einer bestimmten, aus dem Ziele der Untersuchung folgenden Versuchsanordnung ausgehen, der die Versuchspersonen zu entsprechen haben, müssen wir uns bei pathologischem Material den Leistungen der 
Kranken selbst anpassen. Der stets notwendige Vergleich mit dem Normalen zwingt dann, die Kontrollversuche entsprechend zu modifizieren und den Leistungen der Kranken anzugleichen.

Mit den zuletzt gegebenen Erörterungen haben wir bereits die Fehlerquellen der Untersuchung berührt. Die von uns registrierte Stromintensität (i) ist zunächst von der Stromspannung (e) abhängig, die sich in manchen Fällen als zu klein, unserer Beobachtung entziehen kann. Als zweites Moment kommt nach der Formel $i=\frac{\mathrm{e}}{\mathrm{w}}$ auch der Widerstand in Betracht, welcher schon nach den Versuchen beim Normalen als sehr wesentlicher Faktor imponierte. Da der Widerstand wie bekannt, von Individuum zu Individuum variiert und in seiner Größe nicht ermittelt werden kann, ist es unstatthaft, nach den Kurven auf die Größe der Stromschwankungen zu schließen und die Kurvenzacken verschiedener Individuen streng quantitativ zu vergleichen. Eine Berechnung des Widerstandes im menschlichen Körper nach der Methode von Kohlrausch ist am Edelmannschen Apparate leicht durchzuführen, sie ergibt uns aber bloß einen Ausdruck für den Widerstand zwischen den beiden Ableitungsstellen, nicht aber für jenen Widerstand, dem die im Muskel entstehenden elektromotorischen Kräfte begegnen. Wieviele Stromschleifen bei gleicher Muskelaktion und gleichen Elektroden dieselben passieren, sowie welchen Ausdruck eine im Muskel bestehende Potentialdifferenz erhält, hängt von der Stellung der Elektroden zum Nerveneintritte ab. Auf die nicht ganz übereinstimmenden anatomischen Verhältnisse ist es zurückzuführen, daß die Lage der optimalen Ableitungsstellen von Individuum zu Individuum wechselt, so daß namentlich bei Kranken mit geringer Kontraktionskraft die geeigneten Anlegestellen erst durch wiederholte Versuche ermittelt werden müssen.

Weiter wird der Vergleich von Kurven verschiedener Individuen dadurch erschwert, daß wie später noch zu erörtern, die Wellenform bei verschiedenen Personen zu verschiedener Zeit durch Ermüdungseinflüsse abgeändert wird und diese Veränderungen bei einzelnen überraschend früh auftreten. Ein Vergleich der Schwingungszahlen erscheint daher nur für streng analoge Strecken der Kurve statthaft, so etwa für den Anfangsteil bei ansteigender Leistung.

Eine Schwierigkeit, der man bei der Aufnabme schwacher Kontraktionen begegnet, wie z. B. bei vielen Tremorformen oder willkürlichen Kontraktionen paretischer Muskeln ist die Zählung der Kurvenzacken, da dieselben in diesen Fällen eine geringe Höhe erreichen. Diese Fehlerquelle ist am besten durch unmittelbaren Vergleich mit der entsprechenden Kontrollkurve zu beherrschen, da so mindestens der Maßstab der Beurteilung gleichgemacht werden kann. Die erwähnte Schwierigkeit ist auch in den vorliegenden physiologischen Untersuchungen wieder- 
holt aufgetreten und hat zu widersprechenden Annahmen über die Impulsrhythmen geführt. Dittlers Vorschlag, . sich ausschließlich beim Zählen an glatte, nebenzackenfreie Teile zu halten, ist entschieden zu beherzigen und wurde im folgenden, soweit das Material gestattete, auch befolgt. Im übrigen wurden alle im Kurvenbilde vorhandenen

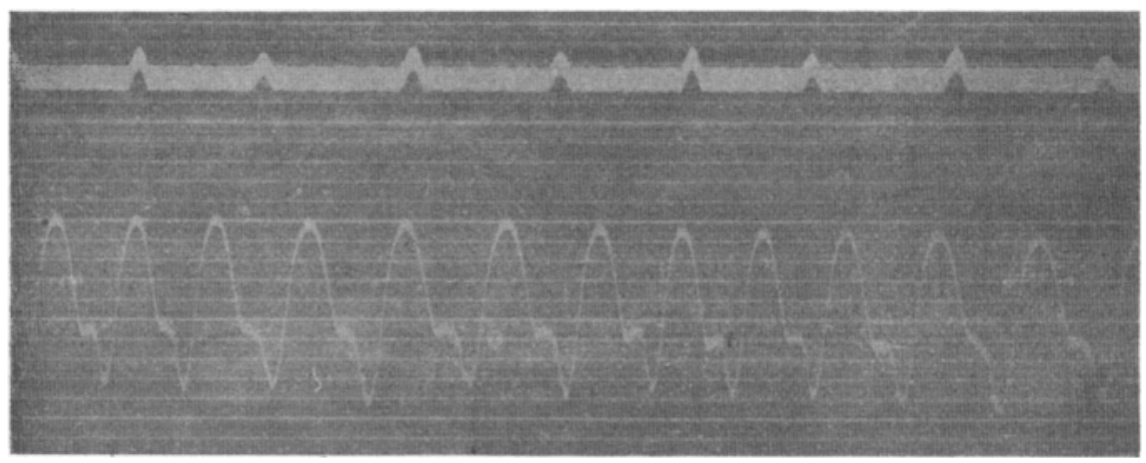

Fig. 1. Große Seitenschwankungen durch mechanischen Effekt des Fußklonus bedingt. Wirkung der Aktionsstromschwankungen tritt daneben fast ganz zurück. Zeit in $1 / \overline{0}$ Sekunde, wie bei allen hier abgebildeten Kurven.

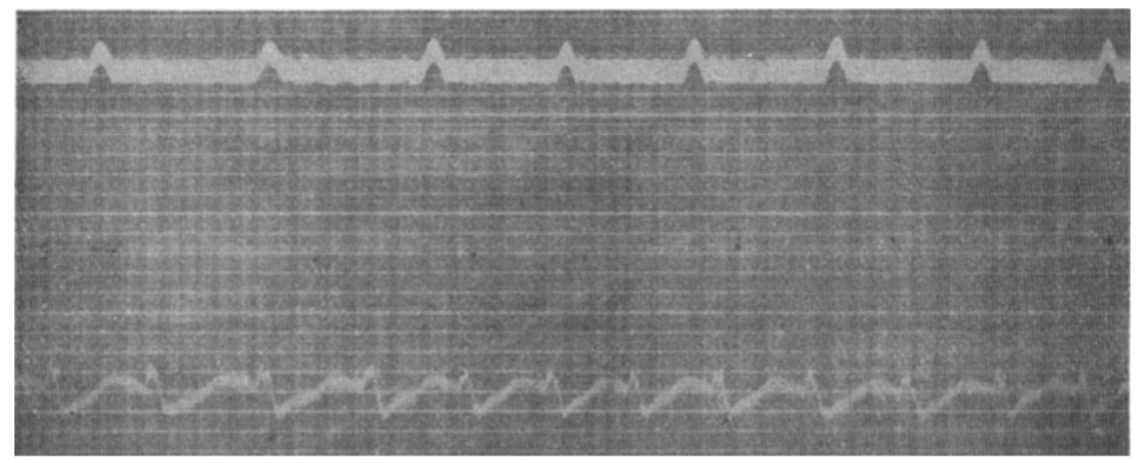

Fig. 2. Große Wellen stellen den mechanischen Effekt des Fußklonus vor, die kleinen Zacken Wirkungen der Aktionsstromschwankungen.

Zacken bei der Zählung berücksichtigt und dieses Prinzip in der Arbeit einheitlich durchgeführt.

Im Verlaufe der Untersuchung wurden wir auf eine Reihe von Kunstprodukten aufmerksam, die oft täuschende Ähnlichkeit mit dem Ausdrucke von Aktionsströmen haben. 1. Schwankungen im Nullstrome (Potentialdifferenz zwischen den Elektroden bzw. den Hautstellen, von denen abgeleitet wird). Sie entstehen durch Verschiebung der Elektroden an der Haut, welche durch Kontraktionen des Muskels von dem abgeleitet wird, sowie durch Körperbewegung verursacht werden (Fig. 1 u. 2). 2. Schwankungen der Saite, die durch for tgeleitete 
Erschütterungen des Bodens zustandekommen. Derartige Saitenschwankungen entstehen bei der üblichen Montierung des Apparates auf einen festen Tisch schon bei relativ geringfügigen Bewegungen der im Zimmer befindlichen Personen. Sie sind natürlich durch Arbeiten in 2 Zimmern zu beschränken, doch bleiben dann immer noch die vom Motor ausgehenden Erschütterungen, die, wie wir uns überzeugen konnten, auch nicht durch die in der Technik verwandten Schall- und Erschütterung dämpfenden Platten beseitigt werden können. Am sichersten ist dieser Fehlerquelle durch Montierung des Apparates an die Wand zu

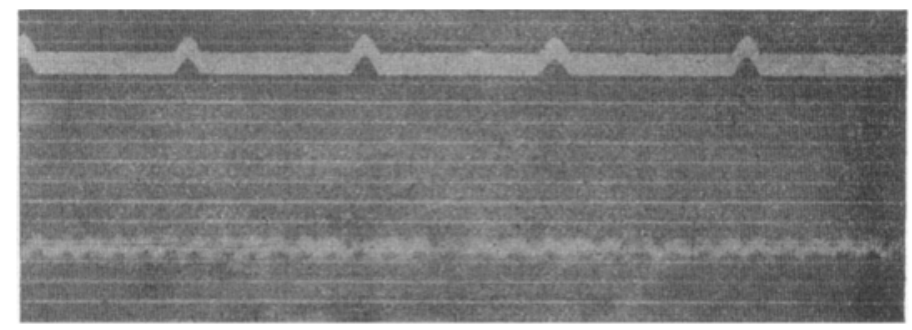

Fig. 3. Durch den Gang des Elektromotors bedingte Saitenschwankungen.

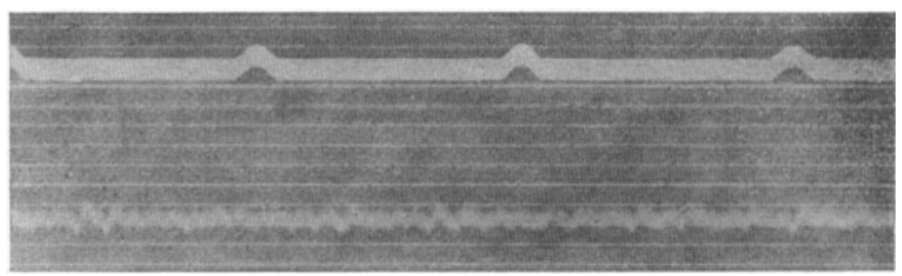

Fig. 4. Aktionsstromschwankungen durch künstliche Schwingungen (wie in Fig. 3) entstellt.

begegnen, wie es auch von Samojloff für elektrokardiographische Zwecke empfohlen wurde. In unseren Vorversuchen, bei denen das Saitengalvanometer auf einem Tisch neben dem Motor stand, konnten wir häufig das Auftreten von kontinuierlichen Saitenschwingungen beobachten, die sich im Kurvenbilde als Wellenzüge von relativ hoher Frequenz (30 in der Sekunde) darstellten. (Fig. 3.) Derartige Kunstprodukte könnten unter Umständen zur Annahme nicht vorhandener oder nicht ableitbarer Ruheströme führen. Bei tatsächlich vorhandenen und im Kurvenbilde auch nachweisbaren Aktionsstromschwankungen bewirkten sie eine Entstellung des Bildes (vgl. Fig. 4).

3. Wesentlich leichter sind Kunstprodukte zu entdecken, die durch Manipulationen am photographischen Apparate (Abstellen des Motors) oder durch Öffnung und Schließung anderer Stromquellen (elektromagretische Zeitregistrierung) zustandekommen. 


\section{Untersuchungen am Normalen.}

Zur Beurteilung der Ergebnisse an pathologischem Materiale erwies es sich als notwendig, eine Reihe von Kontrollversuchen an normalen Versuchspersonen anzustellen, deren Resultate wir, soweit sie die Kenntnisse über die Innervationsprozesse beim Normalen erweitern, gesondert behandeln wollen. Wir geben im folgenden eine Tabelle,

Impulsfrequenz in $1 / 5$ Sekunden.

\begin{tabular}{|c|c|c|c|c|c|c|c|c|c|c|c|c|}
\hline \multicolumn{4}{|c|}{ Normale Individ. } & \multicolumn{5}{|c|}{ Hemiplegie, gesunde Seite } & \multicolumn{2}{|c|}{ Chorea } & \multirow{2}{*}{\begin{tabular}{|c}
$\begin{array}{c}\text { Mult. } \\
\text { Skler. }\end{array}$ \\
S.
\end{tabular}} & \multirow{2}{*}{$\frac{\begin{array}{c}\text { Depres } \\
\text { sion }\end{array}}{\mathbf{H} .}$} \\
\hline W. & J. & K. & Sch. & N. & Th. & B. & K. & M. & V. & W. & & \\
\hline 11 & 13 & 10 & 8 & 14 & 11 & 11 & 7 & 12 & 11 & 15 & 11 & 9 \\
\hline 11 & 14 & 10 & 8 & 11 & 15 & 10 & 9 & 13 & 9 & 12 & 9 & 9 \\
\hline 13 & 13 & 10 & 8 & 11 & 11 & 10 & 10 & 12 & 9 & 12 & 9 & 8 \\
\hline 13 & 12 & 10 & 9 & 11 & 10 & 10 & $9^{1} / 2$ & 12 & 9 & 12 & 12 & 10 \\
\hline 12 & 12 & 9 & 8 & 10 & 11 & 10 & $10^{1 / 2}$ & 13 & 8 & 10 & 12 & 11 \\
\hline 12 & 13 & I1 & 8 & 11 & 14 & 10 & 10 & 11 & 10 & 9 & 11 & 10 \\
\hline 11 & 12 & 10 & 8 & 10 & 15 & 9 & 9 & 10 & 8 & 8 & 11 & 10 \\
\hline 12 & 13 & 10 & 8 & 10 & 11 & 9 & 9 & 10 & 7 & 10 & 14 & 9 \\
\hline 10 & $12^{1 / 2}$ & & 7 & 10 & 10 & 9 & 9 & 10 & 9 & 12 & 11 & 9 \\
\hline 12 & $121 / 2$ & & 8 & 10 & 9 & 10 & 9 & 11 & 6 & 12 & 9 & 10 \\
\hline 11 & 12 & & 7 & 12 & 11 & 10 & 10 & 11 & 9 & 11 & 10 & 10 \\
\hline 11 & 11 & & 8 & 11 & 8 & 9 & 9 & 12 & 8 & 11 & 7 & 10 \\
\hline 11 & 10 & & 8 & 11 & 7 & 8 & 9 & 12 & 8 & 10 & 10 & 9 \\
\hline 11 & & & 8 & 11 & & 7 & 8 & 12 & 9 & 13 & 8 & 9 \\
\hline 9 & & & 8 & & & 8 & 9 & 10 & 7 & 8 & 10 & 10 \\
\hline 10 & & & 7 & & & & 9 & 10 & 7 & 10 & 9 & 10 \\
\hline 11 & & & 9 & & & & 9 & & 7 & 7 & 6 & 11 \\
\hline & & & 9 & & & & 9 & & 10 & 12 & & 10 \\
\hline & & & 8 & & & & & & 9 & 11 & & 7 \\
\hline & & & 9 & & & & & & 7 & 10 & & 9 \\
\hline & & & 8 & & & & & & 5 & & & 10 \\
\hline & & & 9 & & & & & & 7 & & & 8 \\
\hline & & & 8 & & & & & & 4 & & & 7 \\
\hline & & & 8 & & & & & & & & & 8 \\
\hline & & & 8 & & & & & & & & & \\
\hline & & & 8 & & & & & & & & & \\
\hline & & & 8 & & & & & & & & & \\
\hline
\end{tabular}

welche die Impulsfrequenzen in aufeinanderfolgenden 5 Sekunden bei 4 normalen Individuen veranschaulicht und gliedern diesen Werten jene an, welche wir bei 4 Hemiplegikern auf der gesunden Seite, 3 Choreafällen, 1 multiplen Sklerose und 1 Depressionszustande mit leichter motorischer Hemmung fanden. In allen Versuchen hatte die Versuchsperson am Dynamometer einen kräftigen Druck auszuüben. Die Aufnahme mittels des Saitengalvanometers erfolgte in einer Phase, in der keine 
subjektive Ermüdung bestand und auch das Dynamometer keine Verminderung der Ausschlagsgröße anzeigte.

Geht man von der heute vielfach anerkannten Vorstellung Pipers aus, daß die normale Impulsfrequenz in der Fünftelsekunde 10 beträgt, so findet man bei den 2 an erster Stelle stehenden normalen Individuen eine entschiedene Abweichung nach oben. Diese ist nur zum Teil dadurch bedingt, daß bei der Zählung auch größere Nebenzacken berücksichtigt wurden. Wählt man nach dem Vorgange Dittlers nur von Nebenzacken freie Stellen, so findet man einen Rhythmus von 10-11 Wellen vorwiegend in der zweiten Hälfte der Reihen, in deren Anfang aber auch von Nebenzacken ganz freie Stellen mit einer Impuls. frequenz 12 .

Wir sehen ferner, daß die herangezogenen Krankheitsformen einen normalen Innervationsrhythmus zeigen; von vornherein war ein solcher Befund nicht einmal für die gesunde Seite der Hemiplegiker zu erwarten.

Besonders auffällig sind die ganz niedrigen Werte der Versuchsperson Sch. Zahlreiche mit ihr angestellte Versuche lehrten, daß diese langsamen Impulsrhythmen der Ausdruck von Ermüdung sind, die durch die gewöhnlichen Merkmale (Ermüdungsempfindungen einerseits, Abnahme der Leistung anderseits) nicht angezeigt wird. Durch diese Annahme, welche in den später zu besprechenden Versuchen weitere Begründung findet, erklärt sich auch der Abfall der Werte bei einzelnen Patienten, für welche eine abnorm frühe Ermüdung durchaus plausibel ist. Von Interesse ist der Befund, daß die Ermüdungserscheinungen auch bei den sehr muskulösen Versuchspersonen W. und J. merklich sind. Zieht man das Mittel aus der ersten und zweiten Hälfte der Reihen, so findet man in beiden Versuchen einen deutlichen Abfall der Impulsfrequenz, bei $J$ von 11,7 auf 11,3 , bei $W$. von 10,7 auf 10,4 .

Da wie ausgeführt, objektiv kaum zu kontrollierende und nur aus dem Kurvenbild zu entnehmende Ermüdungserscheinungen die gewöhnliche Aufnahme von Dauerkontraktionen komplizieren, so mußte eine besondere Versuchsanordnung gewählt werden, um reine, d.h.durch keine Ermüdungssymptome abgeänderte Bilder zu erhalten. Zu diesem Zwecke nahmen wir bei vollkommen ausgeruhten Muskeln den Anstieg einer Leistung auf. Die nähere Versuchsanordnung bestand darin, daß der Aufnahmeapparat in Tätigkeit gesetzt wurde, bevor noch die Versuchsperson mit dem Dynamometerdruck begann. 3 derartige, bei der Versuchsperson Sch. angestellte Versuche ergaben nachstehende Zahlenwerte:

I. Versuch: $8,9,11,9,9$.

II. $\quad, \quad 9,8,9,10,10,9$.

III. $\quad, \quad 7,9,10,10,10,10,9,10,10,10,10,10,10,9,10$, $10,8,8,9$. 
Wir finden also an dem sicher nicht ermüdeten Muskel normale Frequenzzahlen. Fassen wir die letzte, etwas längere Reihe ins Auge, so fällt ein Anstieg von relativ niedrigen Werten zu solchen von normaler Größe auf. Gegen das Ende wird aber wieder eine Abnahme der Impulsfrequenz für die $1 / \mathrm{s}$ Sekunde merklich. Eine Betrachtung der Kurvenformen zeigt, daß die weniger frequenten Wellen auch niedriger sind als die rasch aufeinanderfolgenden auf der Höhe der Leistung. Dasselbe Verhältnis zwischen den Amplituden war auch in anderen Versuchen zu beobachten, bei welchen die Aktionsströme für mehr weniger rasch aufeinanderfolgende Bewegungen aufgenommen wurden, wie bei der Arbeit am Ergographen, beim Öffnen und Schließen der

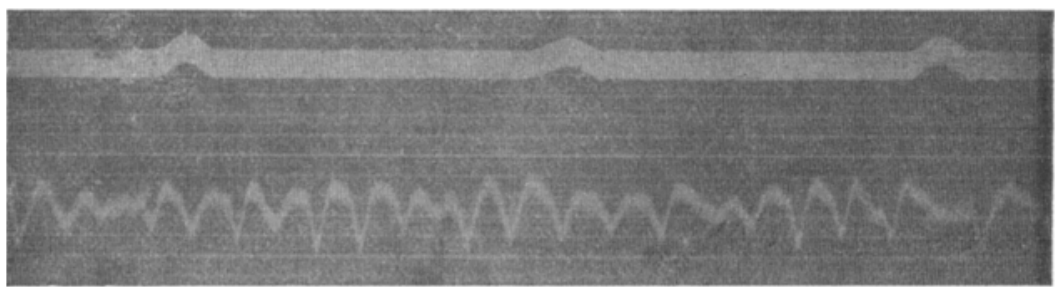

Fig. 5. Aktionsstromschwankungen bei zunehmendem Druck.

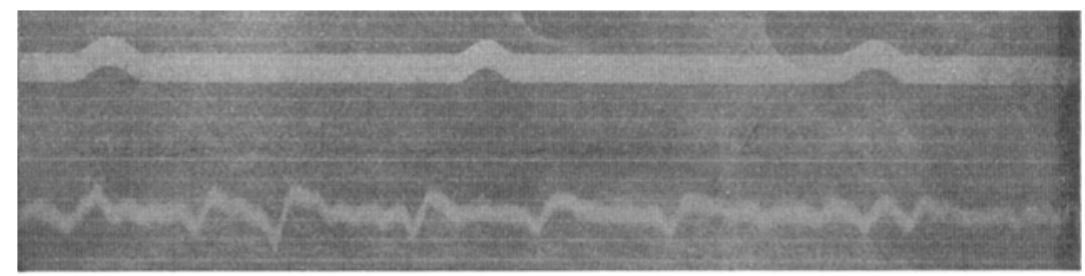

Fig. 6. Aktionsstromschwankungen bei Entspannung.

Faust, beim Beugen und Strecken der Hand. Aus Fig. 10, welche einen derartigen Versuch wiedergibt, ist eine deutliche Zunabme der Wellenfrequenz mit dem Fortschreiten der Leistung zu entnehmen.

Der hier beschriebene Wechsel in der Wellenform im Anstieg der Leistung läßt besondere Verhältnisse der Wellenfrequenz auch für den Abstieg, d.h.für den Nachlaß eines bestimmten Druckes erwarten. Zwei derartige an der Versuchsperson Sch. vorgenommene Versuche ergaben nachstehende Resultate:

I. Versuch: $10,10,10,9,10,9,9,91 / 2,10,9,9,91 / 2,8,10,10,7$, $8,9,8,9,8,7^{1} / 2,7^{1} / 2,7,8,8,9,8,7,8,6,7,7,6,7,6$, $7,8,7,8,6,7,5,6,6,8,7,6,6,4,7,4,6,5,6,4$.

II. Versuch: $7,8,9,10,10,8,7^{1} / 2,10,81 / 2,10,7,10,9,11,8,8,11$, $11,9,7,7,6,7,5,5,4$. 
Diese Werte zeigen deutlich eine starke Abnahme der Impulsfrequenz mit Nachlaß des anfänglich aufgewendeten Druckes an. Eine derartige Kurve, die wir als Entspannungskurve bezeichnen wollen, ist nach dem 2. der ausgeführten Versuche in Fig. 6 wiedergegeben. Sie zeigt im Vergleich zu der bei maximaler Kontraktion gewonnenen Kurve (Fig. 5) ein auffallendes Gepräge, nämlich relativ niedrige Wellenhöhe, Pausen nach den einzelnen, scharf markierten Erhebungen, Nebenzacken, zum Teil deutliche biphasische Schwankungen. Wie aus der Figur kenntlich wird, sind die Zeiten, in denen der Galvanometerfaden sich bei dieser Aktion in Ruhe befindet, viel zu kurz, um auf ein will-

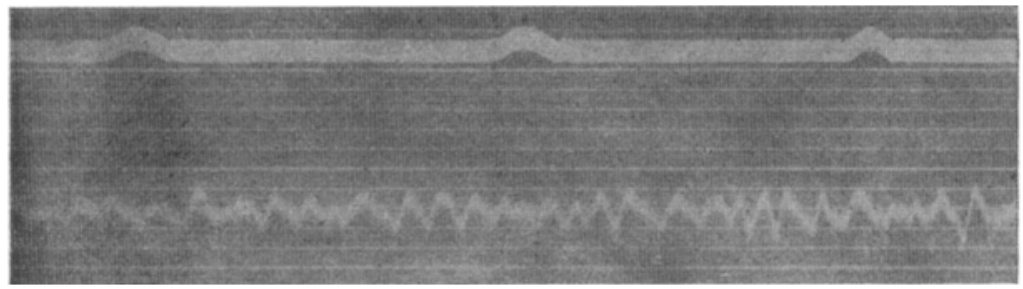

Fig. 7. Aktionsstromschwankungen auf der Höhe der Leistung.

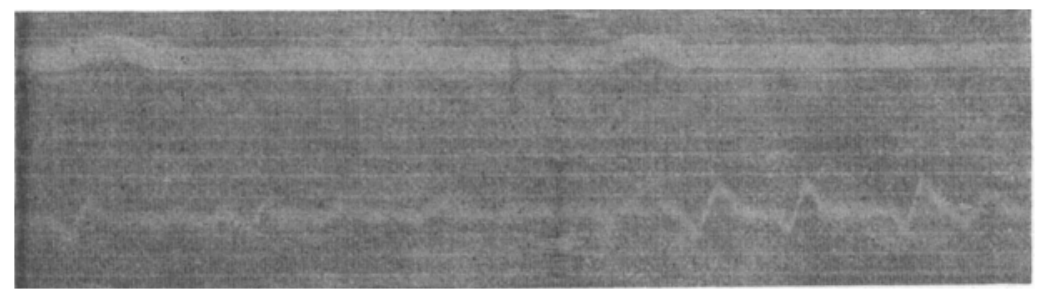

Fig. 8. Aktionsstromschwankungen bei Ermüdung.

kürliches Nachlassen in der Innervation zurückgeführt werden zu können. Im Gegensatz zu derartigen Kurvenformen stehen jene, die bei Versuchen gewonnen wurden, in denen ein plötzliches Sistieren des aufgewendeten Druckes am Dynamometer stattfand. Unter diesen Bedingungen ist eine scharfe Unterbrechung des Wellenzuges zu beobachten.

Die besprochenen Erfahrungen über den Einfluß von Ermüdung auf die Aktionsstromschwankungen veranlaßten uns, die Entwicklung der Ermüđung und ihren Ausdruck im Kurvenbilde näher zu untersuchen. $\mathrm{Zu}$ diesem $Z_{\text {wecke }}$ wurden einige Reihen von Versuchen angestellt, in denen die Versuchspersonen am Ergographen ermüdet wurden, worauf erst die Registrierung der Saitenschwankungen erfolgte. Eine typische Ermüdungskurve ist in Fig. 8 wiedergegeben. Der Vergleich mit der zugehörigen Normalkurve (Fig. 7), welche der Höhe der Leistung im 
gleichen Versuche entspricht, zeigt: starke Abnahme der Wellenzahl, Pausen zwischen den einzelnen Schwankungen, auffälligen Wechsel zwischen niedrigen und hohen Wellen, stellenweise mehr, weniger lange Züge von Nebenwellen (vgl. auch Piper).

Das am besten geeignete Mittel, die Entwicklung der Ermüdung zu verfolgen, ist der Ergographenversuch in Verbindung mit der Aufnahme der Aktionsströme. Hierbei konnte es natürlich weniger interessieren, die Kurvenformen nach Ausbildung stärkerer Ermüdung zu studieren, als die Zeit des Eintrittes der Ermüdungserscheinungen genauer zu verfolgen. Bei einem derartigen Versuche wurden die Muskelaktionsströme im Verlaufe der ersten 8 Züge aufgenommen. Das Tempo betrug 1 Sekunde, die Belastung $5 \mathrm{~kg}$. Die Kurvenbilder zeigen in diesem Versuche Wellenzüge von $2^{1 / 2}-3$ Fünftelsekunden Dauer. Die den einzelnen Zügen am Ergographen entsprechenden Gruppen begannen meist mit wenigen kleinen Erhebungen, die rasch in Wellen von großer Amplitude übergingen. Der Abfall erfolgte vorwiegend plötzlich, zuweilen traten aber gegen Ende der Reihe auch noch einige kleine Wellen auf; die Zählung der Schwankungen begann bei den großen Wellen und erstreckte sich jedesmal auf die Zahl der in $2 / 5$ Sekunden abgelaufenen Schwankungen, die bezüglichen Werte lauten:

$\begin{array}{ll}8 & 7 \\ 9 & 8 \\ 8 & 6 \\ 8^{1} / 2 & 8 \\ 7^{1} / 2 & \\ 7 & 5^{1} / 2 \\ 8 & 7 \\ 7^{1} / 2 . & \end{array}$

In einem zweiten Versuche hatte dieselbe Versuchsperson längere Zeit unter gleichen Bedingungen am Ergographen zu arbeiten, der Versuch wurde noch vor Eintritt der Ermüdung abgeschlossen, auch zeigte die Ergographenkurve keine Abnahme der Hubhöhen, am Saitengalvanometer wurden die Aktionsschwankungen zu Anfang und zu Ende des Versuches aufgenommen. Die Form der Wellenzüge stimmte mit jenen des ersten Versuches überein. Die in gleicher Weise wie im ersten Versuche durchgeführte Zählung ergab nachstehende Resultate:

$\begin{array}{ll}9 & 8 \\ 8 & 6^{1} / 2 \\ 7^{1} / 2 & 7 \\ 8 & 7 \\ 9 & 8 \\ 7 & 7 \\ 9 & 8\end{array}$




$\begin{array}{ll}7 & 6 \\ 71 / 2 & 5 \\ 61 / 2 & 7\end{array}$

Mit einer anderen Versuchsperson wurde zunächst eine sog. unendliche Ergographenkurve entworfen. Sie hatte unter Bedingungen zu arbeiten, bei denen Ermüdung in kürzerer Zeit nicht erfolgen konnte, nämlich jede 7. Sekunde einen Zug auszuführen. Die Aufnahme der Aktionsströme erfolgte fortlaufend. Bei der Zählung wurden die ganzen Wellengruppen berücksichtigt, auch hier bedeuten die nebeneinanderstehenden Werte die Schwingungszahlen für aufeinanderfolgende $1 / 5$ Sekunden.

$\begin{array}{rrrrr}- & - & 10 & 5 & \\ 11 & 7 & 10 & 6 & \\ 10 & 9 & 10 & 7 & \\ 11 & 10 & 9 & 8 & 5 \\ 10 & 12 & 8 & 8 & \\ 11 & 10 & & & \\ 10 & 10 & 7 & & \\ 9 & 10 & 7 & & \\ 8 & 7 & 7 & 6 & \\ 10 & 10 & 7 & 7 & \\ 9 & 7 & 6 & 6 & \\ 7 & 6 & 5 & & \\ 6 & 7 & & & \end{array}$

Die Tabelle zeigt, daß bei langsamerem Tempo auch die Kontraktionsdauer eine wesentlich längere ist, und daß die Differenz zwischen der I. und II. Hälfte der Wellenzahl jeder einzelnen Gruppe eine größere ist als in den ersten Versuchen. Die durchschnittliche Wellenfrequenz ist in diesem Versuche höher als in den beiden anderen, was auf individuellen Verschiedenheiten der beiden Versuchspersonen beruht. Dagegen stimmen aber beide Versuchspersonen darin überein, daß trotz Mangel subjektiver und objektiver Ermüdungserscheinungen die Wellenfrequenz schon nach den ersten Zügen am Ergographen abnimmt und daß diese Abnahme im Laufe der Arbeit immer stärker hervortritt. Das Kurvenbild des letzten Versuches stimmt mit den beschriebenen beiden früheren überein. Auch hier nimmt die Amplitude rasch zu, dagegen fällt den niedrigen Wellen am Ende der Gruppe ein viel breiterer Raum zu $(2 / 5-3 / 5$ Sekunden $)$. Da diese den Typus der oben beschriebenen Entspannungskurven zeigen, so kann man sagen, daß bei langsamerem Arbeitstempo die verlängerte Kontraktionsdauer vorwiegend durch eine Vergrößerung der Entspannungszeit bedingt wird.

Endlich wurde bei derselben Versuchsperson B. ein Ermüdungsversuch vorgenommen, in dem sie bei raschem (Sekunden)-Tempo am 
Ergographen arbeitete und Anfang und Ende der Leistung am Galvanometer aufgenommen wurden. Das Kurvenbild stimmt mit den Ergebnissen bei der Versuchsperson S. überein. In der folgenden Tabelle stehen links die Zahlenwerte für die Schwankungen in aufeinanderfolgenden $1 / 5$ Sekunden, rechts die Gesamtzahl der Wellen.

\begin{tabular}{rrr}
12 & 10 & 22 \\
- & - & - \\
13 & - & - \\
12 & 10 & 23 \\
11 & 8 & 19 \\
13 & 9 & 22 \\
11 & 8 & 19 \\
13 & 7 & 20 \\
\hline 8 & 6 & 14 \\
9 & 6 & 15 \\
10 & 8 & 18 \\
9 & 7 & 16.
\end{tabular}

Auffällig ist, daß vom zweiten Zuge an, die Neigung zur Abnahme der Wellenfrequenz besteht. Nach Eintreten der Ermüdung (unter dem Strich verzeichnete Zahlenwerte) ist die Abnahme der Wellenfrequenz noch deutlicher.

Die besprochenen Ergographenversuche ließen es notwendig erscheinen, Bewegungsformen einer genaueren Analyse zu unterziehen, derart, daß den einzelnen an den Kurven der Aktionsströme unterschiedenen Abschnitten bestimmte Phasen der Bewegung zugeordnet werden konnten. Als Vorarbeit dazu, galt es zu ernntteln, wie weit die Galvanometersaite überhaupt auf derartige ohne eigentlichen Kraftaufwand ausgeführte Bewegungen, wie wir sie hier im Auge hatten, ansprach. Die Versuche fielen durchaus positiv aus, wir erhielten deutliche Saitenschwankungen für einfache, in kurzer Zeit ohne Belastung des bewegten Gliedes ausgeführte Bewegungen. Die mit Pipers Befunden übereinstimmenden Kurvenbilder zeigten dabei einen Tetanus von bekannter Wellenfrequenz (50 Schwingungen in der Sekunde) an. Als Bewegungen wurden gewählt: Strecken und Beugen eines Fingers, Schließen und Öffnen der Faust, Beugung und Streckung der Hand. Die Analyse derartiger Bewegungsformen ließ einen Einblick in die Innervationsverhältnisse synergistisch und antagonistisch wirkender Muskeln erwarten. Eine derartige Versuchsreihe wurde in der Weise durchgeführt, daß mittels eines Federsignales auf den ablaufenden Film neben der Zeitmarke auch noch die Dauer des Faustschlusses bzw. der Handbewegung bezeichnet wurde. Zwei Versuche ergaben nachstehende Werte: 


\begin{tabular}{|c|c|c|c|c|c|c|c|}
\hline \multicolumn{4}{|c|}{ Faustschlu\& und -öffnen } & \multicolumn{4}{|c|}{ Handbeugen und -strecken } \\
\hline 10 & 11 & 9 & 6 & 12 & 12 & 12 & \\
\hline 9 & 10 & 9 & 7 & 13 & 10 & 10 & 10 \\
\hline 13 & 11 & 7 & 9 & 13 & 11 & 10 & 8 \\
\hline 9 & 10 & 10 & & 9 & 8 & 7 & 7 \\
\hline 10 & 10 & 7 & 10 & 13 & 12 & 9 & \\
\hline 12 & 12 & 10 & & 10 & 11 & 11 & 10 \\
\hline \multirow[t]{7}{*}{13} & 10 & 8 & & 11 & 11 & 7 & 10 \\
\hline & & & & 10 & 10 & 10 & 7 \\
\hline & & & & 13 & 10 & 6 & 8 \\
\hline & & & & 8 & 13 & 10 & \\
\hline & & & & 11 & 12 & 9 & \\
\hline & & & & 9 & 9 & & \\
\hline & & & & $10^{1 / 2}$ & 7 & & \\
\hline
\end{tabular}

Man findet auch hier, wie in den Ergographenversuchen, eine größere Wellenfrequenz für die ersten, eine geringere für die späteren Zeitabschnitte. Ein Vergleich der aufeinanderfolgenden Wellengruppen mit den Marken für die Dauer der einzelnen Leistungen läßt erkennen, daß in beiden Versuchsreihen die Wellenzüge länger waren als die objektiv wahrnehmbaren Akte, und zwar war das Überdauern der Aktionsstromwellen besonders auffällig bei der Faustöffnung. Die in dieser Phase auftretenden Wellen waren merklich niedriger und weniger frequent, als die während des Faustschlusses registrierten. Ein ähnliches Ergebnis brachte ein gleicher Versuch bei der Versuchsperson W. Hier waren jedoch beim Schließen und Offnen der Faust kontinuierliche Wellenzüge von einer Phase bis zur nächsten zu verfolgen; dies Verhalten ist durch das Kurvenbild Fig. 9 veranschaulicht. Darin entsprechen die über den beiden kürzeren, tiefer gelegenen horizontalen Linien gelegenen Wellen zwei aufeinanderfolgenden Faustschlüssen, während die längere Horizontallinie die Dauer des Faustöffnens anzeigt. In der Kurve sind auch in dieser Phase deutlich niedere und wenig frequente Wellen wahrzunehmen.

Da wir dabei von der Volarfläche des Armes ableiteten, sind die beobachteten Aktionsstromschwankungen beim Öffnen der Faust auf die Tätigkeit synergistisch wirkender Muskeln zu beziehen. Auffällig ist, daß die Beugemuskel in ihrer Funktion als Synergisten beim Öffnen der Faust einen anderen Innervationsrhythmus aufweisen wie beim Faustschluß, wo sie als Agonisten funktionieren.

In einer anderen Versuchsreihe suchten wir die Analyse antagonistischer Muskelaktion zu gewinnen, dabei wurden bei gestreckt gehaltenen Fingern Beugungen und Streckungen im Handgelenke vorgenommen. Bei dieser Form von Haltung und Bewegung war für die Streckung in diesem Falle eine synergistische Mitwirkung von an der 

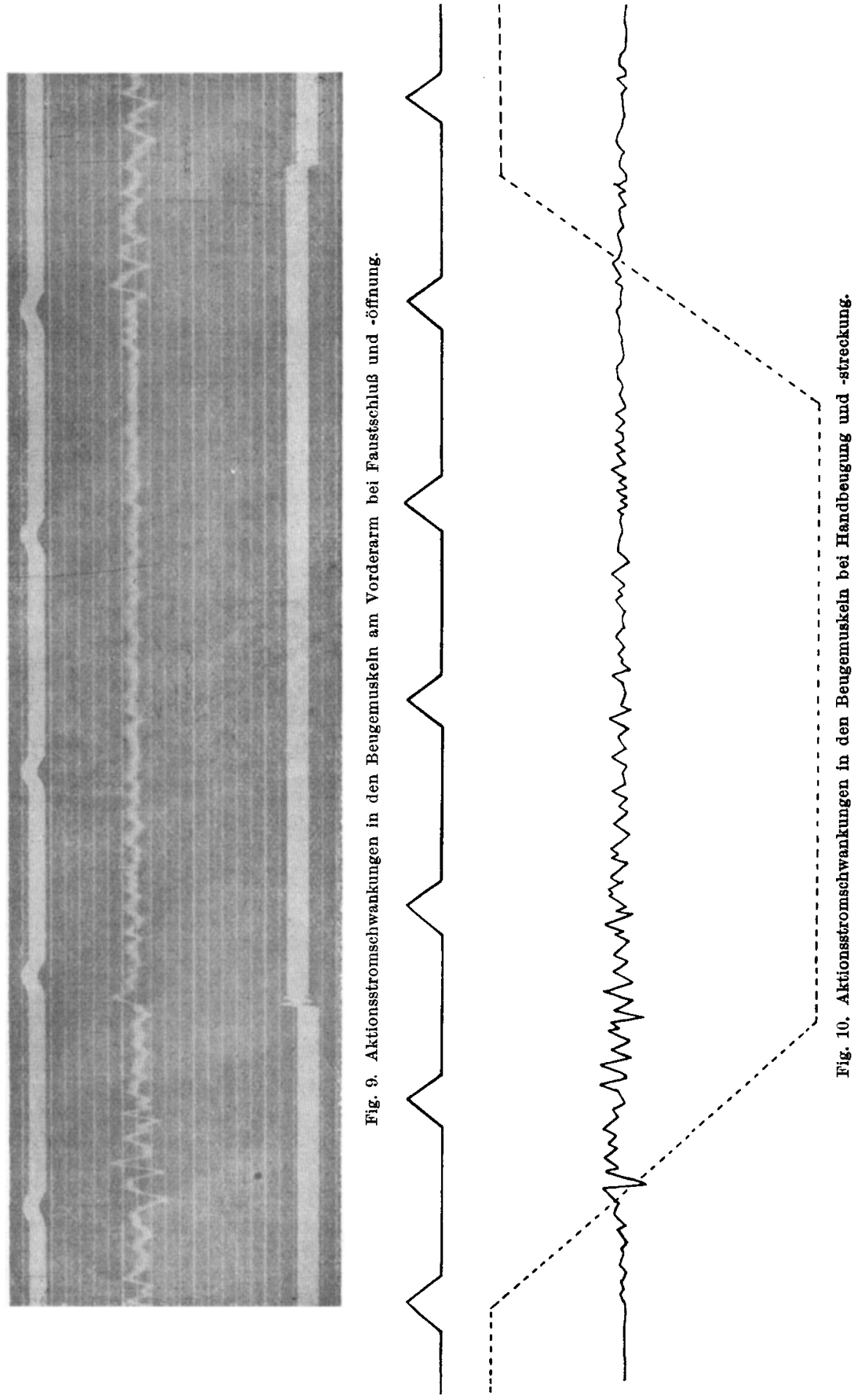
Volarfläche des Armes gelegenen Muskeln, an denen abgeleitet wurde, auszuschließen. Diese standen vielmehr den bei der Streckung innervierten Muskeln als Antagonisten gegenüber. Der Versuch entspricht also jenem, durch den Hering in einem Falle von Lähmung der Handstrecker das Schlaffbleiben der Beuger bei intendierter Streckung nachzuweisen suchte.

In diesen Versuchen kam zu der bisherigen Anordnung (Saitengalvanometer) auch noch die Registrierung der einzelnen Bewegungsphasen auf der rotierenden Kymographiontrommel unter gleicher zeitlicher Markierung hinzu. Die in einem solchen Versuche enthaltenen Werte sind in der folgenden Tabelle zusammengestellt. Ihre ersten Spalten enthalten wie die früheren die Wellenzahlen für aufeinanderfolgende Fünftelsekunden. Die letzte Spalte gibt in $1 / 5$ Sekunden an, wie lange Zeit Beuger und Strecker gleichzeitig innerviert werden.

\begin{tabular}{|c|c|c|c|c|c|c|c|}
\hline \multicolumn{7}{|c|}{ Impulsfrequenz in $1 / \%$ Sekunden } & \multirow{3}{*}{\begin{tabular}{|}
$\begin{array}{c}\text { Dauer der Beuger- } \\
\text { innervation wahrend der } \\
\text { Streckung in Fünftel- } \\
\text { sekunden }\end{array}$ \\
2
\end{tabular}} \\
\hline \multicolumn{4}{|c|}{ Beugung } & \multicolumn{3}{|c|}{ Streckung } & \\
\hline 9 & 11 & 7 & 7 & 7 & 6 & & \\
\hline 6 & 9 & 12 & 11 & 7 & 8 & 6 & 3 \\
\hline 7 & 12 & 11 & 10 & 6 & 5 & & 2 \\
\hline 8 & 11 & 8 & 10 & 9 & 7 & & 2 \\
\hline 7 & 10 & 11 & 9 & 6 & 5 & & 2 \\
\hline 8 & 10 & 9 & 9 & 7 & 5 & & 2 \\
\hline 8 & 11 & 11 & 11 & 9 & 7 & & 2 \\
\hline
\end{tabular}

Aus der Tabelle folgt, daß Schwankungen der Aktionsströme die ganze Zeit der Beugung ausfüllen und noch während der Streckung auftreten, und zwar sind 2--3 Fünftelsekunden der Streckung von Schwankungen der Aktionsströme der Beuger erfüllt. Aus der ersten Spalte ist zu entnehmen, daß die Impulsfrequenz sich nach $1 / 5$ Sekunde zum Maximum erhebt. Nach der Kurve des Kymographions beträgt die Zeit des Anstieges bis zur maximalen Kontraktion ebensoviel. Ob beide Zeiten sich tatsächlich völlig decken, ist noch nicht entschieden, da wir zunächst nicht wissen, ob mit Beginn der Schwankungen des Aktionsstromes der äußere Effekt einsetzt, doch können wir diese eventuelle Zeitverschiebung vernachlässigen, da es sich dabei nach eigenen und fremden Versuchen, in denen die Kurve der Aktionsstromschwankungen auch den mechanischen Effekt der Bewegung anzeigt, dabei nur um minimale zeitliche Differenzen (Hundertel von Sekunden, die hier nicht ins Gewicht fallen) handelt. Die durchschnittlich $2^{1 / 2}$ Fünftelsekunden dauernde maximale Kontraktion ist jedenfalls von einem raschen Impulsrhythmus erfüllt. Die zuletzt auftretenden langsamen Wellenzüge entfallen auf Anstieg und Höhe der Streckung. Fig. 10 enthält die Kopie der einem 
solchen Zuge am Ergographen entsprechenden Wellen. Daneben sind die zeitlichen Verhältnisse der Ergographenleistung in gestrichelter Kurve wiedergegeben. Die Kurve zeigt deutlich die Aktionsstromschwankungen in den Beugemuskeln während der Streckung an und beweist damit, daß entgegengesetzt der Hering-Sherringtonschen Anschauung, bei der Bewegung der Antagonisten auch eine Innervation der Agonisten erfolgt'1).

Die hier im einzelnen beschriebenen Versuche haben unsere Kenntnisse über das Verhalten des Aktionsstromes bei der Innervation der Muskulatur vom Normalen in mancher Hinsicht erweitert.

Wir konnten in zahlreichen Versuchen nachweisen, daß der normale Innervationsrhythmus, welcher nach den Angaben Pipers in der Abgabe von 50 Impulsen in der Sekunde besteht, eigentlich nur für den Anstieg einer Leistung gilt, da vielfach schon auf der Höhe derselben eine Abänderung des Rhythmus eintritt, die nach den bei ausgeprägter Ermüdung erhaltenen Kurven auf Ermüdungseinflüsse zurückzuführen ist. Da aber unter den geläufigen Begriff der Ermüḍng bewußte zentripetale Erregungen bzw. deren Wirkung auf die Leistung fallen, Ermüdungsempfindungen in dem Stadium der Leistung, das wir hier im Auge haben, entschieden fehlen, so liegt es nahe, nach der abgeänderten Form des Rhythmus einen rein motorischen Ermüdungstypus anzunehmen. In der Geschwindigkeit, mit der sich dieser entwickelt, sind zwischen den einzelnen Versuchspersonen individuelle Differenzen nachzuweisen. Wir haben daher bereits anderenorts ${ }^{2}$ ) die Abgrenzung eines besonderen Arbeitstypus in Betracht gezogen.

Die Versuche, welche sich mit der Form des Abschlusses einer Leistung befaßten, haben als bemerkenswertes Resultat die Aufstellung eines besonderen Rhythmus von Impulsen ergeben, die durch relativ geringe Wellenfrequenz, niedrige Amplitude, Nebenzacken und Pausen charakterisiert ist. Dieser Entspannungstypus tritt beim Übergang einer stärkeren zu einer schwächeren Muskelanspannung oder beim allmählichen Aufgeben eines stärkeren Druckes hervor.

Das Studium aufeinanderfolgender rhythmischer Bewegungen zeigt, daß den Wellenzügen von großer Amplitude und rascher Frequenz, welche der Höhe der Kontraktion entsprechen, in mehr oder weniger großer Anzahl kleinere und weniger rasche Wellen vorangehen. Bei antagonistischen Bewegungen erfolgt während des Anspannens der Antagonisten (Strecker) eine Innervation der Agonisten (Beuger).

1) Eine Überleitung von Aktionsstromschwankungen der Strecker kommt für diese Versuchsanordnung nicht in Frage. Das geht schon daraus hervor, daß in denjenigen Teilen der Kurve, die der maximalen Streckung entsprechen, Aktionsstromwellen überhaupt nicht nachweisbar sind.

2) Münch. med. Wochenschr. 1912. Nr. 52. 


\section{Chorea und Athetose.}

Fall I. A. W., Lehrling, 16 Jahre. 1910 Gelenkrheumatismus, seither Zuckungen von choreiformem Charakter. Aufnahme den 16. Aug. 1912. Rechtsseitige Hemichorea mit reichlichen Zuckungen (es überwiegen klonische Zuckungen von kurzer Dauer). Adiadochokinese, Hypotonie und Ataxie angedeutet. Mitbewegungen von der gesunden zur kranken Seite, homolaterale Mitbewegungen der kranken Seite. Sprache durch Spontanzuckungen behindert, Adiadochokinese dieser angedeutet. Neurologischer Befund im übrigen normal. Innere Organe: Mitralinsuffizienz.

Diagnose: Chorea minor.

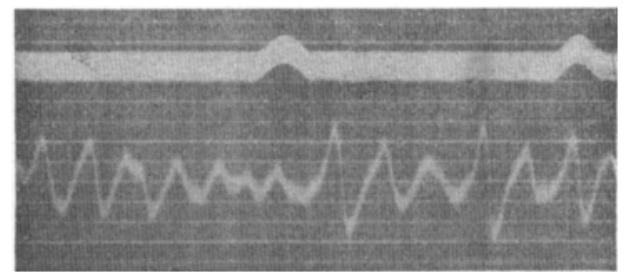

Fig. 11. Fall I. Chorea minor. Unterarmbeuger. Verlängerung der Dauer der einzelnen Stromschwankungen.

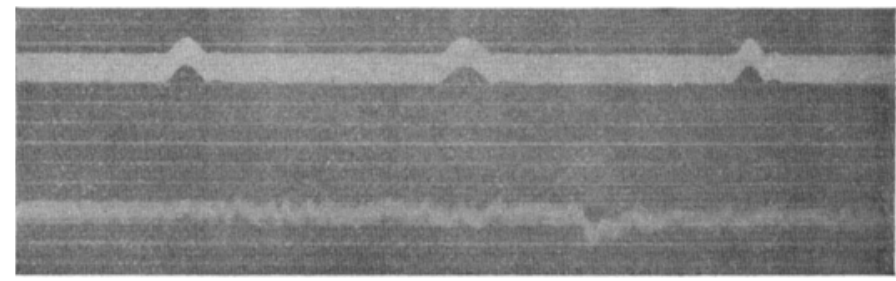

Fig. 12. Fall I. Choreatische Zuckung. Die Zuckung ist in eine Reihe von Impulsen zerlegbar.

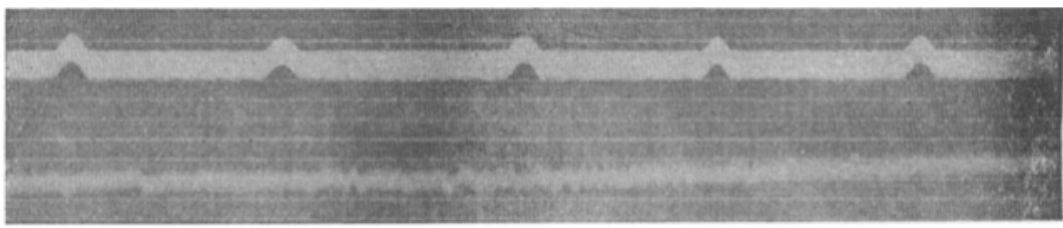

Fig. 13. Fall I. Choreatische Zuckung.

Die Aufnahme der Willküraktion der kranken Seite ergab: 131 $)$, 13, $12,13,14,13,15,15,16,12,12,12,15,13,13,16,13,15,14,16,15$, $12,14,13,13,12,11,11$ (Unterarmbeuger ${ }^{2}$ ).

1) Falls nicht anders bemerkt, gibt die einzelne Zahl die Frequenz der Wellen pro $1 / 5$ Sekunde an.

2) Wir gebrauchen Unterarmbeuger im Sinne von ,die am Unterarm gelegenen Beugemuskeln“. 
Nach dem Eintritt der Ermüdung waren die Werte: 7, 7, 8, 7, 9, $8,7,9,7,8,6,9,7,7,7,5,7,5,8$. Dabei ist bemerkenswert, daß die Verringerung der Innervationsimpulse in einzelnen $1 / 5$ Sekunden mit einer Verlängerung der Dauer der Einzelschwankung des Fadens einhergehen kann, so folgten in der $1 / 5$ Sekunde, welche nur 6 Schwingungen in der 1/5 Sekunde zeigte, die Schwankungen ohne Pause aufeinander (Fig. 11).

Die Zahlen für die Willküraktion der gesunden Seite lauten: 15, 12, 12, 12, 14, 8, 10, 12, 12, 11. Nach Eintritt der Ermüdung: 9, 8, $9,8,9,7,6,9,7$.

Es wurden mehrere choreatische Zuckungen aufgenommen (von den Unterarmbeugern), doch gelang es nur, Teile der Zuckungsdauer einwandfrei darzustellen. Wir erhielten von vier Zuckungen folgende Werte: I. 12, 7; II. 12, 7; III. 11; IV. 12. (Fig. 12 u. 13.)

Fall II. C. W., Lackierer, 49 Jahre, keine Heredität. Seit 6 Wochen Nervenzucken, rechts stärker als links. Hatte mit Blei zu tun, früher Bleivergiftung: Ver-

Fig. 14. Fall II. Choreatische Zuckung.

stopfung, Kopfschmerzen. Jetzt auch Schmerzen im rechten Arm, Kribbeln im rechten Arm und Bein. Untersuchung vom 16. Okt. 1912: Innere Organe: Blasendes systolisches Geräusch an der Herzspitze, keine Verbreiterung des Herzens, sonst o. B. Neurologisch: Choreatische Zuckungen (rascher Typus vorherrschend) im Gesamtbereich des Körpers, insbesonders rechts, an den Beinen stärker als an

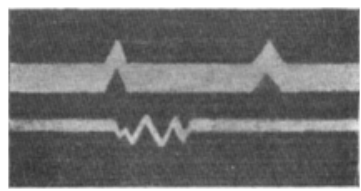

Fig. 15. Fall II. Choreatische Zuckung. den Armen, verstärkbar durch körperliche Anstren. gungen und Rechnen. Im innervierten Gebiet werden sie durch die Innervation ver. ringert. Regellose Mitbewegungen in allen Gliedern. Adiadochokinese nicht nachweisbar. Ataxie angedeutet; an den Beinen geringfügige Hypotonie. Händedruck rechts schwächer als links (dynamometrisch 25:30), sämtliche Reflexe normal. Keine Sensibilitätsstörungen mit Ausnahme von Parästhesien in der rechten Körperhälfte. Psychisch: Stumpf, unaufmerksam, klagt, er sei mißgestimmt.

Im weiteren Verlauf ist ein auffallender Wechsel in der Intensität des Herzgeräusches auffällig. Am 2. Nov. ist das Herzgeräusch verschwunden, sämtliche übrigen Erscheinungen beträchtlich gebessert (As-Therapie).

Diagnose: Chorea minor.

Die Aufnahme der Willküraktion ergab normale Werte 10, 10, 11, 9, 10 .

Eine Zuckung von 6/5 Sekunden Dauer ergab die Zahlen 7, 8, 7, 5, 7, 9, eine solche von $3 / 5$ Sekunden Dauer 9, 7, 7, danach folgten noch einige kaum zählbare niedere Stromschwankungen (Fig. 14). Eine 
Zuckung, die sich in 3 Einzelwellen zerlegen ließ (Fig. 15) hatte eine Dauer von $1 / 10$ Sekunde (doch ist es nicht sicher, ob die ganze Zuckung aufgenommen wurde). Schließlich zeigte ein Teil ei ner Zuckung die Frequenz von 10 in einer Fünftelsekunde (die ande ren Teile gestatteten eine Zählung nicht).

Fall III. E. V., 26 Jahre. Menses seit 2 Monaten ausgeblieben. Seit 14 Tagen unwohl, Unruhe der Glieder. Aufgenommen den 16. Juni 1912. Innere Organe o. B. Typische Chorea minor mit Zuckungen, Mitbewegungen, Hypotonie der Muskeln, Adiadochokinese an sämtlichen Extremitäten; gelegentlich Zuckungen von mehr tonischem Charakter. Psychisch: Labilität der Stimmung mit vorwiegender Euphorie. Am 24. Juli geheilt entlassen.

Diagnose: Chorea minor in graviditate.

Es wurden aufgenommen, die Willküraktion, diese war vollkommen normal (48-52), außerdem wurde eine Reihe von Einzelzuckungen aufgenommen, eine Zuckung von ${ }^{17} / 5$ Sekunden Dauer zeigte pro Fünftelsekunde acht Schwingungen, eine Zuckung von einer Sekunde Dauer bestand aus 37, 3 Zuckungen von je $3 / 5$ Sekunden Dauer aus 25, 28, und 21 Schwingungen.

Fall IV. M. M., 24 Jahre, Haustochter. Erkrankt im Anschluß an Aufregungen, an Zuckungen und Unruhe der Glieder. Aufgenommen am 13. Juni 1912, innere Organe o. B. Mittelschwere Chorea, Tonus herabgesetzt; blitzartige Zuckungen, Mitbewegungen, Adiadochokinese, Sprachstörung deutlich. Psychisch etwas labil.

Diagnose: Chorea minor.

Die Frequenz der Aktionsstromschwankungen der Unterarmbeuger betrug 52-54 pro Sekunde.

Von den mitgeteilten Fällen geben die Fälle I, III, IV, zu keiner Bemerkung Anlaß. Fall II ist den seltenen Fällen von Chorea minor in späterem Alter anzureihen. Aus der Zusammenstellung Bischoffs ist ersichtlich, daß die Kasuistik eine nur wenig zahlreiche ist. Es liegt nicht in unserer Absicht, eine Kritik der einschlägigen Beobachtungen zu geben. In unserem Fall kommt differentialdiagnostisch nur Chorea Huntington in Frage, doch spricht gegen diese das Fehlen schwererer psychischer Defekte, der Mangel an Heredität, der rasche Rückgang der Erscheinungen. Die Endokarditis verweist darauf, daß ätiologisch die gleichen Faktoren in Betracht kommen, wie bei der Chorea minor des jugendlichen Alters. Vielleicht hat Bleiintoxikation die motorische Dekompensation begünstigt (Bleivergiftung wird von Eulenburg als Ursache der Chorea minor angegeben). Symptomatologisch ist die Schwäche des rechten Armes auffällig. Allerdings ist die Differenz am Dynamometer so geringfügig, daß sie durch die größere choreatische Unruhe dieser Seite erkłärt werden kann. Die rechtsseitigen Parästhesien sind als auf den Thalamus verweisend, bemerkenswert.

Uberblicken wir unsere bei der Chorea minor mit dem Saitengalvanometer erhobenen Befunde, so ergibt sich, daß in allen Fällen die chorea- 
tische Zuckung in Einzelwellen zerlegbar war (Fall I-III). Die Zuckungs frequenz war im Vergleich zu der der Willküraktion eine niedere, meist um 40 in der Sekunde. Es bestand kein Unterschied der Sekundenfrequenz zwischen Zuckungen kürzerer und längerer Dauer. Auch war keine Gesetzmäßigkeit in der Anordnung der Wellen erkennbar (Fig. 12 bis 15). (Vgl. hierzu noch Fall XI.)

Es zeigte sich in der Willküraktion der beschriebenen Fälle keine Abweichung von der Norm, wenn man absieht von einer eigenartigen Verlängerung der Dauer der biphasischen Stromesschwankung, die wir in einem Fall nach Eintritt der Ermüdung konstatieren konnten (Fall I). Wir kommen auf diesen Befund noch zurück. Auch in Fällen von Hemichorea konnten wir eine Abänderung in den Aktionsströmen der kranken Seite gegenüber denen der gesunden Seite nicht konstatieren. Das ist um so auffallender, als wir wissen, daß bei der Chorea minor die Willkürinnervation der Muskeln regelmäBig gestört ist. Auch in unseren Fällen waren diese Störungen vorhanden. Das verweist uns darauf, daß die Registrierung der Aktionsströme mit dem Saitengalvanometer Veränderungen, welche klinisch deutlich sind, nicht erkennen zu lassen braucht. Es liegt dies wohl zum Teil daran, daß wir feinere qualitative Abweichungen des Kurvenbildes von der Norm derzeit noch nicht beurteilen können, andererseits muß aber auch stets im Auge behalten werden, daß die Empfindlichkeit des Saitengalvanometers vielleicht eine noch zu geringe ist, um feinste Abänderungen erkennen zu lassen. Beide Einschränkungen wird man sich im Verlauf der Untersuchungen stets vor Augen halten müssen.

$\mathrm{DaB}$ der Hypotonie und Ataxie der Chorea minor überhaupt kein von der Norm abweichendes Kurvenbild zukommt, glauben wir deshalb nicht annehmen zu sollen, weil wir bei der Ataxie der Tabes in hochgradigen Fällen einen charakteristischen Befund erhoben haben, während wir bei wesensgleichen Erscheinungen leichteren Grades sichere Abweichungen von dem normalen Kurvenbilde nicht nachweisen konnten.

Eine Verwertung der Resultate für die pathophysiologische Deutung der choreatischen Zuckungen ist vorläufig nicht möglich. Auf die geringere Frequenz der Aktionsströme bei der Zuckung im Vergleich zu der Frequenz der Willküraktion auf der Höhe der Leistung sei hingewiesen. So betrug z. B. die Zahl der Aktionsströme der Willküraktion in dem Falle II 50, die der Zuckungen etwa 35 pro Sekunde. Ähnlich ím Falle $V I$. Es ist jedoch nicht statthaft, aus diesen Beobachtungen eine differente Lokalisation der Willküraktionen und der choreatischen Zuckung abzuleiten, weil wir ja auch bei corticaler Innervation geringere Frequenzen als 50 pro Sekunde häufig sehen, anderenteils haben wir sehr ähnliche Frequenzen (ja noch geringere) bei Zuckungen erhalten, die man 
ihrem ganzen Typus nach als cortical ausgelöst betrachten mußte. Es fehlen ferner vollkommen die experimentellen Grundlagen (vgl. auch das Folgende) einer lokalisatorischen Verwertung der Abänderung der Aktionsströme. Die Tatsache, daß klonische und tonische Zuckungen die gleiche Wellenzahl pro Sekunde zeigen, ist im Sinne der obigen Auseinandersetzungen gleichfalls nicht dafür beweisend, daß beide Zuckungsformen einen ähnlichen oder identischen Mechanismus haben.

Fall V. L. St., Bergarbeiter, 42 Jahre. Vater gestorben an Chorea Huntington, 47 Jahre alt. Mutter + (an Schlaganfall). Von 4 Geschwistern starb eins unter Zittererscheinungen, eins ist psychisch abnorm. Der Pat. krank seit 3 Jahren. Er bekam den Gang eines Betrunkenen. In letzter Zeit leicht erregbar. Somatisch: Innere Organe o. B. Wassermann - . Es besteht allgemeine Hypotonie, besonders an den Beinen, allgemeine Ataxie, wieder an den Beinen deutlicher. Adiadochokinese an den Armen vorhanden. Rasche klonische Zuckungen in Armen und Beinen und Rumpf, die sich bej hierauf gerichteter Aufmerksamkeit verstärken. Das gleiche gilt von den reichlichen und regellosen Mitbewegungen. Keine Paresen, keine Reflexanomalien. Beim Gang auffallendes Utberwiegen der Dorsalflexoren des Fußes. Sprache verwaschen. Sensibilität o. B. Psychisch: Euphorie und leichte Erregbarkeit.

Diagnose: Chorea Huntington.

Die Aufnahme der Muskelaktionsströme ergab für den Quadriceps Werte, welche der Norm entsprachen: 12, 12, 9, 9, 10, 13, 9, 8, 8, 10. Es gelang uns, eine der Zuckungen vom Quadriceps aufzunehmen. Die Dauer der Zuckung betrug etwa $1 \frac{112}{2}$ Sekunden. Die Zahl der Schwingungen etwa 14. Da an dieser Stelle das Papier nur mit geringer Geschwindigkeit ablief, machen diese Zahlen keinen Anspruch auf große Genauigkeit.

Wir haben also für die Chorea Huntington die gleichen Befunde erhoben, wie für die Chorea minor : normales Bild für die Willküraktion, Zerlegbarkeit der Zuckung. Der Mechanismus der Bewegungsstörung der Chorea Huntington ist ja, soweit dies aus der klinischen Untersuchung beurteilt werden kann, identisch mit dem der Chorea minor.

Fall VI. M. N., 40 Jahre. Dieser Fall ist von Schild er ${ }^{1}$ ) ausführlich publiziert worden ${ }^{1}$ ). Es handelt sich um eine choreatisch athetotische Bewegungsstörung. Im gleichen Muskel treten abwechselnd, bisweilen gleichzeitig klonische und tonische Zuckungen auf; im graphischen Bild der Muskelverdickungskurve waren sowohl die klonischen als auch die tonischen Zuckungen in Einzelwellen von 3-16 Frequenz pro Sekunde zerlegbar. Schon in dieser Mitteilung wurde die Vermutung ausgesprochen, daß diese graphisch nachweisbaren frequenten Einzelwellen nicht durch einen, sondern durch mehrere Impulse zustandekämen.

Wir haben die Untersuchung der Aktionsströme am Musculus biceps der Patientin vorgenommen. Um ein Bild darüber zu gewinnen, welches Kurvenbild den klonischen und welches den tonischen

1) Fall I der dritten Mitteilung. 
Zuckungen entspricht, haben wir gleichzeitig graphische Registrierungen der Muskelverdickung vorgenommen. Wir erhielten für klonische Zuckungen folgende Resultate: $9+9$ in $2 / 5$ Sekunden, 7 in $2 / 5$ Sekunden, $7+8,7+6,8+7,5+4,5+4,6+7,5+6,9+7+7$, $4+5+6$.

Für tonische Zuckungen erhielten wir folgende Werte pro Fünftelsekunde: $7,8,9,8,6,6,7,9,9, \ldots 8,5,6$, und $4,6,5,6,4,6,6,5,6$. Ein wesentlicher Unterschied in den Sekundenfrequenzen ${ }^{1}$ ) klonischer und tonischer Zuckungen findet sich demnach nicht (vgl. Fig. 16).

Zusammenfassung: Sowohl die tonischen als auch die klonischen Zuckungen einer posthemiplegischen, choreatisch athetotischen Be-

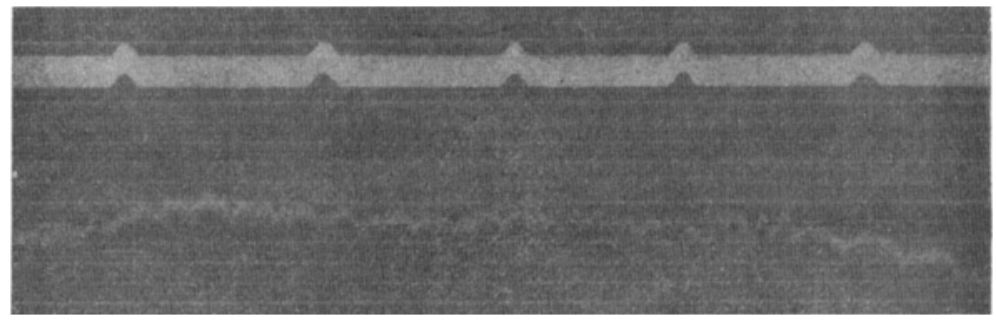

Fig. 16. Fall VI. Choreatisch-athetotische Bewegungsstörung. Spontanzuckung tonischen Charakters. Die Sekundenfrequenz ist eine geringe.

wegungsstörung erwiesen sich als in Einzelwellen von etwa 30-40 Frequenz pro Sekunde zerlegbar. Auch die kürzesten mechanischen Muskel-Einzelwellen ( $1 / 16$ Sekunde) sind demnach nicht auf einen einzelnen Impuls zu beziehen.

Daß klinisch differente Zuckungsformen sich elektromuskulär nicht unterscheiden, sei wieder hervorgehoben.

Es sind also die klonischen Zuckungen der Chora minor, der Chorea Huntington und der postaploplektischen Chorea in Einzelimpulse zerlegbar. Die Frequenz dieser Einzelimpulse steht hinter der Frequenz der normalen Willküraktion zurück. Auch die tonischen Zuckungen einer postapoplektischen Chorea und in der Chorea minor erwiesen sich als Tetani (Fig. 12-16). Irgendwelche lokalisatorische Schlüsse konnten nicht gezogen werden.

Die Willküraktion der Chorea minor und der Chorea Huntington gibt bei Aufnahme mit dem Saitengalvanometer ein Kurvenbild, welches demjenigen entspricht, welches bei der Willküraktion des Normalen erhalten wird.

1) Wir gebrauchen diesen Ausdruck im Sinne der Zahl der Stromschwankungen pro Sekunde. 


\section{Andersartige Zuckungsformen.}

Fall Vir. St. D., Versicherungsbeamter, 45 Jahre. Familienanamnese belanglos, 5 Kinder gesund, 4 Fehlgeburten der Frau. Ausgiebiger Potus seit dem 24. Lebensjahr (bis zu $1 \frac{1}{2}$ Mark Schnaps pro Tag). Mehrfach wegen alkoholischer Exzesse im Krankenhaus. Somatischer Befund damals (1907) negativ bis auf Händetremor. Am 25. Juni 1912 in die Klinik eingeliefert, nachdem er auf der Straße zusammengestürzt war; er soll in der letzten Zeit mehrfach epileptiforme Anfülle gehabt haben. Bei der Aufnahme apathisch benommen, Antworten, wofern sie überhaupt erfolgen, stark verlangsamt. Innere Organe ohne wesentliche Besonderheiten, Wassermann im Serum negativ; Nervensystem: rechte Nasolabialfalte verstrichen, auch der linke Facialis paretisch, jedoch in geringerem Grade, Augenbewegungen frei, Zungenmuskulatur schwer paretisch, die Zunge weicht nach links ab, Masseteren beiderseits schwer gestört. Conjunctival, Cornealreflexe + , rechts $=-$ links, die Pupillen reagieren jedoch etwas träge. Sensorische Funktionen nicht prüfbar. Schlucken leicht gestört, Sprache vollkommen verwaschen, ausgesprochen bulbär. Spontaner Ausdruck mangelhaft, kommt nur bis zum dritten oder vierten Wort eines Satzes; versteht den Sinn der Fragen, befolgt Aufforderungen, genauere Prüfung der Sprache wegen Benommenhejt nicht möglich. Spastische Tetraplegie. Die Störungen am stärksten an der rechten Körperhälfte. Die Beine sind schwerer geschädigt als die Arme. Dauernde ungeordnete, nicht rhythmische Bewegungen der Arme, wobei sämtliche Gelenke beteiligt sind. Die Bewegungen entfernen sich im Typus nur unwesentlich von Willkürbewegungen. Kommt ein Gegenstand in seine Hand so wird er mit großer Gewalt festgehalten.

Gelegentlich orstarren die Arme in irgendeiner Position, so daß bizarre Stellungen, die an die Katatonie erinnern, zustande kommen.

Ahnliches in geringerem Ausmaß an den Beinen.

Mitbewegungen sind reichlich, Gang spastisch, er kann nicht stehen, fällt nach hinten über.

2. Juli. Augenhintergrund o. B. Blutdruck $90 \mathrm{~mm}$.

21. August. Spastische Tetraplegie, auch die unteren Facialisäste beiderseits paretisch, das Gesicht ohne Bewegung, Hände und Arme in eigenartigen steifen und ungeschickten Stellungen; zum Beispiel: Hünde im Handgelenk gestreckt, Finger gespreizt, im Ellenbogengelenk fast stets Beugestellung. Beide Beine in Hüftund Kniegelenk in leichter Beugecontractur, linkes Bein im Hüftgelenk adduziert, hochgradige Spasmen in sämtlichen Muskeln des Beines, auch die Bauchdecken und die Rückenmuskulatur stark gespannt. Die Spasmen sind in geringerem Grade auch in der Ruhe rorhanden, treten aber bei briisker Anspannung besonders deutlich hervor.

In beiden Armen zeitweise rasche Zuckungen von großer Kraft, welche in beiden Armen meist synchron auftreten.

Sie stellen eine komplizierte Synergie dar: Es werden gleichzeitig innerviert: Schulterheber, Deltoideus, die Oberarm-, Handgelenks- und Fingerbeuger unter Mitinnervation des Supinator longus, Dauer etwa $3 / 5$ Sekunden. Die Zuckungen sind kontinuierlich, zeitweise in annähernd rhythmischer Aufeinanderfolge, gelegentlich auch größere Pausen. Bisweilen klappt eine Seite nach, Willküraktion einer Seite stört die Gleichzeitigkeit der Zuckungen: die nicht innervierte Extremität zuckt weiter, in der innervierten sistieren die Zuckungen. Hantierungen mit Gegenständen erfolgen sehr ungeschickt, doch ist eine Störung des Bewegungsentwurfes bei dem leicht benommenen Patienten nicht nachzuweisen. Die schwerste Abänderung erfolgt durch die Zuckungen und Spasmen. Die Greifbewegungen sind zackig und bizarr, erhebliche P'arese sämtlicher Extremitäten. Alle Erscheinungen sind rechts viel ansgesprochener als links. Reichliche regellose (homolaterale und 
kontralaterale) Mitbewegungen. Die Intensität der Erscheinungen ist starken Schwankungen unterworfen. Die Sprache verwaschen, lallend, kaum verständlich, ausgesprochen bulbär. Schwere Parese der Zunge und des Gaumensegels; eine genaue Sprachprüfung nicht möglich, einfache Aufforderungen werden befolgt, einfache Wünsche werden ausgedrückt. Es besteht leichte Benommenheit.

Am 10. September sind sümtliche Erscheinungen sehr erheblich zurückgegangen, doch bestanden die Zuckungen kontinuierlich fort und sind auch jetzt in abgeschwächtem Grade rorhanden. Wortverständnis und Wortfindung, Lesen nicht im wesentlichen Grade gestört. Doch ergibt eine exakte Prüfung, daß eine Apraxie des linken Armes besteht. Die ideokinetischen Eigenleistungen und Objekthantierungen sind ungestört. Er versagt jedoch vollkommen (links) bei Objekthantierungen aus dem Gedächtnis und bei intransitiven Handlungen.

Am 20. Oktober weiterer quantitativer Rückgang der spastischen Erscheinungen und der Zuckungen.

Diagnose: Pseudobulbär paralyse.

In der Zeit vom 21. August wurden Aufnahmen mit dem Saitengalvanometer gemacht. Es gelang, die Spontanspannung am Quadri-

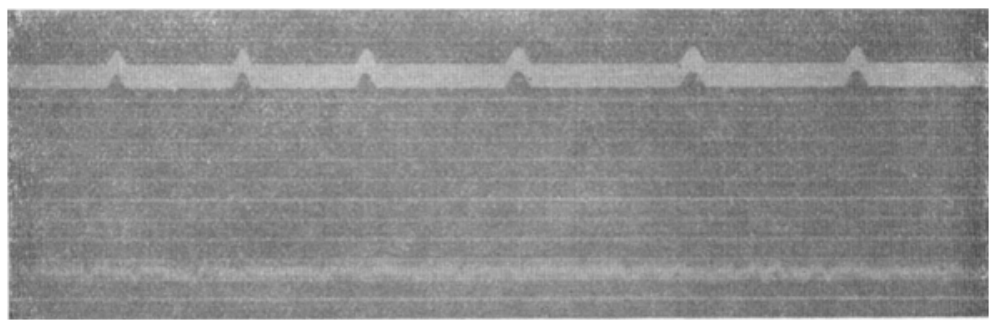

Fig. 17. Fall viI. Pseudobulbärparalyse. Aktionsströme von ruhendem spastisch gespanntem Muskel (Quadriceps). Geringe Sekundenfrequenz, niedere Wellen.

ceps aufzunehmen (Fig. 17); wir zählten in $4 / 5$ Sekunden 10 Schwingungen der Saite, hierauf folgten 3 raschere Zuckungen; wir registrierten ferner eine Fünftelsekunde mit 10 Erhebungen, 3/5 Sekunden mit insgesamt 7 Erhebungen, bisweilen $1 / 5$ Sekunde mit 8 Erhebungen. Die Wellen waren sehr niedrig. Auf weite Strecken gelang die Aufnahme nicht.

Es gelang uns ferner: eine Reihe der oben eingehend beschriebenen Spontanzuckungen aufzunehmen.

$\begin{array}{cc}\text { Zuckungsdauer in } 1 / 5 \text { Sekunden } & \text { Zahl der Einzelschwingungen } \\ 1 / 2 & 18 \text { (vgl. die Fig. 18-20.) } \\ 2 & 17 \\ 1 & 8 \\ 1 / / 2 & 16 \\ 2 & 9 \\ 2 & 17 \\ 1 & 11 \\ 2 & 17\end{array}$


Der Typus der einzelnen Zuckungen ist. sehr variabel, bald finden sich einigermaßen regelmäßige Wellenfolgen, dann wieder überwiegen rasche Schwankungen zu Beginn oder am Ende der einzelnen Zuckungsfolgen, auch die Höhe der Einzelzacken im Verlauf der Zuckungen ist versehieden, doch überwiegen die Bilder, wo die Zuckungskurve mit einer besonders hohen Zacke beginnt. Wir verweisen im übrigen auf unsere Abbildungen (18-20).

Wiederholt haben wir die Willküraktion der Unterarmmuskeln aufgenommen, stets war die geringe Frequenz der Wellenfolgen auf-

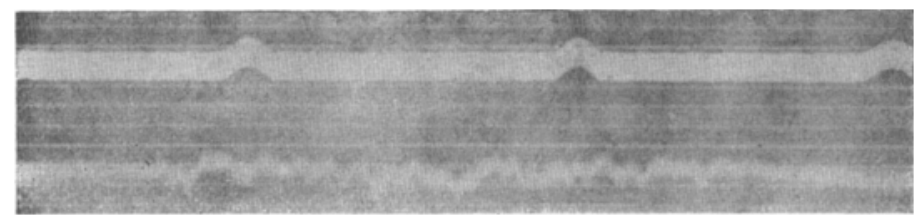

Fig. 18. Fall VII. Pseudobulbärparalyse. Klonische Zuckung aus einem protrahierten corticalenı Krampi.

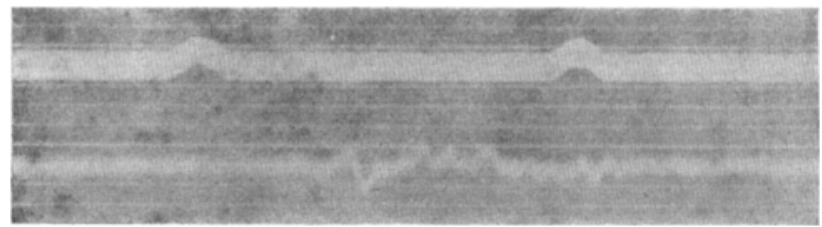

Fig. 19. Fall VII. Klonische Zuckung von anderem Bau als die in Fig. 18 dargestellte.

fällig, wir geben eine größere Reihe von Zahlen von einzelnen Fünftelsekunden wieder: $7,8,6,5,6,4,4,4,7,7,8$; an einem anderen Tag: 9. . . 3, 4, . . 9, 9, 10,6,6,3,4,3,3,3.

Zusammenfassung: Es handelt sich im wesentlichen um einen Fall von Pseudobulbärparalyse mit hochgradigen spastischen Erscheinungen an den Extremitäten. Die Spasmen zeigen die Charakteristica der durch Pyramidenbahnläsion hervorgerufenen Spasmen; bemerkenswert ist die besonders in der ersten Zeit hervorgetretene Neigung zur Beibehaltung passiv gegebener Stellungen, sowie die hochgradigen Mitbewegungen. Besonderes Interesse verdient die eigenartige Zuckungsform der Arme. Im wesentlichen stellt sie eine komplizierte corticale Synergie dar. Auf das gleichzeitige Betroffensein beider Arme sei nochmals verwiesen. Wir glauben auf Grund des klinischen Befundes berechtigt zu sein, diese Zuckungen als den Effekt einer Rindenreizung 
zu betrachten ${ }^{1}$ ) und lassen es dahingestellt, ob diese Reizung direkt durch den Prozeß oder durch Reizirradiation zustande kommt. Sie sind klinisch hinreichend sicher von protrahierten epileptischen Anfällen abzugrenzen, haben aber wohl eine innere Verwandschaft mit diesen. Muratow sah sie sich aus Jacksonanfällen entwickeln. In unserem Fall ist besonders bemerkenswert, daß beide Arme gleichzeitig befallen sind, während die Beine frei sind.

Die Untersuchung dieser Zuckungsform mit dem Saitengalvanometer ergibt die Zerlegbarkeit derselben in eine recht beträchtliche Anzahl von einzelnen Wellen. Hier muß sofort erwähnt werden, daß die

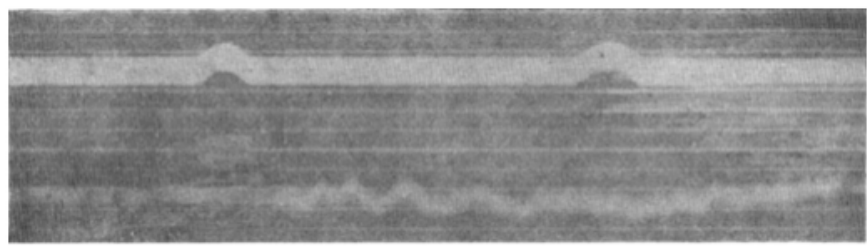

Fig. 20. Fall VII. Klonische Zuckung.

Sekundenfrequenz der Aktionsstromschwankungen eine sehr wechselnde ist, doch bleibt dieselbe fast durchgehends beträchtlich hinter 50 pro Sekunde zurück. Ob der Rindenreiz als solcher die geringere Frequenz der Innervationsströme bedingt oder ob die Erklärung darin zu suchen ist, daß die Erregung sich an einen Muskel wendet, dessen Pyramidenbahn geschädigt ist, kann nicht entschieden werden. Sehr bemerkenswert ist auch, daß die Zuckungen, die man ihrer klinischen Erscheinungsform nach, als gleichwertig anzusprechen hat, im Saitenbild, sehr verschieden erscheinen. Es verweist uns das wieder darauf, daß auch Verschiedenheit der Zuckungsformen im Kurvenbild mit der größten Vorsicht beurteilt werden muß.

Auf die Resultate der Untersuchung der Spasmen gehen wir erst später ein.

Fall VIII. E. M., 46 Jahre. Aufgeregt seit einem Jahr. Sprache schlechter. Am 30. September demolierte er die Wohnung. Aufgenommen am 1. Okt. 1912. Innere Organe o. B. Wassermann +. Lichtstarre Pupillen. Rechter Fac. schlaff. Händetremor. Patellar- und Achillessehnenreflex fehlen beiderseits. Psychisch: Örtlich und zeitlich nicht orientiert. Leicht delirant. Sprache verwaschen. Am 15. Okt. Zucken der Muskulatur des linken Armes: es zucken die Schulterheber, die Arm-, Hand- und Fingerbeuger unter Mitinnervation des Supinator longus.

1) Selbstverständlich ist auch das hypothetisch. Einzelne Autoren sind ja geneigt, auch sehr komplizierte Synergien beim Menschen dem Subcortex zu zuweisen (z. B. Valekenburgh). Immerhin scheint uns besonders die Mitbeteiligung des Supinator longus an dem Faustschluß auf den Cortex zu verweisen. (Hering hat diese Synergie durch corticale Reizung erzielen können.) 
Am Beine zuckt der Quadriceps und die Glutäen. Auch die Bauchdecken sind beteiligt. Sämtliche Muskeln zucken gleichzeitig. Es sind sehr rasch verlaufende Zuckungen. Sie erfolgen rhythmisch, wiederholen sich etwa alle $2^{\prime \prime}$. Sie sistieren im Schlaf. Links Hemiparese und Hemianästhesie. Keine Bewußtseinstrübung. Gang wegen allgemeiner Schwäche unmöglich. -... Die Zuckungen nehmen erst am 20. Okt. etwas ab, der Typus ist der gleiche geblieben. Incontinentia urinae.

Diagnose: Progressive Paralyse.

Es wurde eine Reihe dieser Zuckungen (des Biceps) aufgenommen, sie zerfielen in Einzelwellen. Die Zahlen sind: 6 (Dauer der Zuckung 2/3 einer 1/5 Sekunde), 6 (Dauer 1/5 Sekunde), 6 (Dauer 1/5 Sekunde), 6 (Dauer mehr als 1/5 Sekunde), 7 (Dauer 1/5 Sekunde), 6 (Dauer $2 / 3$

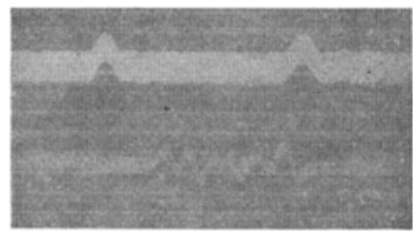

Fig. 21. Tall VIII. Progressive Paralyse. Protrahierte corticale Krämpfe. Klonische Zuckung.

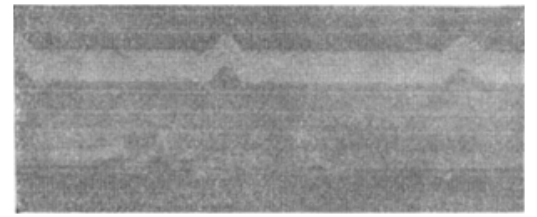

Fig. 22. Fall VIII. Klonische Zuckung.

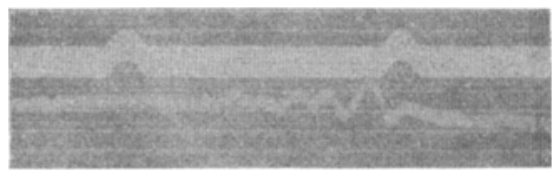

Fig. 23. Fall VIII. Klonische Zuckung, differenter Typus.

einer $1 / 5$ Sekunde), 9 (Dauer $1 / 5$ Sekunde), 8 (in mehr als $1 / 5$ Sekunde), 6 (in $1 / 5$ ), 5 (in $2 / 3$ einer $1 / 5$ Sekunde), 7 (in $1 / 5$ Sekunde), 6 (in $2 / 3$ einer $1 / 5$ Sekunde), 5 (in $2 / 3$ einer $1 / 5$ Sekunde), 6 (in $2 / 3$ einer $1 / 5$ Sekunde) Wellen (vgl. Fig. 21-23). Wieder ist cine ganz auffällige Differenz im Kurvenbild dieser klinisch völlig identischen Zuckungen vorhanden (vgl. Fig. 21-23). Bald sind sämtliche Zacken von etwa gleicher Höhe, bald finden sich hohe Zacken im Beginn, bald gegen das Ende der Kontraktion zu. Bald finden sich nach der ersten, bald nach den letzten Zuckungen größere Pausen. Häufig findet sich nach der vorletzten Erhebung eine etwas längere Pause im Ablauf der Wellen. Bemerkenswert ist, daß auch hier die Frequenz im allgemeinen zurückbleibt hinter der Frequenz, welche der normalen Willküraktion auf der Höhe der Leisturg zukommt.

Zusammenfassung: Es handelt sich um einen Paralytiker, der Zuckungen zeigt, welche in ihrer Erscheinungsform einigermaßen den oben beschriebenen entsprechen. Nur ist in diesem Falle die Zuckung von hemiplegischem Typus. Mit den oben vermerkten Vorbehalten 
wird man auch hier eine Entstehung durch direkte Rindenreizung vermuten dürfen. Auch hier ist bemerkenswert, daß gleichen Zuckungen differente Kurvenbilder entsprechen.

Wir haben also in zwei Fällen Zuckungsformen, welche am ehesten den ,protrahierten corticalen Krämpfen“" Muratows entsprechen, in Einzelimpulse zerlegen können, in beiden Fällen blieb die Zahl dieser Einzelimpulse pro Sekunde geringer als dies der normalen Willkürinnervation entspricht. Bedenkt man, daß diese Zuckungen sich nach Muratow direkt aus einem Jackson-Anfall entwickeln können, so wird die Zerlegbarkeit des Einzelklonus des epileptischen Anfalls fast zur Gewißheit. Daß die tonische Komponente derselben zerlegbar ist, halten wir nach unseren ganzen Befunden für sicher. Wir hoffen, in Kürze den Beweis für diese Behauptung erbringen zu können.

Wir beschreiben noch eine interessante Bewegungsstörung im epileptischen Dämmerzustand, die man am ehesten als pseudoathetotisch bezeichnen könnte.

Fall IX. K. H., 19 Jahre. Mutter leidet an Migräne. Mit dem 10. Jahre epileptische Anfälle, zunächst einfache Bewußtlosigkeit, seit 1907 Krämpfe, Anfälle jetzt etwa alle acht Tage, Gedächtnis in den letzten Jahren schwächer, seit dem 16. Okt. psychische Störungen: habe keinen Kopf mehr, sei tot. Gleichzeitig eigenartige Bewegungen. Status somaticus: ausgesprochen degenerative Merkmale am Schädel, innere Organe o. B. Neurologisch: bei der Aufnahme eigenartige Spontanbewegungen: drehende und bohrende Bewegungen in den Handgelenken, bisweilen lïnger dauernde Anspannungen, die Bewegung ist kontinuierlich, zeitweise athetoide Fingerbewegungen, welche eine komplizierte Bewegungsfigur darstellen, nur selten Bewegungen in den Ellbogengelenken, zeitweise dreht er rasch die Unterarme umeinander. Beide Siiten in nicht merklich verschiedenem Grade betroffen. Die Bewegungsstïrung erinnert anı meisten an katatonische Bewegungsstörungen, hat aber auch mit Athetose eine gewisse Ähnlichkeit. Der neurologische Befund im übrigen negativ. 1'sychisch: schwerer Dämmerzustand, spricht nur sehr wenig. Leerer, wie suchender Gesichtsausdruck, unrein; wird erst im Verlauf der nächsten 'Tage wieder freier, typisch epileptisch im Wesen und Benehmen, am 2. Nov. zwei epileptische Anfülle (vom Pflegepersonal beobachtet).

Diagnose: Epileptischer Dämmerzustand mit pseudoathetotischen Bewegungen.

Es wurden von den Unterarmflexoren während der Spontanbewegungen die Aktionsst:öme abgeleitet. Sie unterschieden sich in nichts von der normalen Willkürinnervation, ihre Frequenz betrug annähernd 50 pro Sekunde.

Eine ausreichende Beurteilung der Lokalisation der Bewegungsstörung ist derzeit unmöglich, am ehesten möchten wir sie als Fehlarbeit der Rinde unter dem Einfluß abnormer Reize deuten. Abänderungen der Aktionsströme fanden sich nicht.

\section{Idiadochokinese und Tremor.}

Fall X. A. 11., 57 Jahre, Tischler. Familienanamnese belanglos. Lues negiert, ebenso Potus. 1907 Klagen über Sehschwäche, später ängstlich, es wäre ihm auf 
der Brust so, als wenn es ihn packen täte. Leichte Ermüdbarkeit, konnte nicht mehr denken, konnte sich in nichts mehr hineinfinden, sprach den Wunsch aus, tot zu sein; Klagen über Schwindel, die rechte Seite sei nicht in Ordnung. Seit Weihnachten 1908 Zittern in den Gliedern. 1909 zum ersten Male in der Klinik; damals an den inneren Organen kein wesentlicher Befund; neurologisch: die rechte Seite etwas ungeschickter, zeitweise Tremor, rechts geringer als links; rechts Fußklonus, die Sprache etwas verwaschen. Psychisch: ausgesprochene Depression. Motorisch leicht gehemmt. Bewegungsarm. Miene depressiv. Er klagt, nicht richtig denken zu können. Zeitlich mangelhaft orientiert (am 8. Mai 1908). Fir rechnet leidlich, geographische und geschichtliche Kenntnisse etwa entsprechend, findet sich häufig im Zimmer nicht zurecht. Am 14. Mai steigert sich die ängstliche Unruhe, er will immer aus dem Bett. Beiderseits Patellar- und Fußklonus. Am 4. Juli schwere Störungen in der Merkfähigkeit nachgewiesen, findet sich immer schlechter zurecht, kann nicht angeben, wieviel Fenster das Zimmer hat, auch nicht wieviele Betten im Zimmer stehen, hält sich für gesund. Am 21. August wieder orientiert.

Bei den folgenden Aufnahmen 1909 Ängstlichkeit, Unschlüssigkeit, sturk depressive Miene, Recurrenslähmung rechts, Zittern des Unterarms rechts.

1911 tritt Rigor an sämtlichen Extremitäten stark hervor.

Bei der vierten Aufnahme am 28. Mai 1912 wird der folgende Befund erhoben, der seither unverändert geblieben ist. Innere Organe: Ausgesprochene Aortensklerose mit diffuser Erweiterung und Hochstand des Bogens. Im übrigen o. B. Keine Degenerationszeichen. Neurologisch: Haltung: Beim Stehen nach vornüber geneigt, Kopf nach vorne, rechter Arm adduziert, im Ellbogengelenk halb gebeugt, im Handgelenk gestreckt, Finger gebeugt, Daumen adduziert; linker Arm in gleicher Haltung, nur sind sämtliche Anomalien quantitativ geringer. Ausgesprochene Pro- und Retropulsion, Mimik starr und maskenartig, Bewegungsantriebe sämtlich stark herabgesetzt, statuenhafte Unregsamkeit. Im Liegen Beine in Hüftgelenk leicht gebeugt und adduziert.

Ruhetremor des Kopfes: regelmäßige rhythmische Schwingungen, die jedoch nur zeitweise auftreten; auf Aufforderung können sie unterdrückt werden. Langsam schwingender Tremor in beiden Ellbogengelenken im Sinne der Beugung; keine Pillendrehbewegung. Bei darauf gerichteter Aufmerksamkeit wird der Tremor geringer, er verschwindet bei Intentionsbewegungen und bei der Aufforderung, den Tremor $\mathrm{zu}$ unterdrücken. Sonst nirgends Tremor.

Die Ruhespannung ist in sämtlichen Muskeln vermehrt, die Muskelkonturen springen plastisch vor, rechts etwas stärker als links. Gegen passive Bewegungen von Beginn der Bewegung an ein Widerstand, der sich im Verlauf der Bewegung nicht wesentlich ändert, besonders starke Spannungen im Bereich der Rumpfmusknlatur, die Spannung betrifft Agonisten und Antagonisten in gleicher Weise. Kein Prädilektionstypus. Die Spannung ist an den Beinen stärker als an den Armen und rechts stärker als links. l'assiv gegebene Stellungen werden katalepsieartig festgehalten. läßt man ihn sich aus liegender Stellung rasch aufrichten und wieder hinlegen, so bleiben die Beine im Hüftgelenke gebeugt und heben sich von der Unterlage $a b$.

Die Bewegungsstörung am rechten Arm ist folgende (an den übrigen Extremitäten die gleichen Störungen nur in geringerem Grade): sämtliche Bewegungen sind verlangsamt, doch sind sämtliche Bewegungen in vollem Ausmaß und ohne wesentliche Schädigung der groben Kraft möglich. Bei Zielbewegungen geringe ataktische Unsicherheit, die sich bei Augenschluß verstärkt, auch sonst Störungen der Koordination: bei Faustschluß geringe Extension im Handgelenk. Bei sämtlichen Bewegungen ausgesprochene Adiadochokinese, am deutlichsten bei Pro- 
nation und Supination. Mitbewegungen außerordentlich geringfügig, insbesondere keine kontralateralen Mitbewegungen bei Händedruck.

Hirnnerven: Beim Blick nach beiden Seiten nystagmoide Schläge, nur geringe Verlangsamung der Augenbewegungen; doch ist die Adiadochokinese der Augenbewegungen auffällig, geringe Spontaneität der Augenbewegungen. Die Entspannung des Stirnfacialis ist auffällig verlangsamt. Eine Parese liegt im Bereich des Facialis nicht vor, doch wird der rechte Mundfacialis meist weniger innerviert als der linke. Beim Zähnezeigen wird die Innervation bei Wiederholung insbesondere rechts, allmählich schwächer und hört schließlich vollkommen auf. Das Aufhören der Bewegung erfolgt niemals bei gehobener Lippe. Man kann sehr schön beobachten, da 3 der rechte Mundfacialis nicht später, sondern nur weniger innerviert wird als der linke. Die Zunge runzlig, etwas eingesunken, aber ohne deutliche Atrophie (elektrische Reaktion prompt), mäßiges Zittern, die Zunge wird zunächst auf Aufforderung nur wenig vorgestreckt, erst auf nochmalige Aufforderung vollständig. Auch Zunge und Masseteren zeigen Adiadochokinese. Das Gaumensegel wird bei der Phonation meist nicht gehoben, doch gelingt gelegentlich das Heben desselken. Das Zäpfchen weicht nach links ab (beim Essen verschluckt er sich häufig, dic Füssigkeit kommt durch die Nase heraus). Reichlicher Speichelfluß. Die Stimme ist heiser, er spricht langsam und schwerfällig, es besteht Recurrenslähmung rechts (diese ist auf die Aortenerkrankung zu beziehen). Er spricht Vokale tonlos heiser, in übrigen keine elektive Störung der Konsonanten. Die Sprache zeigt, von den durch die Recurrenslähmung bedingten abgesehen, zwei verschiedene Störungen: zunächst ist zu Beginn des Sprechens die Spannung zu überwinden, bei mehrmaliger Wiederholung desselben Wortes kommt es zu einer deutlichen Adiadochokinese der Sprache, die Stimme wird leiser, außerdem folgen die Worte in etwas größeren Pausen. Die Atemmuskulatur zeigt bei willkürlicher Innervation keine Adiadochokinese.

Die Armreflexe sïmtlich vorhanden, Patellarreflexe rechts $=$ links, beiderseits organischer unerschöpflicher Klonus, es besteht auch unerschöpflicher Fuß. klonas, Fußsohlenreflexe normal, kein Oppenheim, obere und mittlere Bauchdeckenreflexe + die unteren fehlen, Cremasterreflex + Pupillar-, Conjunctivalund Corneal-, Rachenreflexe + .

Sensorische Funktionen (Sehen, Geruch, Gehör, Geschmack) ungestört, keine Störungen der Hautsensibilität.

Er ist psychisch nicht anffällig, hat Einsicht für seine Erkrankung, klagt über häufiges Verschlucken und Speichelfluß und über Behinderung durch die Spannungen, klagt nur zeitweise über Ausbleiben der Gedanken.

Mit dem Saitengalvanometer haben wir aufgenommen: die Willküraktion, es ergab sich keine Abweichung von der Norm. 50 Impulse pro Sekunde auf der Höhe der Leistung (Musculus biceps und Unterarmbeuger). Auch die Ermüdung zeigte nichts Auffallendes.

Wir haben ferner die Adiadochokinese einer genauen Untersuchung unterzogen, dazu erwiesen sich graphische Vorstudien der Muskelvolumzunahme als unbedingt erforderlich. Wir gingen in der Weise vor, daß wir vermittels eines Jaquetschen Sphygmographen mit Luftübertragung, die Verdickungen des Biceps bei Pro- und Supinationsbewegungen graphisch registrierten. Bekanntlich ist der Musculus biceps bei gebeugtem Arm ein Supinator des Unterarms, während andere Oberarmmuskeln an Pro- und Supination nicht beteiligt sind. Es gelingt so vollkommen 

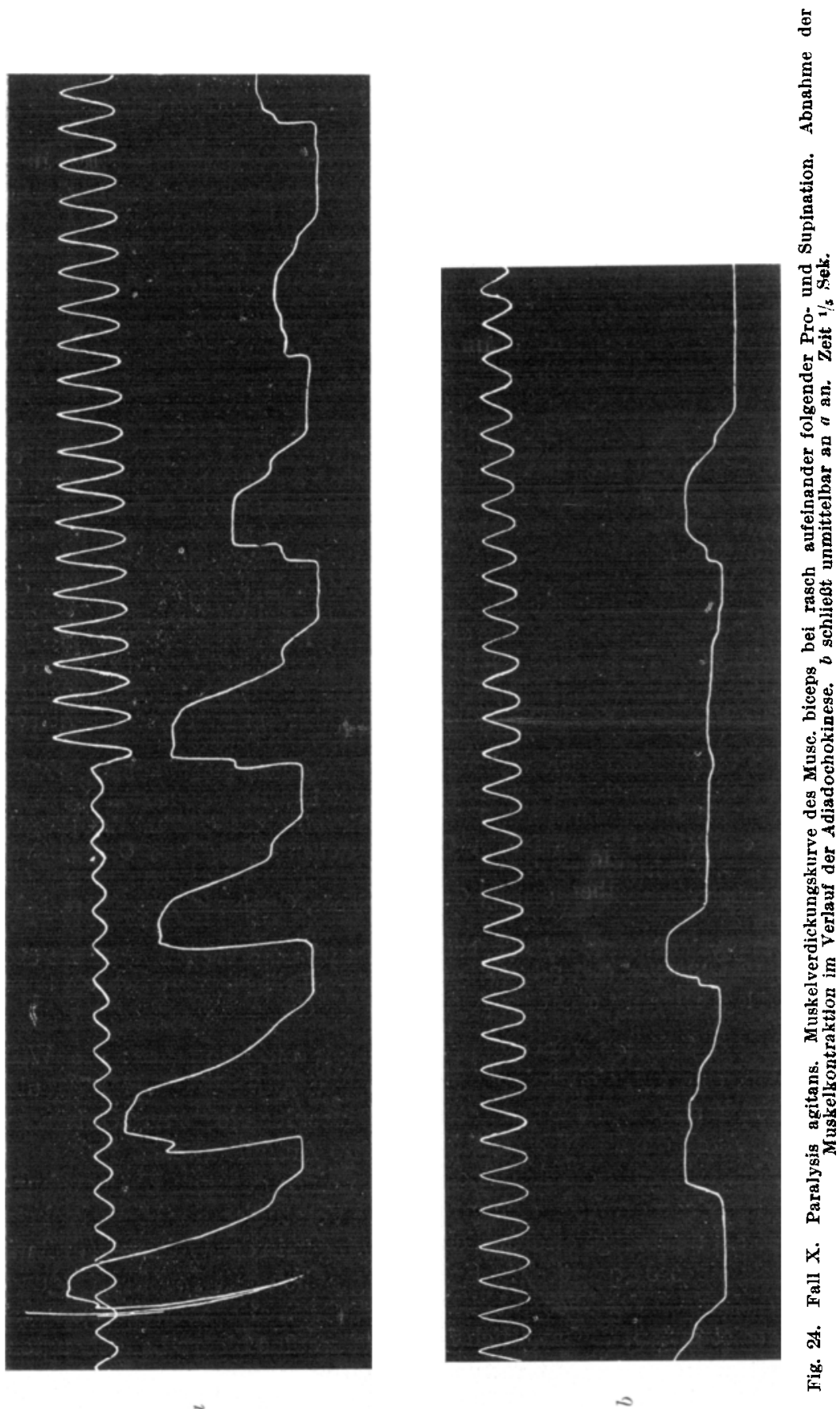
einwandfreie und klare Kurven zu bekommen, die nicht durch Mitaktion anderer Muskeln gestört sind. Nur eine Fehlerquelle ist zu berücksichtigen: es zeigte sich, daß der Patient nach Erschöpfung der Pround Supinationsbewegung die Neigung hatte, eine Ersatzbewegung: Beugung im Ellbogengelenk auszuführen, doch gelang es leicht, diese Ersatzbewegungen hintanzuhalten. Wir haben mit dieser Methodik etwa 30 graphische Aufnahmen der Adiadochokinese gemacht und haben stets das gleiche Resultat erhalten. Es wird durch die Abbildung veranschaulicht. Die Bewegung ist von vornherein eine langsamere als die des normalen, jedoch nimmt die Dauer der einzelnen Bewegung im Verlauf der Untersuchung nur in ganz unbeträchtlichem Maße zu, ja nicht selten kommt es gegen das Ende des Versuches zu besonders kurzen Stößen. Die charakteristische Störung ist die, daß die Kurvenhöhe (das heißt die Muskeldickenzunahme und damit das Ausmaß der Bewegung) rapide abnimmt, bis schließlich eine Kontraktion überhaupt nicht mehr zustande kommt. Sehr rasch tritt dann wieder die Erholung ein. In dieser Phase zeigt sich dann im Kurvenbild eine Verspätung des Einsetzens der Kontraktion. Bemerkenswert ist noch, daß in den ersten Bewegungen der Tremor nur in geringem Grade hervortritt, sich aber allmählich mit der Abnahme der Willküraktion immer mehr verstärkt, bis schließlich beim Versagen der Willkürinnervation der Tremor das Bild beherrscht. (Fig. 24.)

Wir haben nun bei Handbeugung und bei Handstreckung die Aktion der Beuger des Unterarms mit dem Saitengalvanometer aufgenommen, und es zeigte sich auch bei dieser Untersuchungsmethodik, daß beim Eintreten der Adiadochokinese eine Verlängerung der Zuckungsdauer nicht eintritt. Darüber orientiert die folgende Tabelle:

Tabelle.

Dauer der Innervation Dauer der Pause

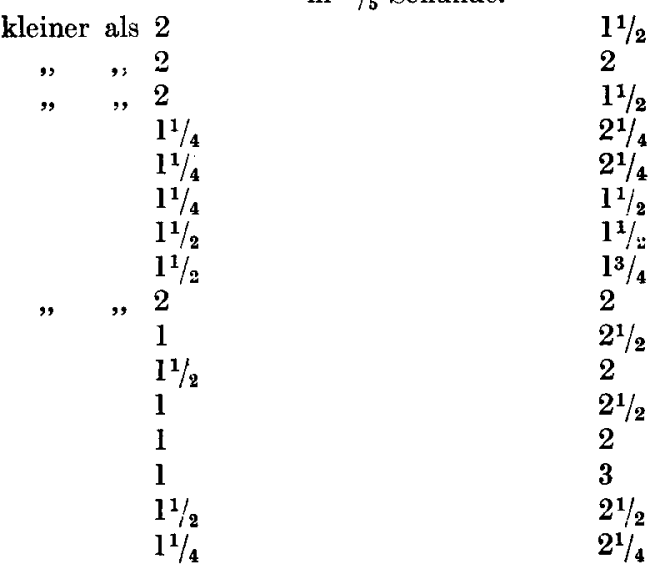


A. Gregor und P. Schilder: Beitrüge zur Kenntnis

Dauer der Innervation

Dauer der Pause in $1 / 5$ Sekunde.

$\begin{array}{ll}11 / 2 & 11 / 2 \\ 11 / 2 & 13 / 1 \\ 11 / 2 & 2 \\ 13 / 4 & 2 \\ 11 / 2 & 21 / 2 \\ 1 & 21 / 2 \\ 1 & 21 / 2 \\ 1 & 3 \\ 1 & 2 \\ 1 & 21 / 2\end{array}$

Besonders bemerkenswert hierbei ist, daß die einzige Veränderung, die im Verlauf der Adiadochokinese im Kurvenbild auftritt, eine Abnahme der Amplitude der einzelnen Schwingung ist. Wiewohl wir in unseren Kurven ein so feines Reagens auf Ermüdung haben, konnten wir eine Abnahme der Sekundenfrequenz nicht nachweisen. Wie das graphische Bild zeigt, sind in der Willküraktion die Stöße des Tremors mitenthalten, wir zählten bei graphischen Aufnahmen des Tremors 5 (mechanische) Schwingungen pro Sekunde. Es ergibt sich hieraus, daß auch die Zuckung der Paralysis agitans als Tetanus aufzufassen ist (vgl. Fig. 25 u. 26).

Es ist uns jedoch auch gelungen, den direkten Nachweis hierfür zu erbringen. Wir haben vom Musculus biceps während des Tremors Aktionsströme abgeleitet. Es ergab sich, daß jeder Schlag des Tremors als Tetanus aufzufassen war. (Fig. 27.)

Bemerkenswert ist, daß wir vom Triceps surae beider Beine bei Auslösung des unerschöpflichen Fußkilonus Kurven erhielten. welche sich dadurch auszeichneten, daß dem Einzelschlag des Klonus eine Reihe von Impulsen entsprachen (2-4, meist 3), ein Verhalten, das von dem des Klonus bei Hemiplegie abweicht. (Fig. 28.)

Auch die Schrift zeigt Veränderungen, die zum Teil der Adiadochiokinese, zum 
Teil den Spannungen zuzuschreiben sind. Das Nachzeichnen kleiner Wellen gelingt nicht, während das Nachzeichnen größerer leicht möglich ist. Wir verweisen auf die Publikation Fischers, wo die einschlägigen Störungen eingehend beschrieben sind. Wir haben versucht, durch graphische Registrierung der Druckgröße bei möglichst rascher Folge von Haar- und Schattenstrichen ein genaueres Bild über die hier zugrunde liegende Veränderung zu bekommen ${ }^{1}$ ). Als das wesentlichste Resultat möchten wir hervorheben, daß die Druckgrößè während des
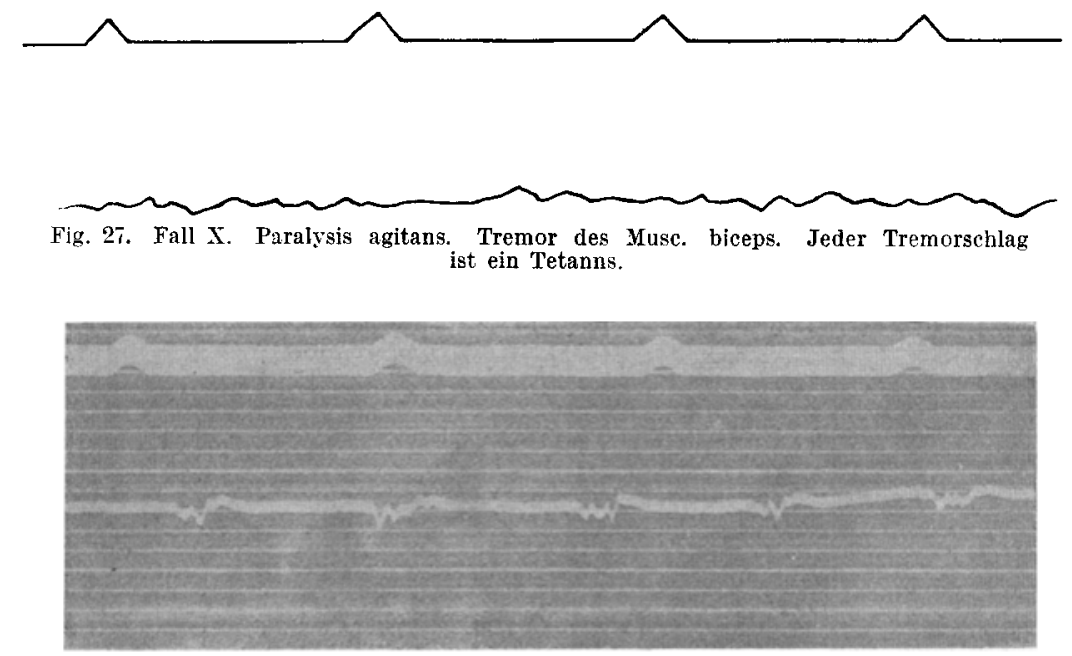

Fig. 28. Fall X. Paralysis agitans. Fußklonus. Jeder mechanische Klonusschlag kommt durch mehrere Impulse zustande.

Schreibens nicht zunimmt; das ist um so bemerkenswerter, als die Größe der Schriftzeichen im Verlaufe einer derartigen Untersuchungsreihe zunimmt. Auch wird die Dauer, innerhalb deren ein Druck ausgeübt wird, nicht größer, ja sie wird sogar geringer. Wie aus der beigegebenen Kurve ohne weiteres ersichtlich ist, vergrößern sich die Zeiten zwischen den Druckanstiegen. Eine genauere Prüfung ergibt jedoch, daß diese Verlängerung nur eine geringfügige ist. Die großen Pausen zwischen den Erhebungen kommen zum Teil dadurch zustande, daß die Druckdauer verringert ist. Auch hier ist das Resultat besonders auffällig dadurch, daß die Größe der Schriftzeichen im Verlaufe der Beobachtung zunimmt. Das beschriebene Resultat haben wir in übereinstimmender Weise bei 9 Aufnahmen erhalten. Fig. 29 gibt eine derartige Reihe wieder.

Zusammenfassung: Es handelt sich um einen recht typischen Fall von Paralysis agitans. Wir haben ihn deswegen eingehend geschildert,

1) Technik siehe bei Gregor und Hänsel.

z. f. d. g. Neur. u. Psych. O. XIV. 

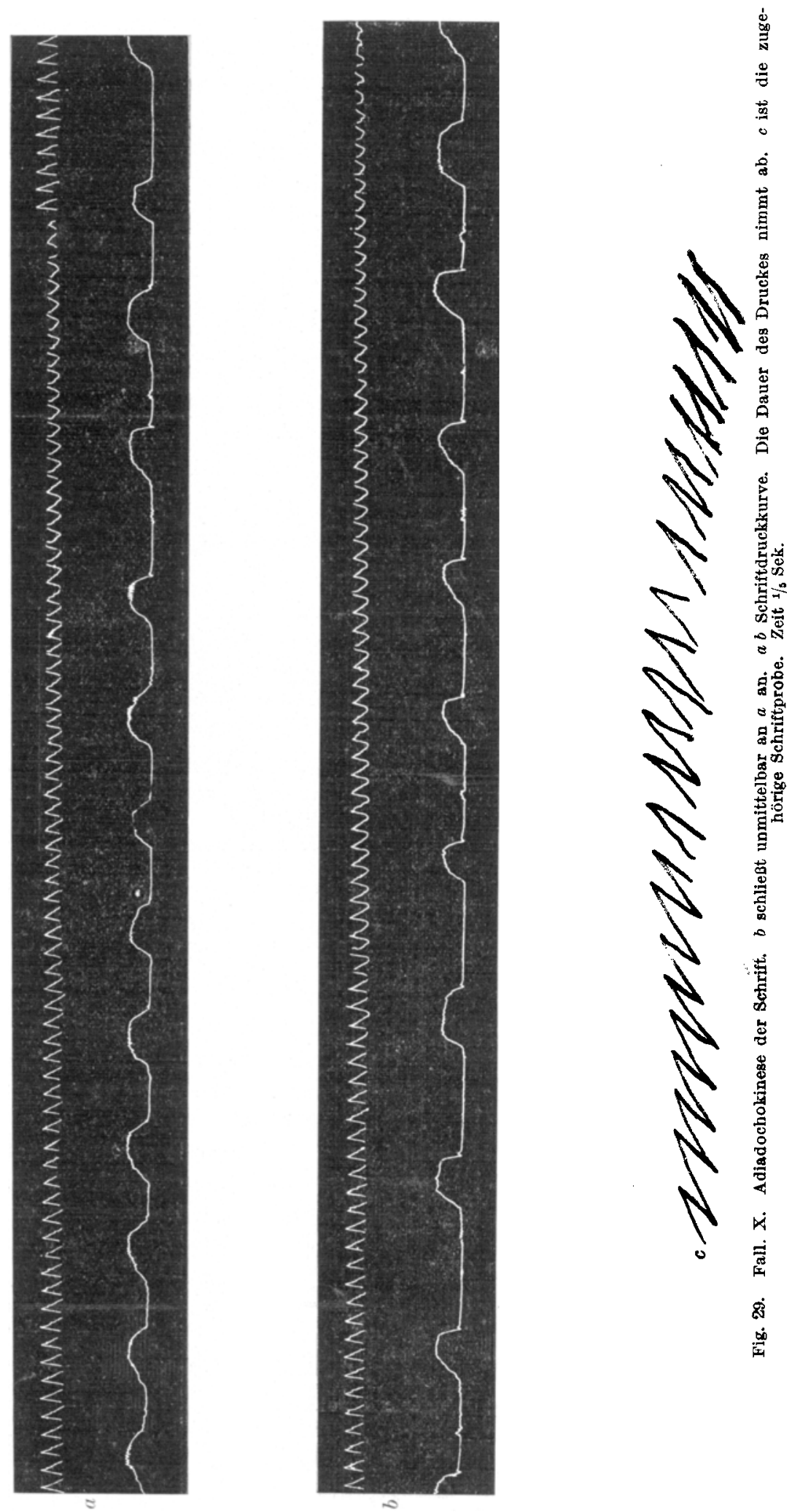
weil wir im Anschluß daran auf einige symptomatologische Fragen etwas näher eingehen möchten.

Bemerkenswert ist der Beginn mit psychischen Erscheinungen. Im Vordergrunde stehen Unruhe, Angstgefühle und Desorientiertheit (mit Merkfähigkeitsstörungen). Es liegt nahe, an die begleitende Arteriosklerose zu denken, doch spricht das rasche Abklingen der Psychose, sowie die Identität mit den auch sonst bei Paralysis agitans vorkommenden psychischen Störungen dafür, daß auch diese Erkrankung für die Psychose mitbestimmend war. Es ist auffallend, wie geringfügig im allgemeinen die psychischen Störungen bei der Paralysis agitans sind, wo doch die Motilität des gesamten Körpers in so schwerer Weise geschädigt ist. Gegenwärtig bietet unser Patient nur sehr geringfügige psychische Störungen. Es scheint uns insbesondere mit Rücksicht auf die Ideengänge, die Kleist eingeschlagen hat, bemerkenswert, daß es cerebrale Störungen der Motilität des Gesamtkörpers gibt, welche zwar Verarmung an Bewegungsantrieben hervorbringen können, aber doch die psychischen Mechanismen nicht in schwerer Weise tangieren müssen (bezüglich der psychischen Störungen bei Paralysis agitans vgl. auch die jüngst erschienene Arbeit von König, welcher allerdings die hier berührten Fragen nicht berücksichtigt).

Was nun die neurologischen Symptome der Krankheit angeht, so scheinen uns die Symptome der Adiadochokinese eine größere. Beachtung zu verdienen, Adiadochokinese ist bei der Paralysis agitans wiederholt festgestellt worden (insbesondere Zi ingerle, Ja nis c he ws k y, Forster).

Die Adiadochokinese der Augenmuskeln, der Sprache und Schrift ist jedoch an sich nicht oft beobachtet worden (vgl. Fischer) bei dieser Krankheit nur von Janischewsky erwähnt.

Bevor wir jedoch auf diese Dinge näher eingehen, müssen wir versuchen, den Mechanismus der Störung klarzulegen.

Babinskis Beschreibung der Bewegungsstörung geht dahin, daß die einfache Bewegung, Pronation und Supination, prompt ausgeführt werden kann, daß aber die Gesamthandlung eine viel größere Zeit in Anspruch nimmt, als beim Normalen. Diese Störungen treten bei Wiederholungen noch viel deutlicher hervor. Nach unseren Untersuchungen (Muskelverdickungskurven) ist die Bewegungsstörung mit der Bezeichnung Verlangsamung nicht genügend gekennzeichnet. Unsere Untersuchungen ergaben als besonders auffällig eine Abnahme der Dickenzunahme des Muskels. Die Innervation nimmt einfach ab, und hört schließlich vollkommen auf; dabei wird die Bewegung in der gleichen Zeit aber in geringerem Ausmaß ausgeführt. Eine Verlangsamung der Bewegung besteht nun insofern, als ja in der gleichen Zeit ein kleinerer Weg zurückgelegt wird, die Gesamtbewegung nimmt aber zu Beginn 
und gegen das Ende der Bewegungsreihe die gleiche Zeit in Anspruch. Wir sehen also, in der Abnahme der Kontraktion das wesentliche Merkmal der Adiadochokinese ${ }^{1}$ ). (Fig. 24.)

Eins ist hervorzuheben: In unserem Falle erfolgen die Willkürbewegungen von vornherein langsam, wir glauben aber, daß diese Langsamkeit der Bewegungen eine Störung ist, welche selbständig neben der anderen steht; dafür spricht, daß es zweifellos Fälle gibt, in denen bloß diese Langsamkeit der Bewegungen besteht, ohne daß der Muskel im weiteren Verlauf der Bewegungsfolgen im geringeren Grade innerviert wird. Wir haben selbst Gelegenheit gehabt, einen derartigen Fall graphisch aufzunehmen, es war dies ein Fall von Friedreichscher Ataxie (auf den wir noch zurückkommen); einen weiteren derartigen Fall hat Schilder in Halle Gelegenheit gehabt, zu untersuchen. Anderesteils zeigten uns klinische Untersuchungen in einem Fall von Kleinhirnbrückenwinkeltumor, daß die erste Bewegung einer Bewegungsfolge bei gestörter Diadochokinese durchaus nicht verlangsamt sein muß, die gleiche Beobachtung haben wir an unseren Choreafällen gemacht. Diese Darlegung entspricht auch der ursprünglichen Schilderung Babinskis.

Wir trennen also die Abnahme der Kontraktion im Verlauf einer Bewegungsfolge von der Langsamkeit der Bewegungen.

In dem Falle F. zeigt es sich z. B. bei Pro- und Supinationsbewegung schon klinisch (wenn man erst aufmerksam geworden ist), daß die Bewegung sehr bald nur in geringerem Ausmaß ausgeführt wird, während die kürzere Bewegung noch immer die gleiche Zeit in Anspruch nimmt, wie die längere.

Es drängt sich nun die Frage auf, ob die Abnahme der Kontraktion begründet sei in abnorm rascher Ermüdung. Die Untersuchung mit dem Saitengalvanometer hat uns mit Bestimmtheit gezeigt, daß diese $\mathbf{A b}$ nahme mit Ermüdung nichts zu tun hat, es fehlten die charakteristischen Bilder, welche bei Ermüdung auftreten. (Fig. 26.)

Ein Blick auf unsere Kurven ergibt, daß (Fig. 24-26) wir uns mit einer Theorie, welche die Adiadochokinese auf eine abnorm lange Nachdauer der Muskelkontraktion zurückführt, nicht einverstanden erklären können. Es nimmt die Spannung in Muskel, wie die Aufnahmen mit dem Sphymographen zeigt, im Verlauf einer Bewegungsfolge nicht $\mathrm{zu}$, sondern ab. Es läßt sich das übrigens auch klinisch ohne weiteres nachweisen. Dieses Verhalten ist Schilder bei der Untersuchung cer Adiadochokinese der Chorea minor aufgefallen, und hat ihn zu der Annahme geführt, daß die Adiadochokinese der Chorea minor nicht,

1) Der einzige Hinweis in der Literatur findet sich, soviel uns bekannt, in der Arbeit Zingerles, der bei Ergographenversuchen den raschen Abfall der Leistung konstatiert hat. 
wie dies von Kleist, Zingerle und Forster angenommen wird, auf abnormer Nachdauer der Muskelkontraktion beruht (vgl. Abb. Fall XI). Wir glauben auf Grund unserer Untersuchung am Paralysisagitans-Kranken und nach Untersuchungen an einem Kleinhirnkranken diese Behauptung verallgemeinern zu können.

Auf die Genese der Langsamkeit der Bewegung gehen wir hier nicht ein, wir können nicht sagen, ob nicht diese mit abnormer Kontraktionsdauer etwas zu tun hat. Es scheint uns um so notwendiger, die Besonderheit dieser Erscheinung ausdrücklich zu betonen, als in der Literatur vielfach Langsamkeit der Bewegungen völlig gleichgestellt wird der Adiadochokinese (Isserlin und Lot mar, Markuse, Fischer und andere). Mögen auch beide Symptome auf das Kleinhirn und auf Haubenbahnen verweisen, so muß doch daran festgehalten werden, $\mathrm{da} ß$ es sich um klinisch verschiedene Erscheinungen handelt. $\mathrm{Ob}$ es neben diesen Elementarstörungen noch andere gibt, die in gewissen Adiadochokineseformen enthalten sind, steht dahin.

Eine ausreichende Erklärung der Adiadochokinese scheint derzeit nicht gut möglich, an Gedankengänge Zingerles über die Verarmung der Willkürbewegungen und über die Langsamkeit der Bewegungen bei der Paralysis agitans anknüpfend, möchten wir die Vermutung aussprechen, daß der Ausfall subcorticaler Mechanismen als Ursache anzusehen ist und daß wir es hier mit Leistungen zu tun haben, welche der Cortex mit mangelhafter oder fehlender Unterstützung des Subcortex zustande bringt. $\mathrm{Ob}$ es sich hier um eine Schädigung afferenter oder efferenter Mechanismen handelt, bleibe dahingestellt.

Wir gehen dazu über, die Adiadochokinese der einzelnen Hirnnerven zu besprechen. Sehr auffällig zeigt sie die Gesichtsmuskulatur. Am Mundfacialis läßt sich klinisch ohne weiteres beobachten, daß die verschieden schwer geschädigten Körperhälften mit der Innervation gleichzeitig einsetzen, daß aber auf der schwer geschädigten bei öfterer Wiederholung der Effekt immer geringer wird. Gar nicht selten ereignet es sich auch, daß schon beim ersten ,Zähnezeigen“ die Lippe rechts ungenügend gehoben wird. Bei entsprechend oft wiederholter Untersuchung läßt sich jedoch zeigen, daß eine Parese nicht vorliegt. Es besteht vielmehr eine verminderte Ansprechbarkeit. Es scheinen uns überhaupt zwischen verringerter Ansprechbarkeit und Adiadochokinese außerordentlich enge Beziehungen zu bestehen.

Störungen der Diadochokinese trafen wir auch an, im Bereich der Bulbärmuskeln, Bruns und Op pe nhei m haben auf bulbärparalytische Symptome bei der Paralysis agitans verwiesen. Zingerle hat demgegenüber darauf aufmerksam gemacht, daß vielleicht doch nur eine mangelnde Ansprechbarkeit, aber keine Parese vorliegen könne. Es ist interessant, daß in unserem Falle von den ersten Untersuchern 
Pseudobulbärparalyse diagnostiziert worden war. Es gelang aber der Nachweis, daß das Gaumensegel nicht paretisch war, sondern erschwerte Ansprechbarkeit und höchstgradige Adiadochokinese aufwies. Das einzige sichere Lähmungssymptom, die Recurrensparese, ist nach dem ganzen Befunde (diffuse Erweiterung der Aorta) eine Komplikation. Der eine von uns hat auf die Möglichkeit verwiesen, daß der bulbärparalytische Symptomenkomplex bei Chorea (Bruns) durch Adiadochokinese vorgetäuscht sein könne.

Viel größere Schwierigkeiten macht die Beurteilung der Sprachstörungen. Vorausgeschickt sei, daß die Recurrensparese nur die Heiserkeit, nicht aber die mannigfaltigen anderen Störungen erklärt. Der Kranke hat zunächst Schwierigkeiten, mit dem Sprechen zu beginnen. Schon diese Störung ist schwer zu deuten. Das Nächstliegende ist mit Oppenheim anzunehmen, daß Sperrungen durchbrochen werden müssen. Es muß jedoch auch verminderte Ansprechbarkeit in Erwägung gezogen werden. Betreffs der übrigen Störungen vermerken wir folgendes: Für das Sprechen genügt es nicht, wie für die Pro- und Supination, daß eine Bewegung überhaupt begonnen wird, sie muß vielmehr auch in einem gewissen Ausmaß durchgeführt werden. Es kann so, wenn nicht wie bei der Pro- und Supination die rasche Folge, sondern eine Bewegung bestimmter Größe als Hauptforderung erscheint, diese quantitativ geforderte Bewegung eine größere Zeit in Anspruch nehmen. Den hier dargelegten Mechanismus wird man erst recht für Wortfolgen in Anspruch nehmen können und es wäre dann für das Gebiet der Sprache ein deutlicheres Hervortreten der Verlangsamung zu erwarten. Bei unserem Patienten ist ein Langsamwerden der Sprache auch deutlich bei raschen Silbenfolgen. Zugleich wird das Sprechen aber auch, und darauf legen wir Gewicht, leiser. Die gleichen Sprachstörungen haben wir auch in dem Falle XI angetroffen. Wo diese Erscheinungen nicht vorhanden sind, hat man unseres Erachtens nicht das Recht, von Adiadochokinese zu sprechen. Wir betonen das um so mehr, als eine Reihe von Autoren (z. B. Fischer, Marc use) Langsamkeit der Sprache und Verlangsamung der Sprache nicht trennen. Es sind klinisch differente Erscheinungen. In unserem Falle $\mathrm{X}$. ist die Sprache auch an sich langsam, daneben besteht Verlangsamung, in dem Falle XI besteht nur Verlangsamung, in den Fällen XII (Haubenerkrankung) und XVI (Friedreichsche Ataxie) Langsamkeit der Sprache.

Recht interessant sind die graphischen Aufnahmen des Schreibdruckes. Leider sind die Verhältnisse so kompliziert, daß auch hier die Deutung nur höchst rudimentär sein kann. In einer ganzen Anzahl der Kurven ist auffällig, daß die Zeit, innerhalb derer ein Druck ausgeübt wird, im Verlauf einer Folge von Haar- und Schattenstrichen geringer wird. Verhältnisse, die sich gewiß am ehesten unter Berücksichtigung 
dessen erklären lassen, was wir oben über Pro- und Supination mitgeteilt haben. Daß sich auch eine Vergrößerung der Zeiten zwischen dem Ansteigen des Schreibdruckes findet, ist darauf zurückzuführen, daß es beim Schreiben nötig ist, daß eine ganze Reihe von Muskeln, (z. B. Schulterabduktoren) beim Schreiben doch auch Bewegungen von einem gewissen Ausma $B$ machen müssen, hier wird dann der Mechanismus in Kraft treten, dessen wir bei der Adiadochokinese der Sprache gedachten. Es muß beim Schreiben versucht werden, unter Verlängerung der Innervationsdauer die quantitativ notwendige Leistung hervorzubringen. Selbstverständlich ist das nur eine Hypothese (vgl. Fig. 29).

Ein Versuch, die Sprechatmung während des Eintrittes der Adiadochokinese graphisch zu registrieren, führte nicht zu eindeutigen Resultaten.

Es erübrigt darauf hinzuweisen, daß wir mit dem Seitengalvanometer trotz der Hochgradigkeit des Rigors keine Abweichungen von dem normalen Typus der Willküraktion antrafen. Es ist uns auch nicht gelungen, von dem ruhenden gespannten Muskel Ströme abzuleiten.

Hingegen ist uns die Aufnahme des Tremors gelungen, jeder Tremorschlag war in eine Reihe von Einzelimpulsen zerlegbar. (Fig. 27). Das gleiche Resultat haben Bornstein und Sänger erzielt.

Schließlich ist noch hervorzuheben, daß wir am Bein einen unerschöpflichen Fußklonus erzielen konnten, der sich klinisch nicht unterschied von dem Fußklonus bei Pyramidenbahnläsion. Wir haben jedoch den mechanischen Einzelsto $ß$ des Klonus mit Sicherheit und ausnahmslos in zwei bis vier Wellen zerlegen können. Das ist um so auffälliger, als dem mechanischen Einzelstoß des Klonus bei Pyramidenbahnläsion zwar gelegentlich 2-3 Impulse entsprechen, aber doch überaus häufig ein Innervationsimpuls zugrunde liegt. Zittern war am Bein im übrigen nicht nachweisbar, die Zerlegbarkeit des Einzelstoßes drängt jedoch zu der Annahme, daß hier nicht der Mechanismus des Klonus, sondern der des Zitterns vorliegt. Man wird also das Vorkommen des ,echten“ Fußklonus für die Paralysis agitans verneinen müssen, die feinere Untersuchung deckt auch bei denjenigen Fällen, welche der gewöhnlichen Betrachtung nicht als „Fußzittern“ (vgl. O p penheim) imponieren, den von dem Klonus der Hemiplegie differenten Mechanismus auf. (vgl. Fig. 28). Es sei nochmals erwähnt, daß Zittern am Bein nicht sichtbar war.

Fall XI. 30 Jahre. Invalide. Familienanamnese und Vorgeschichte belanglos. Vor 2 Jahren 6 Monate lang Gelenkrheumatismus. Im Anschluß hieran die jetzige Erkrankung, die mit Sprachstörungen und Zuckungen einsetzte. Eine wesentliche Anderung ist seither nicht eingetreten. Die körperliche Untersuchung ergibt bei der Aufnahme vom 18. Nov. 1912 folgendes: Degenerative Physiognomie: Schmale niedrige Stirn, außerordentlich kleiner Unterkiefer. Innere Organe: Herz, Lunge o. B. Pulsfrequenz um 50. Wassermann -. Neurologisch: Mäßig reichliche 
choreatische Spontanzuckungen im Gesamtbereich des Körpers. Dabei überwiegen in typischer Weise die distalen Gelenke. Auffallend ist die Reichlichkeit tonischer Zuckungen, insbesonders treten tonische Extensionszuckungen der großen Zehe und des Daumens häufig auf. Eigenartig ist, daß von den Gesichtsmuskeln nur der linke untere Facialis betroffen ist. Dieser zeigt rasch aufeinanderfolgende Stöße. Die Zunge zeigt im Munde keine Zuckungen bei Ruhe. Die Zuckungen schwinden während des Schlafes. Regellose generalisierte Mitbewegungen. Hypotonie und Ataxie sind im Gesamtbereich des Körpers nicht sicher nachweisbar. Es besteht sowohl an den Armen als auch an den Beinen eine sehr hochgradige Adiadochokinese. Auch hier nimmt die Bewegung sehr rasch ab und hört schlieBlicb vollkommen auf. Sehr ausgeprägt ist diese Erscheinung im Gebiete der Gesichtsmuskulatur (er kann nicht pfeifen!), während die Zunge weniger deutlich betroffen ist. Die Zunge zeigt beim Vorstrecken ein grobes Zittern, das man am ehesten als Folge mehrerer klonischer Stöße bezeichnen könnte. Die vorgestreckte Zunge ist ruhig. Sehr ausgesprochen ist eine Störung der Sprache, die sich in gelegentlichem plötzlichen Versagen geltend macht. Er stockt bisweilen plötilich, kommt nicht recht weiter. Das Sprechen ist langsam. Besonders deutlich ist diese Störung dann, wenn man ein Wort (z. B. 66) mehrmals hintereinander sagen läßt. Es tritt dann eine lang. samere Folge der Worte ein, dabei wird die Stimme leiser. Die grobe Kraft und die Beweglichkeit zeigt im Gesamtbereich des Körpers keine Störungen. Der Gang ist durch die Mitbewegungen und durch die choreatischen Zuckungen gestört. Hautreflexe und Sehnenreflexe sind normal; nur zeigen die Patellarsehnenreflexe tonische Verlängerung (mäßigen Grades). Die sensiblen und sensorischen Funktionen ungestört (insbes. Augenhintergrund o. B.). Er ist psychisch nicht auffällig.

Diagnose: Chorea minor.

Wir haben zunächst in der oben beschriebenen Art die Adiadochokinese graphisch aufgenommen (vom Musculus biceps). Die Resultate waren, wie die beifolgende Fig. 30 zeigt, die gleichen wie bei der Untersuchung des vorangehenden Falles, es ergab sich im wesentlichen Abnahme der Kontraktionshöhe. Die Kurve zeigt eklatant, daß von einer Nachdauer der Spannung nicht die Rede sein kann. Nur eine der Erhebungen zeigt ein Plateau.

Mit dem Saitengalvanometer haben wir den tonisch verlängerten Patellarreflex untersucht. (Fig. 31). Er ließ sich stets in eine größere Reihe von Stromschwankungen zerlegen. Die Anordnung dieser war insofern charakteristisch, als auf die biphasische Schwankung, die dem Reflex entspricht, eine Pause von etwa $1 / 5$ Sekunden Dauer folgte, an die sich dann eine größere Reihe von verhältnismäßig langsam aufeinanderfolgenden Stromschwankungen (etwa 7 auf $1 / 5$ Sekunde) anschloß. Eine dieser Reihen dauerte 6 Sekunden. Die Willküraktion des Musculus quadriceps zeigte Aktionsstromfrequenzen von etwa 45 pro Sekunde.

Zusammenfassung: Es liegt Chorea minor vor. Der Fall zeigt eine Reihe von Besonderheiten: die schwere Beteiligung der Sprache, das starke Hervortreten der Adiadochokinese, die Lokalisation der Zuckungen in einem Facialisast; schließlich ist die Dauer der Erkrankung eine große. Für eine andere Erkrankung (etwa Tumor) fehlen jedoch die Anhaltspunkte. 

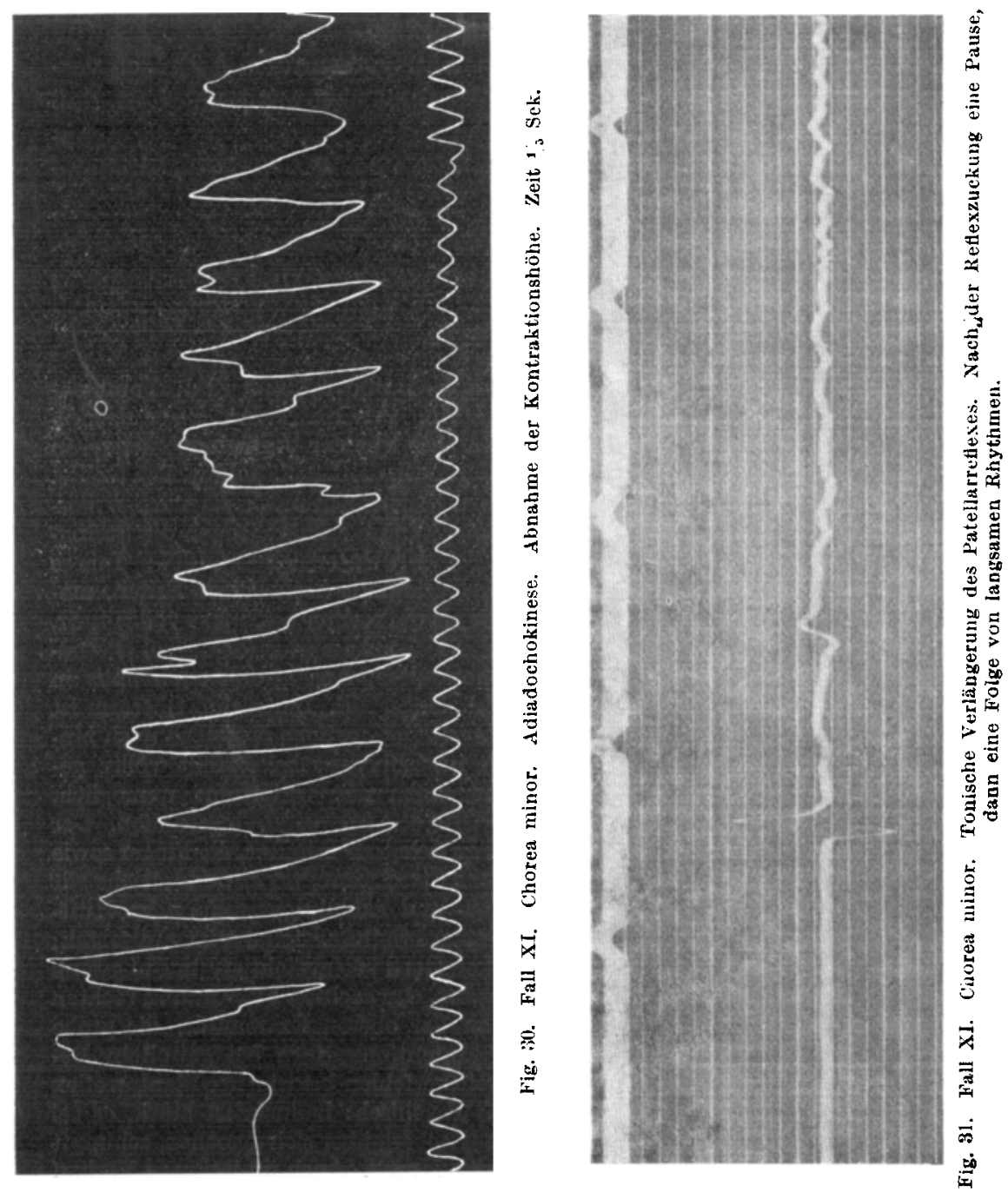

Die graphische Aufnahme der Verdickung des Musculus biceps bei rascher Folge von Pro- und Supination ergab eine Bestätigung der Resultate, die an dem vorangehenden Fall gewonnen wurden. Wieder zeigte sich Abnahme der Kantraktion. Nur selten findet sich Plateaubildung. Ob hier interkurrente choreatische Zuckungen oder Spannungsverlängerung vorliegt, läßt sich nicht entscheiden, jedenfalls ist das Vorkommen derselben viel zu selten, um für die Erklärung der Bewegungsstörung in Betracht zu kommen. Da wir es hier mit einem Fall 
zu tun haben, wo die erste Bewegung vollkommen prompt vonstatten geht, so bietet dieser Fall eine Ergänzung zu dem vorigen.

Bemerkenswert erscheint das Untersuchungsresultat des tonisch verlängerten Patellarreflexes. (Fig. 31). Es ergibt sich mit Sicherheit, daß es sich um eine tetanische Innervation handelt. Naheliegend ist, anzunehmen, daß der Patellarreflex reflektorisch eine choreatische Zuckung auslöst. Für diese Annahme, die schon klinisch sehr wahrscheinlich ist, spricht, daß zwischen beide Erscheinungen eine Pause eingeschaltet ist. Die tonische Nachdauer hat aber auch eine geringere Sekundenfrequenz als die Willküraktion, ein Verhalten, das wir auch bei der choreatischen Zuckung vorgefunden haben.

Fall XII. J. D. Q. 51 Jahre, zum ersten Male in der Klinik 1891. Familien. anamnese belanglos, 10 lebende Kinder, 2 Aborte. Von 10 Kindern 6 vor Beendi. gung des ersten Lebensjahres gestorben. 3 Jahre vor der Aufnahme Zittern in beiden Händen, vorwiegend dann, wenn die Patientin die Hände gebrauchen wollte. Allmählich Steifheit im rechten Arm und Bein. Seit einem Jahre eigenartige Veränderung der Sprache. Nach den Angaben des Mannes scheint jedoch die Steifigkeit rechts plötzlich eingetreten zu sein. Bei der Untersuchung 1891: Innere Organe o. B., Zunge weicht nach rechts ab, Nystagmus nach beiden Seiten, motorische Hirnnerven o. B., linke Pupille weiter als die rechte, beide fast völlig starr, Kopf nach rechts gezogen, durch Spasmen der Halsmuskulatur (Scalenus, Sternocleidomastoideus, Trapezius). Leichte Kyphoskoliose, Ausbiegung nach links in der Brust - nach rechts in der Lendenwirbelsäulengegend. Der rechte Oberarm ist abduziert und nach rückwärts gehalten, zuckende Bewegungen desselben nach hinten, Schulter fixiert. Der rechte Arm kann im Ellbogengelenk nicht völlig gestreckt werden, Pro- und Supinationsbewegungen des Unterarms unmöglich, ebenso die Fingerspreizung, rechts Spasmen, die Spatia interossea eingesunken. Der rechte Unterarm in ständiger Bewegung, die an Athetose erinnert, die Finger sowie der Daumen machen kontinuierlich Beuge- und Streckbewegungen; das gleiche gilt vom Handgelenk. Das rechte Bein in Beuge- und Adduktionsstellung im Hüftgelenk und leichter Beugung im Kniegelenk, starke Spitzfußstellung im Fußgelenk; die aktive Beweglichkeit in sämtlichen Gelenken stark beeinträchtigt, im Fußgelenk fast aufgehoben, passive Beweglichkeit erschwert. Im rechten Fuß-und in rechten Zehengelenken ähnliche Bewegungen wie an der oberen Extremität, die grobe Kraft links nicht wesentlich herabgesetzt. Intentionszittern bei gewollten Bewegungen. Die Patellar- und Achillessehnenreflexe fehlen beiderseits, Plantarreflex links stärker als rechts. Sensibilität intakt. Psychisch: halluziniert stark, es sei schlechter Geruch im Zimmer, hört eine Frau Kleeberg über sich sprechen, schimpft dann laut, hört auch Beschimpfungen, ,sei eine Hure". Auch im weiteren Verlauf Juni 1891 bis 1894 Zustand unverändert, halluziniert dauernd, hört geschlechtliche Verdächtigungen, sei ein Freudenmädchen gewesen, rechtfertigt sich gegen die Beschuldigung der Stimme, daß sie mit dem Arzt im Kastenbett gelegen habe, hört ihren Mann vor dem Fenster mit einer Wärterin sprechen, glaubt sie bekäme Schlafpulver, um nachts mißbraucht zu werden. 1894 macht der rechte Vorderarm fortwährend Flexions- und Extensions, Pronations- und Supinationsbewegungen, im Fuß fortwährende Plantarflexionen, das linke Bein kann nur wenig gehoben werden, kann nicht gehen. Auch in den folgenden Jahren hört sie häufig Schimpfreden, auf die sie antwortet. Der körperliche Befund zeigt keine wesentlichen Veränderungen. 1895 ist Beschränkung der Augenbewegungen nach oben und außen notiert. Mai 1901 wird durch spezialistische Untersuchung festgestellt, daß eine 
Parese des gesamten linken Oculomotorius besteht. Die zeitliche und örtliche Orientierung ist nach wie vor gut, das Gedächtnis zeigt keine wesentlichen Defekte, hört jetzt viel ,die Geistmenschen schimpfen, diese kämen aus dem Geistersaal, welcher in der Unterwelt sei". Unter der Klinik sei ein Keller- voller Kinder, sie höre diese schreien, die Geistmenschen ermordeten sie wegen der schönen Kleider. Früher sei eine Rädermaschine dagewesen, sie habe sie jedoch durch folgende Verse verscheucht. „Rädermaschine wandere fort, geh an einen anderen Ort". Seither im psychischen Zustande keine wesentliche Änderung. Der somatische Befund ist gegenwärtig folgender: Innere Organe im wesentlichen o. B., Wirbelsäule kyphoskoliotisch, Wassermann negativ. Neurologisch: Facialis rechts eine Spur schwächer innerviert als links, weicher Gaumen links etwas besser gehoben, die Zunge weicht stark nach rechts ab, die rechte Zungenhälfte stark atrophisch und rissig: Parese des gesamten linken Oculomotorius ${ }^{1}$ ), die Konvergenz und Lichtreaktion beider Pupillen ist fast aufgehoben, Corneal und Conjunctivalreflexe sind erhalten, Geruch, Geschmack, Sehnerven o. B. Hörschärfe rechts etwas herabgesetzt.

Die Beweglichkeit der Wirbelsäule in dem unteren Abschnitt durch Verkalkung der Bänder so gut wie aufgehoben, sitzt deshalb ständig im Bett, kann nicht gehen. Der rechte Arm befindet sich in typischer Contracturstellung, die Hand zeigt einen rhythmischen grobschlägigen Tremor, der betrifft 1. die Handbeuger, 2. die Fingerbeuger, insbesondere aber den Adductor pollicis. Der Tremor ist kontinuierlich und verstärkt sich bei Aufregungen und nach Willküraktion. Das Bein ebenfalls in Contracturstellung: Adduction, Außenrotation im Hüftgelenk, minimale Beugung im Kniegelenk, Spitzfußstellung unter gleichzeitiger erheblicher Kontraktion der Zehenbeuger. Tremor von der gleichen Struktur wie der Tremor der Hand am Triceps surae. Die Contractur entspricht sowohl im Arm als auch im Bein der wächsernen Contractur, indem das Glied bei passiv gegebenen Stellungen außerordentlich rasch fixiert wird. Außerdem herrscht eine nicht unbeträchtliche Ruhespannung. Die aktive Beweglichkeit ist im Bereich der rechten Extremitäten in sämtlichen Gelenken mehr oder minder stark behindert, der Prädilektionstypus ist dabei nicht gewahrt, im allgemeinen ist die Beweglichkeit in den distalen Gelenken stärker behindert als in den proximalen. An den linken Extremitäten keine Änderungen des Tonus, der Beweglichkeit und Kraft. Sämtliche Sehnenreflexe sowohl rechts als auch links nicht auslösbar. Bauchdeckenreflexe fehlen. Kein Babinski. Kein Oppenhein, Sensibilität, soweit zu prüfen, o. B. Die Patientin ist psychisch unverändert, halluziniert dauernd, hört meistens die Stimmen von oben und von links kommen.

Diagnose: Benediktscher Symptomenkomplex.

Wir haben zunächst zahlreiche Aufnahmen des Tremors gemacht und haben mit Sicherheit nachweisen können, daß der mechanische

1) Der Befund war 1901: Fixiert mit dem rechten Auge, das linke steht in Deviationsstellung, ist nicht zur Akkomodation zu bringen. Das linke Auge bleibt beim Blick nach oben und rechts zurück, über den Blick nach unten ist nichts Genaues festzustellen. Doppelbilder: Das Bild des linken Auges steht rechts von dem des rechten. Der Abstand nimmt zu beim Blick nach rechts, ab nach links, beim Blick nach oben steht das Bild des linken Auges höher, mit Höherwandern des Bildes nimmt der Abstand der Doppelbilder zu. Beim Blick nach unten keine sicheren Angaben. Es besteht links eine Parese der inneren Aste des Oculomoto. rius, ferner des Rectus internus, der beiden Heber (rectus superior, obliquus inferior). U̇ber die Beteiligung der Senker läßt sich keine bestimmte Angabe machen Diagnose: Parese des gesamten linken Okulomotorius. Eine Prüfung der Doppelbilder ist gegenwärtig nicht mehr möglich. 
Einzelstoß des Tremors durch eine Reihe von Impulsen zustande kommt. Wir haben kontinuierliche Rhythmen erhalten und geben einige der Frequenzzahlen wieder: $11,4,12,8,5,5, \ldots \ldots 2,8,6,3,5,6,6,6$, gelegentlich treten etwas längere Pausen auf, welche die Dauer von einer $1 / 5$ Sekunde haben. Derartige Kurven haben wir zunächst von den Unterarmbeugern erhalten (Fig. 32), doch ergab die Aufnahme von Triceps surae im wesentlichen identische Resultate, einige Werte seien angeführt: $5,7 \ldots 6,5,4,4, \ldots .5,4,3,5,5,4$ usw. (Fig. 33).

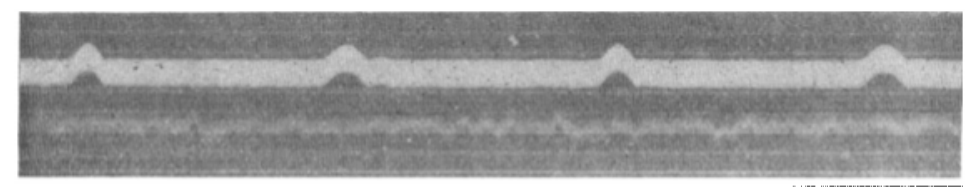

Fig. 32. Fall XI1. Benediktscher Symptomenkomplex. Tremor der Hand. Unterarmbeuger. Jeder Tremorschlag ist ein Tetanus.

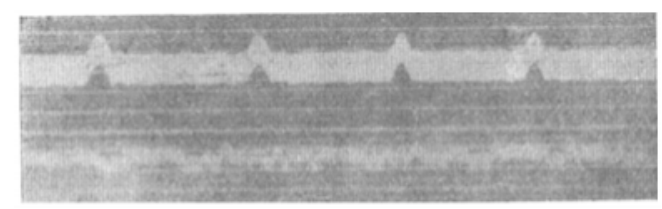

Fig. 93. Fall XII. Benedilitscher symptomenliomplex. Tremor des Fußes. Triceps surae.

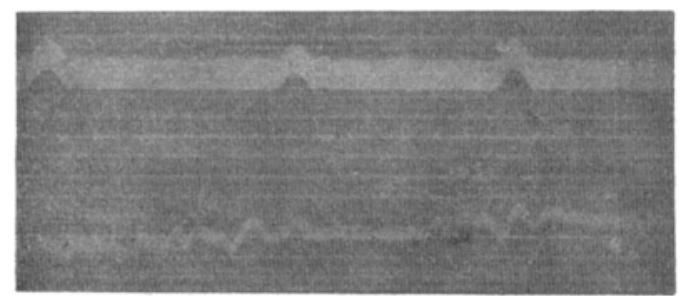

Fig. 34. Fall XII. Reflektorische Gegenspannung des wächsern gespannten Quadriceps. Langsame Rhythmen.

Die Willküraktion haben wir zunächst an den erkrankten Unterarmbeugern studiert. Wir erhielten folgende Werte: 5, 9, 6, 6, 8, 9, 9, 10, 3, 6 usw. Wir haben ferner die Willküraktion und die Gegenspannung am Quadriceps aufgenommen, für die Gegenspannung (diese wurde in der Art erzielt, daß der gestreckte Oberschenkel im Kniegelenk brüske gebeugt wurde) erhielten wir die folgenden Zahlen: 5, 6, 7, 4, 3, ... $6,3,3,5,6$, für die Willküraktion: 4, 4, 6, 6, 4, 7, 4, 4, 4, 3 (Fig. 34 und 35). Bei der Willküraktion traten gelegentlich auch Zuckungsgruppen auf, doch waren diese nur außerordentlich selten im Ver- 
gleich zu den später zu erwähnenden Fällen von spastischer Hemiplegie. Wurde das Bein aus gestreckter Stellung aktiv gebeugt (im Kniegelenk), so traten auch an den Streckern Aktionsstromwellen hervor: $4,3,5,5,7,5,5,7,4,4,4,5,5$ usw. Dieser Versuch ließ sich jederzeit mit dem gleichen Resultate wiederholen (Fig. 36). Von dem Quadriceps des in Streckstellung befindlichen ruhenden rechten Beines konnten Aktionsströme abgeleitet werden, die Werte lauteten: $5,8,6,4,3,3, \ldots \ldots 4,4,5$, 3 usw. Die Wellen waren außerordentlich niedrig, aber doch deutlich zählbar (Fig. 37).

Zusammenfassung: Wenn wir resümieren, so liegt ein recht typischer Fall Benediktscher Lähmung vor, es besteht Oculomotoriuslähmung links und eine hypertonische Parese mit Zittern rechts. Doch ist auch der Oculumotorius der anderen Seite mit geschädigt (Pupillenstarre) und an der linken Körperhälfte, für deren Schädigung die anamnestische Angabe spricht, daß auch sie Schüttelbewegungen zeigte, fehlen die Sehnenreflexe vollkommen. Das Fehlen der Sehnenreflexe und die beiderseitigen Pupillensymptome könnten den Gedanken einer diffusen luetischen oder einer metaluetischen Erkrankung nahelegen, eine Vermutung, welche durch das Fehlen der Wassermannschen Reaktion im Blute (Lumbalpunktion war wegen Verkalkung der Bänder nicht durchführbar) nicht vollkommen entkräftet wird.

Es führen jedoch Halban und Infeld in ihrer Zusammenstellung einen Fall von Gilles de la Tourette und Charcot an, wo bei einseitiger durch Herdlaesion bedingter Chorea beiderseits die Sehnenreflexe fehlten. Bedenkt man ferner, daß bei Erkrankungen der Haube eine mehr oder minder starke Beeinträchtigung der Sehnenreflexe in 15 bis $20 \%$ der Fälle vorkommt (nach Halban und Infeld), so wird

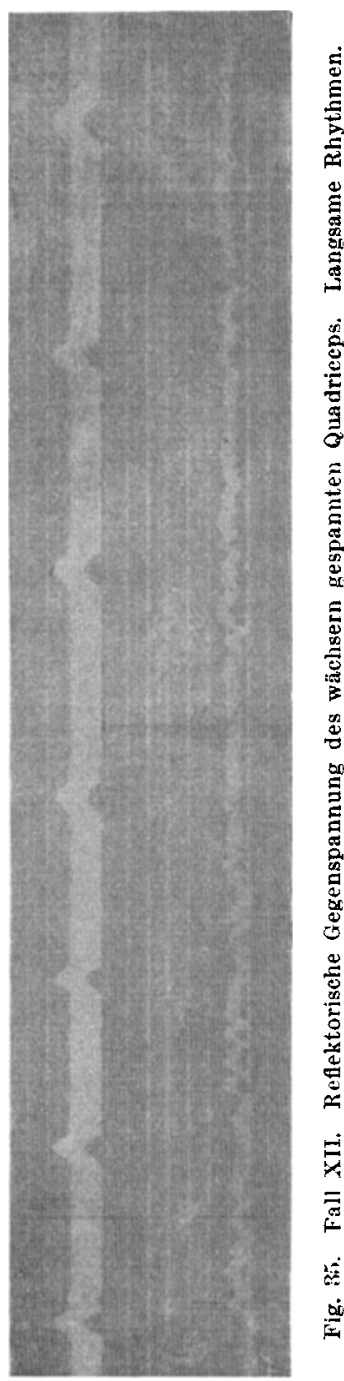
man in dem Fehlen der Patellarreflexe kein Symptom sehen, das nicht auf den Haubenherd bezogen werden könnte. Auch die Schädigungen des rechten Oculumotorius hat bei einem solchen nichts Auffallendes. Es scheint uns demnach berechtigt, 
sämtliche neurologische Erscheinungen auf einen Haubenherd zu beziehen, die Möglichkeit, daß dieser luetischen Charakters sei, ist nicht auszuschließen.

Soviel zur Diagnose; wir gehen jetzt auf einige Punkte der Symptomatologie etwas näher ein. Die Psychose läßt eine sichere Klassifikation nicht zu, im Vordergrunde stehen Gehörshalluzinationen beschimpfenden Inhalts, doch ist es weder zu einer Systematisierung gekommen, noch haben sich typisch schizophrene Symptome eingestellt, aller-

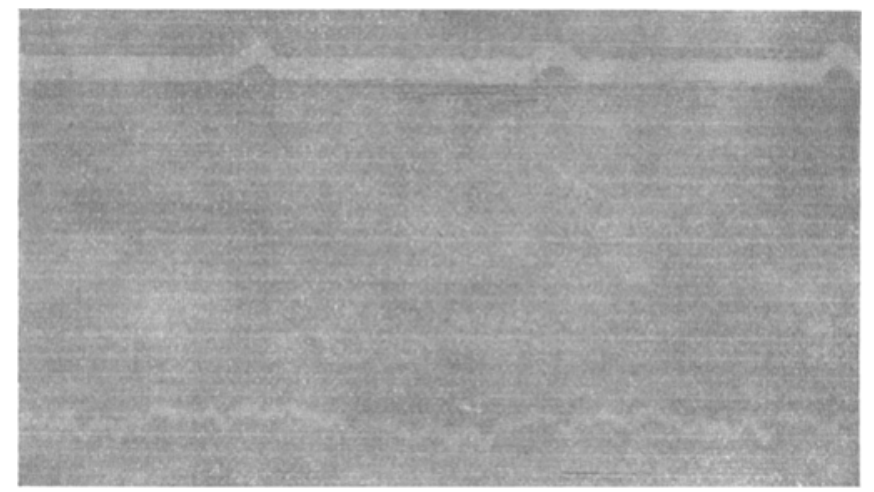

Fig. 36. Fall XII. Ableitung vom wächsern gespannten Musculus quadriceps bei Kniebeugung. Langsame Rhythmen.

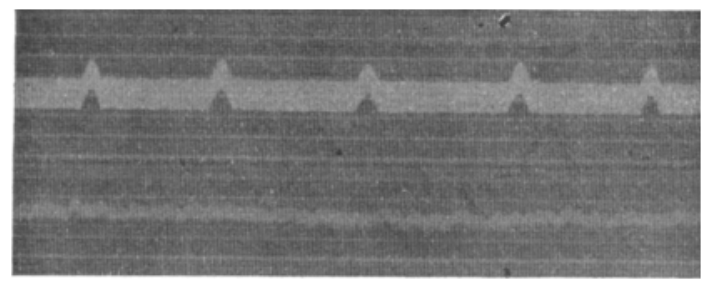

Fig. 37. Fall XII. Ableitung der Aktionsströme von dem ruhenden, wächsern gespannten Quadriceps. Weitere Wellen im langsamen Rhythmus.

dings ist eine gewisse Einengung auffallend. Da die Psychose nicht ohne weiteres einer der gangbaren Formen anzugliedern ist, so wird man irgendwelche Beziehungen zu der Herderkrankung nicht mit Sicherheit ausschließen können. Von den neurologischen Symptomen möchten wir folgende hervorheben. Die Veränderung der Sprache ist auch anamnestisch, an das Auftreten der Herderscheinungen gebunden, es ist auffällig Modulationslosigkeit und Verlangsamung des Sprechens. Es ist berechtigt, diese Sprachstörung auf mit dem Cerebellum in Zusammenhang stehende Bahnen zu beziehen, sie ist erst vor kurzem in einem ähnlichen Falle von Markuse beobachtet worden. Wir haben oben 
auseinandergesetzt, daß wir diese Sprachstörung nicht ohne weiteres der Adiadochokinese unterordnen können. Beachtenswert ist das Fehlen der Sehnenreflexe bei der Steigerung des Muskeltonus, auch das ist bereits in analogen Fällen (Fall $I$ von Halban und Infeld) beobachtet worden. Höchstwahrscheinlich besteht ein innerer Zusammenhang zwischen dem Fehlen der Sehnenreflexe und der Art der Steigerung der Muskelspannung, es stellen die Spannungen ein klassisches Beispiel einer wächsernen Biegsamkeit dar, insbesondere an den Beinen. Es ist unseres Wissens in den früheren Krankengeschichten auf die Art des Rigors nicht entsprechend geachtet worden, wir legen auf die Besonderheit dieser Contractur deshalb Gewicht, weil gerade hierdurch das ganze Bild eine besonders große Ähnlichkeit mit einer Paralysis agitans bekommt; der Tremor der Hand entspricht ja fast vollkommen dem dieser Krankheit. Wir können hier auf die Frage nicht eingehen, ob derartige Spannungen nicht auch ohne Mitergriffensein der Pyramidenbahn zustande kommen können, und heben in diesem Zusammenhang hervor, daß in dem Falle von Halban und Infeld trotz spastischer Parese die Pyramidenbahn bei Anwendung der Weigert-Methode vollkommen intakt befunden wurde. Wie noch später ausführlich zu erörtern sein wird, sind die mit dem Saitengalvanometer erhobenen Befunde bei diesen Spasmen im wesentlichen identisch mit denen, welche wir bei der gewöhnlichen spastischen Hemiplegie erhoben haben (vgl. Fig. 34-37). An dieser Stelle gehen wir nur darauf ein, daß sich die mechanischen Einzelstöße des Tremors zerlegen ließen in eine größere Anzahl von Aktionsstromwellen, wieder ist auffällig, daß diese Rhythmen verhältnismäßig langsam sind. Es stimmt dieser Befund sehr gut überein mit den Befunden, welche wir bei der Paralysis agitans erhoben haben. Es ist uns noch nicht möglich gewesen, eine größere Anzahl von Tremorformen zu untersuchen; bedenkt man jedoch, daß Bor nstein und Sänger den Alkoholikertremor und den Intentionstremor in Einzelschwingungen zerlegen konnten, daß es uns gelungen ist, auch noch die kürzesten mechanisch nachweisbaren Muskelwellen einer choreatisch athetotischen Bewegungsstörung zu zerlegen, so wird man als wahrscheinlich hinstellen dürfen, daß die mechanische Einzelschwingung jedes Tremors als Tetanus aufzufassen ist. Damit ist eine scharfe Abgrenzung gegenüber dem Einzelstoß des Klonus gegeben, denn in einer großen Anzahl von Fällen kommt dieser nur durch einen einzigen Impuls zustande. Ob es möglich ist, Eigenheiten der verschiedenen Tremorformen im Kurvenbilde nachzuweisen, werden erst weitere Untersuchungen zeigen müssen ${ }^{1}$ ).

1) Der Vollständigkeit halber sei erwähnt, daß auch die Crampi bei amyotrophischer Lateralsklerose als Tetani aufzufassen sind. Die Frequenz der Im. pulse entspricht etwa der der Willküraktion (Simons u. Hoffmann). 


\section{Ataxie.}

Fall XIII. F. J., Kellner, 38 Jahre. 1892 Lues, Schwäche und Schwanken in den Beinen seit 3 Jahren, stechende ruckweise Schmerzen in den Beinen, seit 2 Jah. ren bettlägerig, gelegentlich Harnträufeln. Aufnahme am 21. August 1912. Genu recurvatum rechts, Arthropathic des Kniegelenks und Spitzfußstellung links. Hochgradige Ataxie der Beine bei guter Kraft. Fxtreme Hypotonie der Beine. Schwere Störungen des Lagegefühls und der oberflächlichen Sensibilität an den Beinen, Patellar- und Achillessehnenreflexe fehlen, Armsehnenreflexe schwach, Baucdeckenreflexe erhalten, Sprache ungestört. Hirnnerven o. B. Psychisch: schwere Defekte des Gedächtnisses und der Urteilsfähigkeit, Wassermann im Liquor 0,6 bis 0,8 positiv, Phase 1, positiv, Wassermann im Blut + .

Diagnose: Taboparalyse.

Die Aufnahme der Willküraktion der Beine (Quadriceps) ergibt eine beträchtliche Herabsetzung der Wellenfrequenzen pro Sekunde: eine

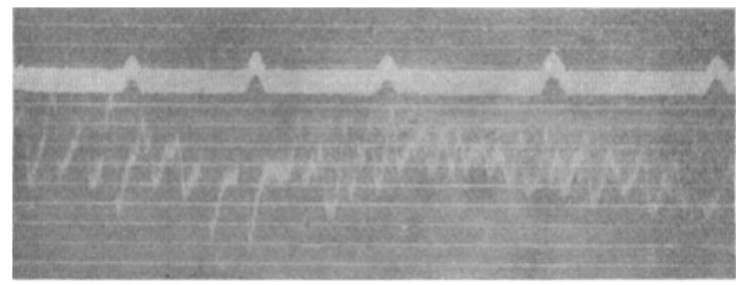

Fig. 38. Fall XIII. Tabes dorsalis. Willküraktion des hypotonischen Museulus quadriceps. Herabsetzung der Impulszahl. Verlängerung der Dauer der Stromschwankungen. Ungleiche Höhe der Zacken.

Reihe lautet $6,10,7,9,7,6,5,5,7,5,5,12,6,7$, eine andere 3,5 , $8,5,5,6,7,6,6,4,3,5,3,7,7,4,3, \ldots .5,5,5,5,3,3$, dabei ist nicht nur auffällig, daß die Frequenz eine niedere ist, es findet sich auch ein sehr auffallender Wechsel in der Höhe der Zacken. Es sind meistens die Zacken dann höher, wenn die Frequenz eine geringere ist. Die geringe Frequenz der Zacken kommt zum Teil dadurch zustande, daß zwischen die einzelnen biphasischen Schwankungen Pausen von etwa $1 / 25$ Sekunden Dauer eingeschoben sind, zum Teil aber ist eine Verlängerung der Dauer der einzelnen biphasischen Schwankungen. auffällig, wir haben Schwankungen beobachtet, deren Dauer $1 / 25$ Sekunde betrug. Auffallend ist, daß gelegentlich ganze Fünftelsekunden nur von derartigen langdauernden Stromschwankungen ausgefüllt werden (Fig.38).

Fall XIV. H. V., Schuhmacher, 53 Jahre, zum ersten Male aufgenommen 1906 wegen Angst und Verfolgungsideen, damals tabische Erscheinungen; die psychischen Störungen wurden auf chronischen Alkoholismus zurückgeführt. Seither noch wiederholte Aufnahmen wegen Vagabundage. Gegenwärtig beiderseits enge, lichtstarre Pupillen, Sehnenreflexe an den Beinen aufgehoben, ziemlich starke Ataxie und Hypotonie dor Beine, stampfender Gang, schwere Sensibilitätsstörungen an den Beinen und in der rechten Thoraxhälfte. Romberg positiv. Wassermann negativ. Psychisch leicht eingeschränkt, keine Sprachstörungen.

Diagnose: Tabes dorsalis. 
Die Aufnahme der Aktionsströme des Musculus quadriceps ergab niedere Werte: 6, 6, 9, 7, 9, 5, 8, 8, 8, 7. Ein rascher Wechsel zwischen niederen und höheren Wellen ist auch hier auffällig. Eine Verlängerung der Dauer der einzelnen Stromschwankung haben wir nicht gefunden (Fig. 39).

Fall XV. K. L., Kellner, 49 Jahre, 2 Aborte der Frau. Krank seit 1906, Reißen in den Beinen, Reizbarkeit. Bei der ersten Aufnahme 1910, leichte Einschränkung der Intelligenz, Klagen über leichte Ermüdbarkeit und Unsicherheit beim Gehen. Somatisch: Lichtstarre Pupillen, Ptosis, Koordinationsstörungen der Arme und Beine, ataktischer Gang, Fehlen der Patellar- und Achillessehnenreflexe. Neuerlich aufgenommen wegen VergeBlichkeit, Zerstreutheit, leichter Erregbarkeit. Psychisch: Klagen über Nervenzuckungen, Rheumatismus. Mangelhafte örtliche Orientierung, Urteilslosigkeit, Euphorie. Somatisch: außer den $\mathrm{Pu}$ pillensymptomen, Ataxie, Hypotonie mittleren Grades, Störungen des Lagegefühls und Störungen der oberflächlichen Sensibilität an den Beinen, leichte Ataxie der Arme, Andeutung von Silbenstolpern. Er kann ohne Unterstützung gehen und stehen.

Diagnose: Taboparalyse.

Die Willküraktion der hypotonischen Beinstrecker ergab normale Werte: 45,

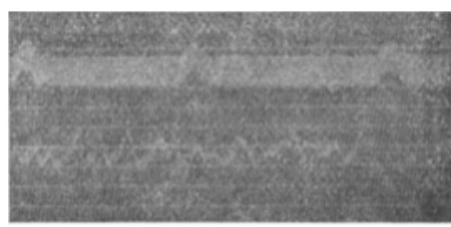

Fig. 39. Fall XIV. Tabes dorsalis. Willküraktion des hypotonischen Quadriceps. Verringerung der Sekundenfrequenz. 50,50 pro Sekunde.

Bei der tabischen Ataxie haben wir also nur in demjenigen Fall charakteristische Veränderungen gefunden, welcher sehr schwere Störungen aufwies (Fall XIII). In einem mittelschweren Falle (XIV) waren die Veränderungen leichter, sie fehlten völlig in dem letzten Falle (XV). Die Veränderungen sind: 1. Herabsetzung der Zahl der Innervationsimpulse in der Sekunde, 2. eine Verlängerung der Dauer der einzelnen biphasischen Schwankung (nur im Fall XIII), 3. eine auffallende Ungleichheit der Stärke der einzelnen Stromschwankungen (Fig. 38 und 39). Da wir die unter 2. angeführte Veränderung nur in einem Falle gefunden haben, werden weitere Untersuchungen hierüber notwendig sein. Eine praktisch diagnostische Verwertung dieser Befunde ist, wie aus dem Angeführten ersichtlich, zunächst nicht möglich, da sie nur bei schweren und schwersten Fällen gefunden werden; doch ist das Bild an sich charakteristisch, es ist von dem Bilde der spastischen Lähmung schon durch die Ungleichheit der Höhe der einzelnen Zacken unterschieden. Die Herabsetzung der Frequenz ist beiden in ihrem Mechanismus so außerordentlich verschiedenen Störungen gemeinsam.

Theoretisch sind diese Befunde von hohem Interesse, weil sie auf sehr innige und direkte Beziehungen der sensiblen Zuflüsse, welche bei der Tabes gestört sind, zu den impulsgebenden motorischen Apparaten verweisen. Wir haben uns diese Beziehungen so vorzustellen, daß die 
hintere Wurzelschädigung einesteils die Zuleitung der Eindrücke zum Großhirn hindert, so daß ein zweckentsprechender Bewegungsentwurf nicht möglich ist, daß sie anderenteils die subcorticalen motorischen Apparate (insbesondere Kleinhirn und Vorderhornganglienzelle) direkt in Mitleidenschaft zieht (vgl. z. B. Förster).

Auf die zahlreichen einschlägigen Untersuchungen einzugehen, liegt nicht im Plane dieser Arbeit. Wir erwähnen nur, daß Buytendyk bei der decerebrierten Katze Änderungen im Kurvenbilde des reflektorisch gespannten Muskels erhielt, wenn er die hinteren Wurzeln reizte, es änderte sich zwar nicht die Zahl, wohl aber die Höhe der Zacken. In einer etwas entfernteren Beziehung zu dem hier Mitgeteilten steht die Tatsache, daß Hoff ma n n beim Strychnintetanus des Frosches durch Reizung der sensiblen Nerven eine Abänderung (Beschleunigung) des Innervationsrhythmus erzielte.

Wir fügen kurz einen Fall Friedreich scher Ataxie an. Trotz ziemlich hochgradiger Ataxie (die Hypotonie ist relativ geringer) fanden wir in unseren Kurven nichts Auffälliges.

Fall XVI. E. F., 30 Jahre alt, Arbeiter, uneheliches Kind. Vater und Mutter gesund, Stiefbruder gesund, ein Cousin von väterlicher Seite von Jugend auf verkrüppelt, schwankt beim Gehen, der Patient hatte als Kind Masern und Schafblattern, im 16. Lebensjahre im Dunkeln unsicher, im 21. Jahre Oberschenkelbruch, das Gehen wurde schlechter, seit 4-5 Jahren arbeitsunfähig, die Sprache ist eintönig geworden, beim Urinieren Nachträufeln des Wassers, Potenz erhalten, Stuhlgang o. B., seit dem 16. Lebensjahre Skoliose, Potus, Lues negiert. Der gegenwärtige Befund ist folgender: hochgradige dextrokonvexe Kyphoskoliose der Brustwirbelsäule, Fußwölbung beiderseits sehr ausgeprägt, starke Behaarung des Körpers, beide kleine Finger abgebogen, Ohrmuschel flach. Motorische Hirnnerven ohne Besonderheiten, nur der rechte Facialis spurweise schwächer innerviert als der linke, Augenbewegungen frei. Kein Nystagmus, Sprache ohne Modulation, Stimme hoch, bisweilen wie beim Mutierenden umschlagend. Er spricht langsam und häsitierend, Adiadochokinese im Sprachmuskelbereich nicht nachweisbar. Corneal-, Conjunctival-, Pupillarreflexe +, sensorische Funktionen o. B., Muske]volumen der rechten Hand etwas geringer als das der linken (elektrisch o. B.) Tonus der Arme gering, sowohl bei Ruhe als auch bei Bewegung, an den Beinen etwas stärker herabgesetzt; aktive Beweglichkeit ungestört, Faustschlu 3 rechts schwächer als links, Bauchmuskulatur schwach, sonst keine Störung; hochgradige statische und dynamische Koordinationsstörungen am Rumpf und etwas schwächer an den Extremitäten, sämtliche Bewegungen erfolgen sehr verlangsamt, doch keine Veränderung im Sinn der Adiadochokinese. Gang spastisch ataktisch, er geht mit durchgebogenen Knien und unter starkem Schwanken des Rumpfes, ausgesprochene Asynergie zwischen Rumpf und Beinbewegungen, die Zehen haften am Boden, Gehen und Stehen ohne Unterstützung unmöglich, Patellar- und Achillessehnenreflexe fehlen beiderseits, ebenso der Tricepsreflex, die übrigen Armreflexe sind beiderseits vorhanden, Bauchdeckenreflexe und Cremasterreflexe + , beiderseits Babinski und Strümpell +, Oppenheim 0, Vasomotoren- und Muskelerregbarkeit leicht gesteigert, Empfindlichkeit für Stich und Berührung links unterhalb der Mamillen in einer handbreiten Zone, die den Rumpf umgreift, herabgesetzt, starke Herabsetzung der Empfindlichkeit für Stich, Berührung und Temperatur, 
insbesondere an den Unterschenkeln, und zwar durchgehends rechts stärker als links; Lagegefühl an den Armen intakt, an den Beinen besonders schwer gestört, in Zehen und Fußgelenken, links auch im Kniegelenk, tiefe Druck- und Schmerzempfindlichkeit (bei grober Prüfung) nicht beeinträchtigt, innere Organe o. B., Wassermann negativ.

Diagnose: Friedreichsche Ataxie.

Die Willküraktion der Unterarmbeuger zeigte folgende Wellenfrequenzen: $12,12,13,7,11,7,7,8,7,7$, die des Quadriceps: 12 , $11,11,11,11,11,12,11,11,11$. Also nichts Abnormes.

Die graphische Aufnahme der Muskelverdickung des Biceps bei Pronation und Supination ergab außer langsamer Folge der Bewegungen nichts Auffälliges.

\section{Hemiplegie und Contractur.}

Fall XVIr. II. K., 27 Jahre, Invalide. Lues 1907. Hemiparese links, in der Nacht vom 28. Juni 1910: zunächst schlaff, Spannung seit 1911, Stuhlgang angehalten, Wasserlassen in Ordnung, Untersuchung am 28. August 1912. Innere Organe o. B., Wassermann +; neurologisch: Oxycephaler Schädeltyp, Parese des unteren Facialis links, Zunge zittert, motorische Hirnnerven, sonst o. B. Beide Pupillen fast starr. Gehör, Geruch, Geschmack, Gesichtsfeld, Augenhintergrund o. B. Beim Gang werden Schulter und Oberarm der linken Seite nach hinten gezogen, der Arm wird im Ellbogengelenk leicht gebeugt, im Handgelenk extendiert, Finger und Daumen in der gewöhnlichen Contracturstellung. Er tritt links mit der äußeren Fußsohle auf, circumduciert, Gangmitbewegungen des Armes fehlen. Spastische Hemiplegie links mit Ruhespannungen im Handgelenk und in den Fingergelenken, Abweichung vom Prädilektionstypus, nur insoweit als diese in der beschriebenen Haltung zum Ausdruck kommt; Bewegungen in ihrem AusmaB eingeschränkt, in der Kraft sehr wesentlich herabgesetzt, Fingerbewegungen durch Spasmen verhindert, Bauchdeckenreflexe rechts gleich links, links Babinski, Mendel-Bechterew, Oppenheim +, sämtliche Sehnenreflexe links erheblich gesteigert, Hand-Fuß-Patellarklonus links, keine auffälligen Mitbewegungen, keine Sensibilitätsstörungen. Seither keine Veränderung.

Diagnose: Spastische Hemiplegie auf luetischer Basis.

Es wurde zunächst versucht, die Ruhespannung aufzunehmen. Da ergab sich sofort bei der klinischen Beobachtung, daß diese Spannung in höherem Grade nur immer im Anschluß an kleine Reize auftrat, wenigstens in den der Aufnahme zugänglichen Muskeln. (Die kurzen Fingerbeuger erscheinen dauernd gespannt.) Trotzdem gelang uns mehrfach die Aufnahme der Aktionsströme von den ruhenden Unterarmmuskeln. zu machen. Es zeigten sich von größeren Pausen getrennte niedere Wellenzüge von einer Frequenz von etwa 30 pro Sekunde.

Zahlreiche Kurven haben wir von den klonischen Erscheinungen aufgenommen. Häufig gelang es nicht, im Einzelversuch den Klonus auszulösen, wir haben dann die Gegenspannung, die stets deutlich war, registriert. Solche Aufnahmen haben wir zunächst an den Unterarmbeugern gemacht. Wir erhielten beim Klonus folgende Werte: $4,3,2,2,2,4, \ldots .4,3,2,2,3,3$. Dabei ist die Anordnung dieser 
Zacken meist so, daß häufig auf zwei rasch aufeinanderfolgende Schwankungen eine größere Pause folgt. Ein Vergleich mit den grob mechanischen Stößen des Klonus ergibt ohne weiteres, daß ein Teil dieser mechanischen Einzelstöße durch einen Impuls hervorgerufen ist (Fig.40), daß aber ein anderer Teil als durch mehrere (2-3) Innervationsimpulse zustande gekommen zu denken ist. Die Kurven bei Gegenspannung, ohne daß Klonus zustande kam, zeigen gegenüber diesen vielfach keinen irgendwie wesentlichen Unterschied- Wir notieren einige Zahlen: 3, 2, 4, 2; daß gelegentlich auch für kurze Strecken höhere Frequenzzahlen

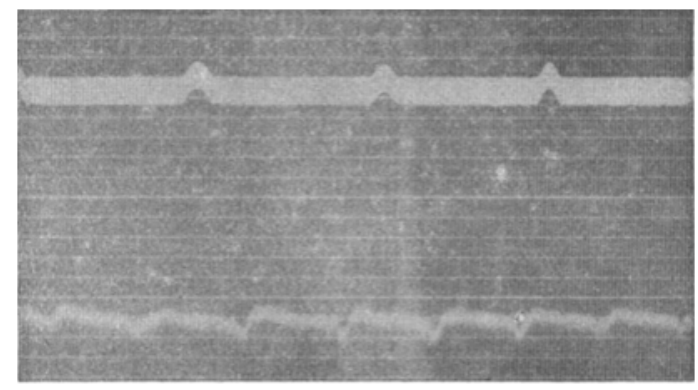

lïg. 40. Jall XVII. Spastische Hemiplegie. Klonus der Hand. Dem mechanischen Klonusstoß entspricht eine biphasische Stromsehwankung.

zu beobachten sind, zeigt die folgende Reihe $6,5,5,3,3,3$. Eine andere Gegenspannungskurve ergab: $5,5,5,5,5,5,5,5,3,5,7,4,4,5$. Dabei war die Anordnung wieder die, daß 2-3 Zuckungen rasch aufeinanderfolgten und dann eine längere Pause eintrat. Zeitweise erschien über den Klonusrhythmus ein rascherer superponiert (Fig. 41). Da Wertheim-Salomonson für seine Klonusbilder die Vermutung ausspricht, daß der Einzelschlag des Klonus stets nur durch einen Impuls zustande komme und die zweite Zacke nur auf Interferenz der Stromschwankungen diesseits und jenseits des nervösen Äquators beruhe, so haben wir einige eigens hierauf gerichtete Untersuchungen unternommen. Wir nahmen zunächst den Klonus bei einer Stellung der Elektroden auf, welche mit Sicherheit gewährleistete, daß der nervöse Äquator zwischen beiden Elektroden lag. Wir erhielten vielfach Doppelzacken für einen mechanischen Stoß. Aber auch wenn beide Elektroden sicher auf einer Seite des nervösen Äquators sich befanden, waren diese Doppelzacken nachweisbar. Sie sind also, wie uns das auch nach Durchmusterung unserer Kurven als wahrscheinlich erschien, nicht auf Interferenzerscheinungen zurückzuführen. Die Aufnahme des Fußklonus ergab die gleichen Resultate wie die des Handklonus: dem mechanischen Einzelstoß entsprachen 1-2 Aktionsströme.

Am Unterarm haben wir auch die Innervationsvorgänge beobachten 
können, wenn die Contracturstellung des Gliedes sich einstellt, nachdem sie passiv überwunden worden war. Wir haben die gleichen Bilder erhalten, wie vom Klonus und von der Gegenspannung. Wir geben einige Werte: 3 , $4,4,3, \ldots .3,2,3$. Endlich haben wir bei der Willküraktion des Triceps surae folgende Frequenzen verzeichnet: $6,4,4, \ldots$. $5,6,5,4,4,8$. Ähnlich wie beim Klonus waren auch hier längerdauernde Pausen (etwa $1 / 20$ Sekunde) auffällig (Figut 42).

\section{Zusammenfassung:}

Bei einem Hemiplegiker, bei dem Art und Verteilung der Spasmen in den meisten Punkten dem Prädilektionstypus entsprach, konnte sowohl für den Fuß-als auch für den Handklonus gezeigt werden, daß dem mechanischen Einzelstoße nur 1-2 Impulse entsprechen. Ganz ausnahmsweise wurden auch 3 Impulse registriert. Sehr ähnliche Rhythmen ergab die Aufnahme der reflektorischen Gegenspannung; auch hier bestanden Pausen zwischen den Innervationsimpulsen. Etwas größere Zahlen ergaben sich für die Sekundenfrequenz der Willküraktion. Doch war auch hier die prinzipielle Übereinstimmung mit den Bildern, welche von Klonus und Gegenspan-

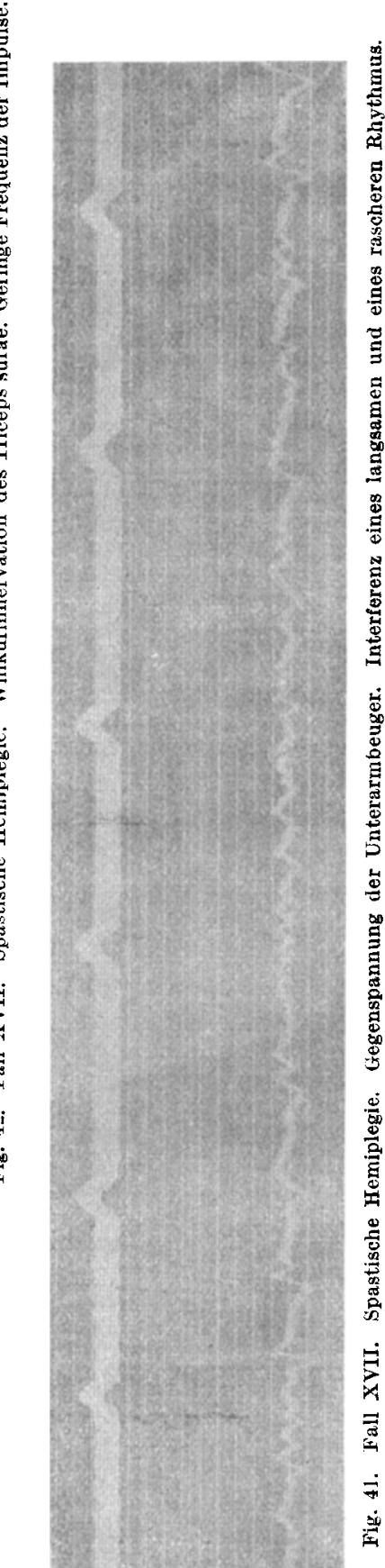


nung gewonnen wurden, deutlich. Schließlich sind auch für den ruhenden spastisch gespannten Muskel Innervationsimpulse nachweisbar, jedoch erfolgen sie nicht kontinuierlich, sondern in einzelnen Schüben. Innerhalb des einzelnen Schubs ist die Sekundenfrequenz eine auffallend geringe (30). (Fig. 40-42).

Fall XVIII. H. K., 46 Jahre, Invalide. 1900 Lues. Seit 1903 im Anschluß an Rippenfellentzündung allmähliche Entwickelung einer linksseitigen Hemiparese, die seit 1907 stark hervortritt. In den Jahren 1900 bis 1905 Kopfschmerzen, Krämpfe mit Ohnmacht und Zucken; seit 1912 im Pflegehaus. Potenz erloschen. Wasserlassen und Stnhl ungestört, Potus zugegeben. Innere Organe: Narben nach Empyemoperation, Wassermann negativ. Neurologisch: Parese des linken unteren Facialis und Hypoglossus, Augenmuskel, Masseteren o. B., Pupillen eng, sonst o. B. Conjunctivalreflex rechts stärker als links, Cornealreflex o. B., beiderseits Hyposmie und Hypogeusie, Gehör, Sehfunktion und Augenhintergrund o. B. Linksseitige spastische Parese, nach dem Prädilektiontypus. Nur im Schultergelenk sind sämtliche Muskeln in etwa gleichem Grade geschädigt. Ruhespannung nicht wesentlich erhöht, bei den Bewegungsversuchen beträchtliche initiale Spasmen (im Ellbogen-, Schulter-, Hand- und Fingergelenken), beim Gang stellt sich der sonst herabhängende Arm in typische Contracturstellung. Auch sonst bewirken Reize leicht das Auftreten einer typischen Beugecontractur des Armes. Keine Gangmitbewegungen des Armes; das Bein wird beim Gang circumduciert. Sämtliche Sehnenreflexe der paretischen Extremitäten klonisch; Babinski, Mendel-Bechterew +, Oppenheim -, Bauchdeckenreflexe und Cremasterreflex links herabgesetzt, aber sämtlich vorhanden, homolaterale Mitbew'egungen an der kranken Seite reichlich, zahlreiche Mitbewegungen (identische) von der gesunden zur kranken Seite. Motilität der gesunden Körperhälfte o. B. Sensibilität 0 . B.

Diagnose: Spastische Hemiplegie a uf luetischer Basis.

Dem klinischen Befund entsprechend haben wir Ruhespannungskurven nicht erhalten. Hingegen haben wir Kurven von Handklonus und Gegenspannung der Unterarmmuskeln erhalten. Die Resultate decken sich mit denen des vorangehenden Falles, dem mechanischen Einzelstoß entsprechen 1-2 Schwingungen der Saite. Einen Unterschied in der Anordnung der Doppelzacken je nach dem Verhältnis der Elektroden zum nervösen Aquator konnten wir auch in diesem Falle (untersucht wurde am Quadriceps) nicht nachweisen. Wir haben zeitweise für den Patellarklonus sehr niedrige Sekundenfrequenzen (7-9) beobachtet. Jedem mechanischen StoB entspricht dann ein Innervationsimpuls (Fig. 43). Auffälligerweise war die Frequenz der Aktionsströme bei Gegenspannung am Quadriceps eine beträchtlich höhere (am gleichen Tag aufgenommen), die Frequenzen waren hier 6, 5, 9, 8, .. $5, \ldots 7,6,6$ (Fig. 44). Es betrugen die Werte für Gegenspannung am Biceps 5, . 2, 3, 3. Schließlich ergab auch die Untersuchung der Gegenspannung des Triceps ähnliche Werte.

Zahlreiche Versuche beschäftigten sich mit der Willküraktion. Wir nahmen auf Biceps brachii 10, 9, 4, 8, 8, 8, 6, 8, 6, 6, 4, 5, 6, 6, 5. Dabei ist angedeutet eine Neigung, zu kleinen Gruppen zusammenzutreten, 

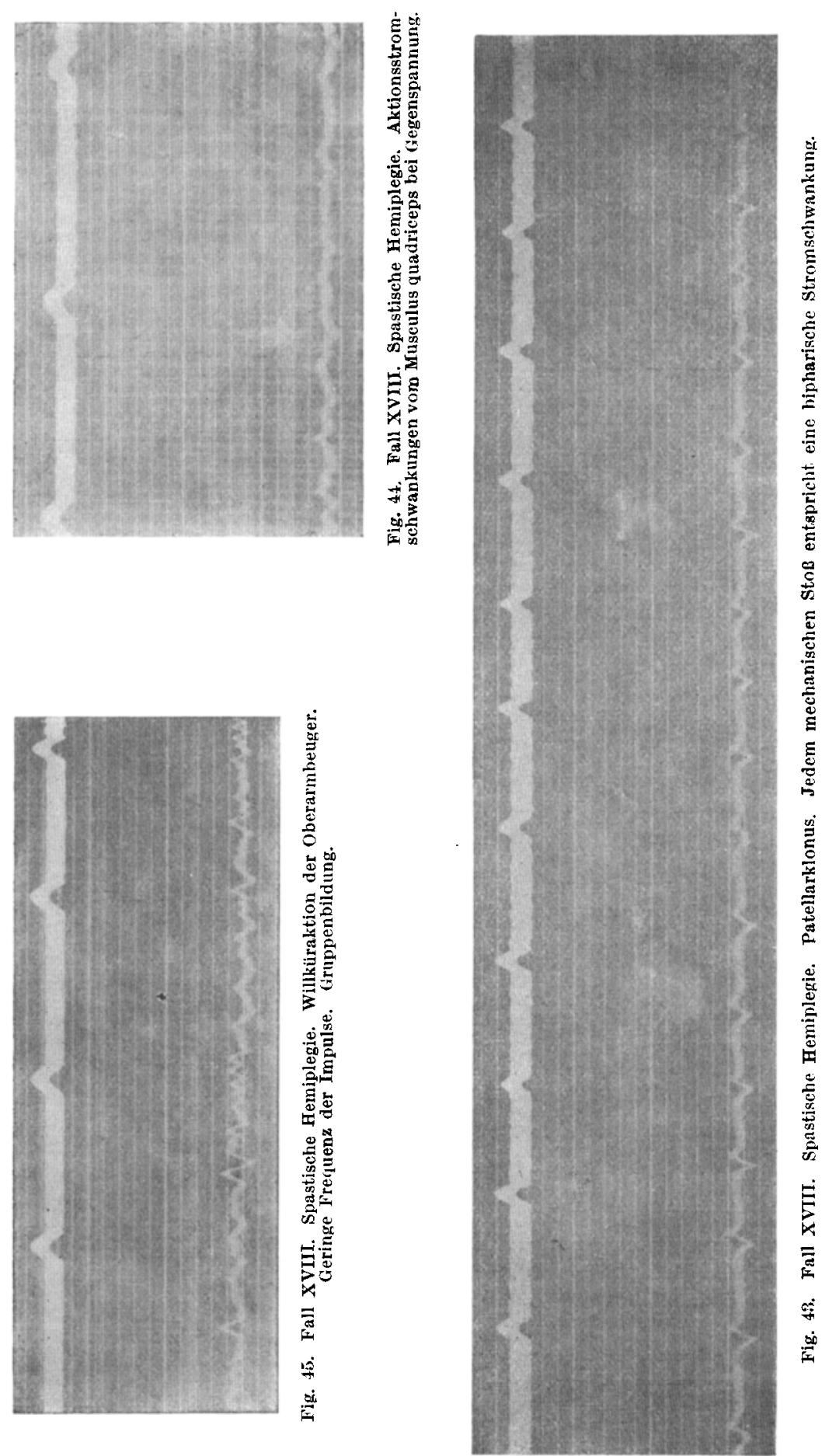
von denen etwa 2-3 auf eine 1/5 Sekunde kamen (Fig. 45). Auf vielen Strecken zeigen jedoch die Bilder wenig Auffallendes. Viel schwerere Veränderungen zeigt die Kurve der stärker betroffenen Unterarmbeuger. Hier entspricht die Kurve im wesentlichen der Klonuskurve; die Frequenzen sind: 3, 2, 3, 2, 4 usw. Zeitweise ist die Sekundenfrequenz etwas höher (20) (Fig. 46). Auch treten gelegentlich Nebenzacken hervor. Vom Quadriceps erhielten wir Kurven, die zunächst. der Norm zu entsprechen schienen, 10, 10, 11, 11, aber die schon erwähnte Neigung zur Gruppenbildung trat schon anfangs hervor. Im weiteren Verlauf wird diese immer mehr beherrschend, bis schließlich

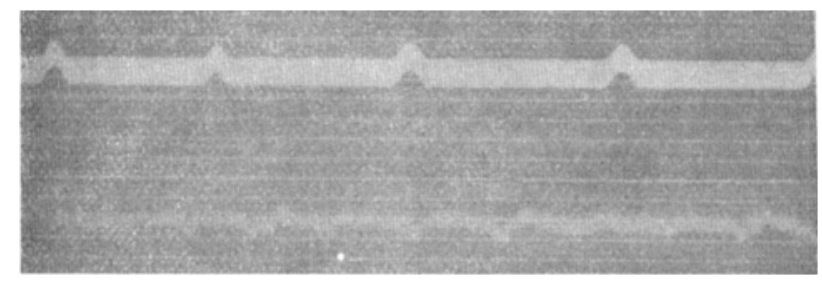

Fig. 46. Fall XVIII, Spastische Hemiplegie. Willküraktion der Unterarmbeuger. Klopusrhythmen z. T. mit Nebenzacken.

das fast reine Bild des Klonus erscheint. Sekundenfrequenz 10 (vgl. die Abbildungen 47). In einer unserer Kurven zeigten sich über diesen Klonus superponiert kleine Nebenzacken (Fig. 48).

Besonderes Gewicht legen wir auf jene Aufnahmen, die sich auf das Studium antagonistischer Innervationen beziehen ${ }^{1}$ ). Wir ließen zunächst rasche Beugung im Kniegelenk aus gestreckter Stellung ausführen. Mit aller Bestimmtheit ergab sich, daß die Strecker aktiv innerviert werden im Verlaufe der Beugung. Die Werte betrugen: 7, 7, 6. usw. (Fig. 49). Die Anordnung war eine ähnliche wie bei der Willküraktion. Besonders deutlich und schön waren die Kurven, wenn wir diese Beugung kraftvoll ausführen ließen. Die Werte waren: 6, 7, 7, 7, 6 usw. (Fig. 50). Wir haben dann die Aktionsstromschwankungen der Strecker des Knies aufgenommen, wenn die Kniebeuger maximal kontrahiert waren und das gebeugte Knie gewaltsam aufgerissen wurde. Es traten erst dann kleine Wellen auf, wenn es der gegenwirkenden Kraft gelungen war, den Widerstand der Beuger teilweise zu besiegen. Die Werte waren: 5, 6, 5, 2, 4. Wir haben hier unmittelbar das Wiedereintreten der Fixationsspannung vor uns (Fig. 5l). Wir reproduzieren ferner eine Kurve, die von den Oberarmbeugern gewonnen

1) Wir haben uns durch Kontrollversuche versichert, daß Uberleitung von einem Muskelgebiet zum anderen für diese Versuche nicht in Frage kommt. 


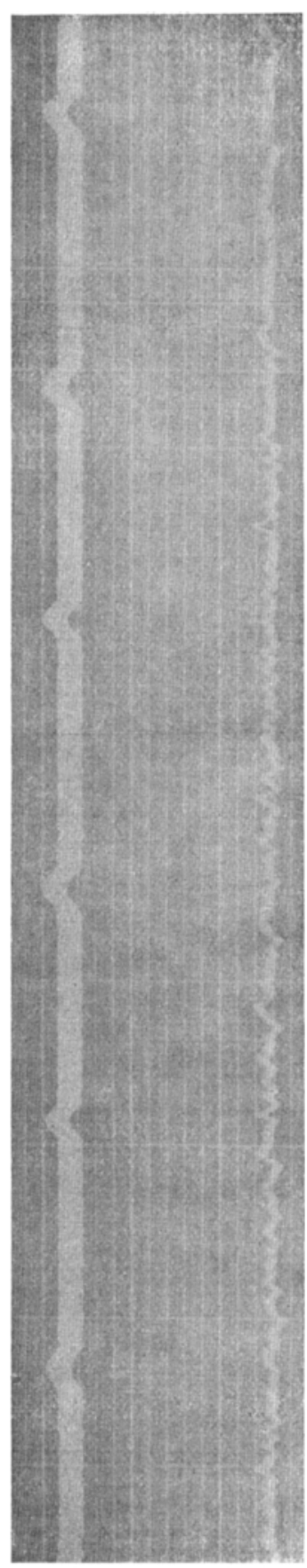

$\theta$

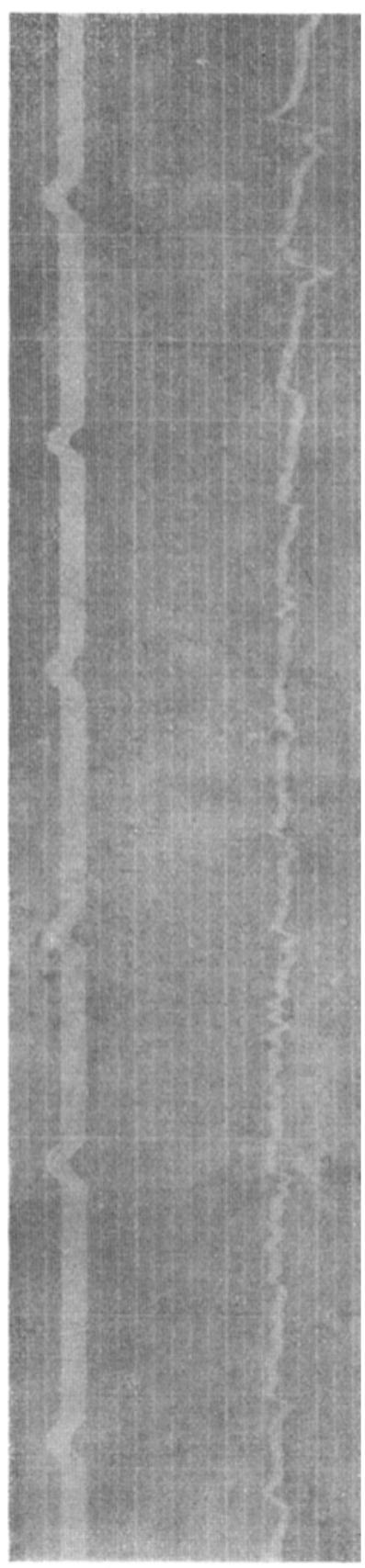

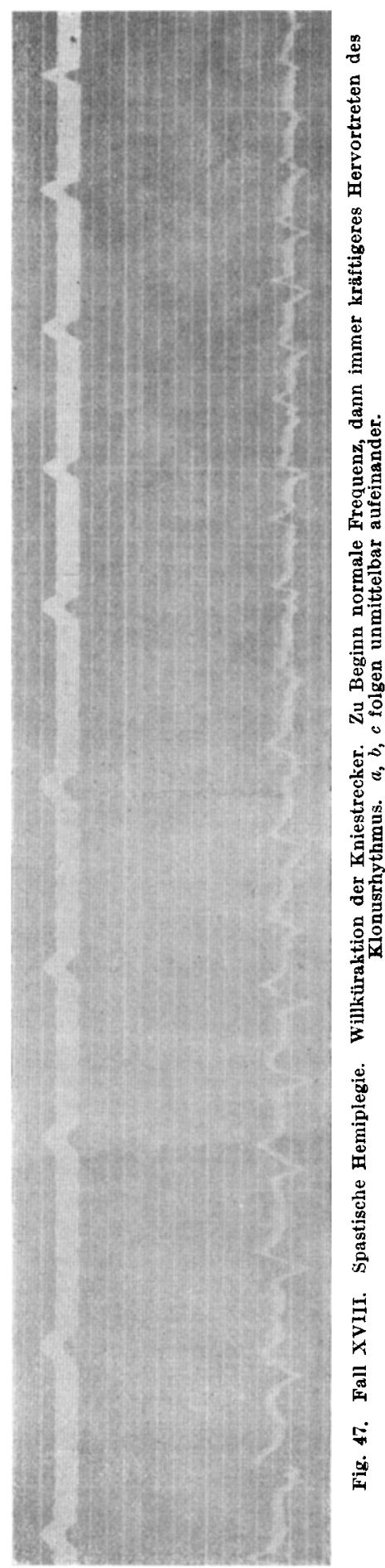

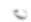


wurde, während der Streckung des Armes (aus gebeugter Stellung). Die Werte sind folgende: 6, 6, 7, 6, 7, 6, 7 (Fig. 52).

Wir haben schließlich vom Musculus triceps Kurven aufgenommen, wenn der Unterarm aktiv gegen den Oberarm (aus gestreckter Stellung) gebeugt wurde. Auch dann ließen sich am Triceps Aktionsströme von geringer Sekundentrequenz (25-30) nachweisen (Fig. 53). Wir

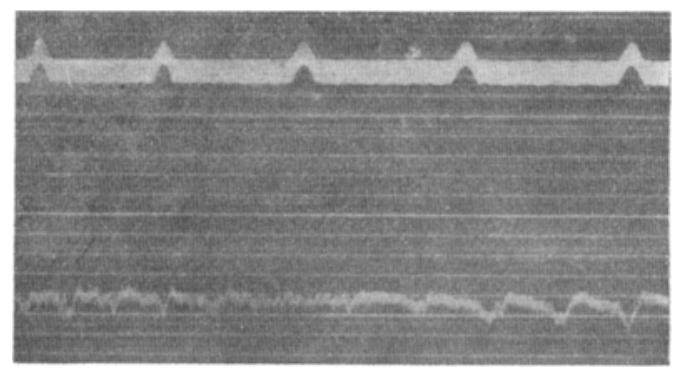

Fig. 48. Spastische Hemiplegie. Klonusrhythmus mit Nebenzacken.

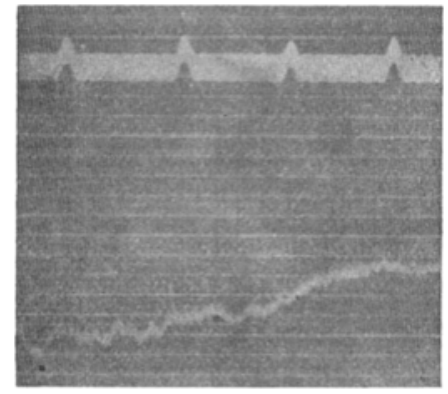

Fig. 49. Fall XVIII. Spastische Hemiplegie. Beugung im Kniegelenk aus gestreckter Stellung. Ableitung vom Musculus quadriceps. Der Antagonist wird aktiv mit innerviert.

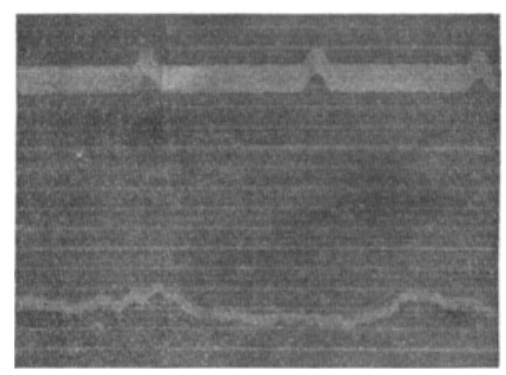

Fig. 50. Fall XVIII. Spastische Hemiplegie. Ableitung der Aktionsströnte der Strecker bei kräftiger Beugung im Kniegelenk. (Aus gestreckter Stellung.)

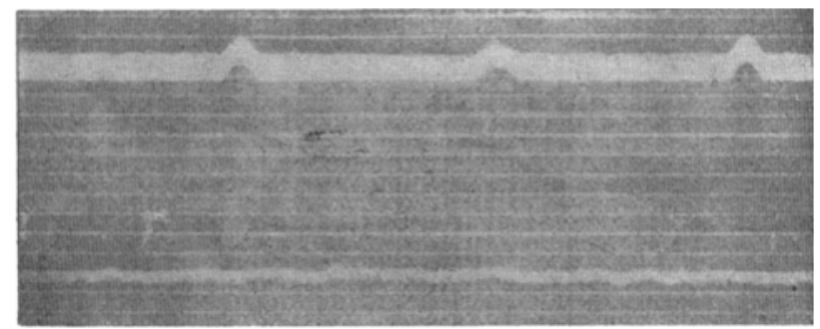

Fig. 51. Fall XVIII. Spastische Hemiplegie. Registrierung der Aktionsströme des Musculus quadriceps bei kräftig gebeugtem Kniegelenk, wenn die Beugestellung allmählich gewaltsain überwunden wird. Kleinste, nicht zählbare Zacken im letzten Teil der Kurve. 


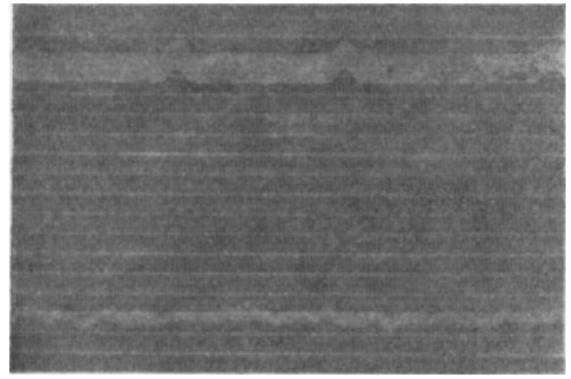

\section{s.}

Fig. 53. Fall XVIII. Spastische Hemiplegie. Aktionsströme des Musculus trỉceps bei aktiver Beugung des, Unterarmes gegen den Oberarm (aus gestreckter Haltung).

glauben also den Nachweis geliefert zu haben, daß eine gleichzeitige aktive Innervation der Agonisten und Antagonisten der spastischen Hemiplegie zukommt.

Die Willküraktion der gesunden Seite ergab folgende Werte: 7, 9, 10, $9,10,10,9$ usw.

Zusammenfassung: Bei einer nach dem Prädilektionstypus angeordneten spastischen Contractur ergaben sich für den mechanischen Einzelstoß des Klonus 1-2 Aktionsstromschwankungen. Bei der Gegenspannung wurden am Quadriceps etwas raschere Zuckungsfolgen vorgefunden. Auch die reflektorische Gegenspannung des Musculus biceps ergab verhältnismäßig rasche Rhythmen. Die Willküraktion zeigte beträchtliche Frequenzzahlen, doch traten daneben die Rhythmen des Klonus hervor und beherrschten zeitweise das Bild. Die aktive Innervation der Kniebeuger war von einer aktiven Innervation der Kniestrecker begleitet, wenn die Beugung aus der Streckstellung erfolgt. Kraftvolle Innervation der Beuger $b, i$ gebeugtem Bein ist von einer aktiven Inner-

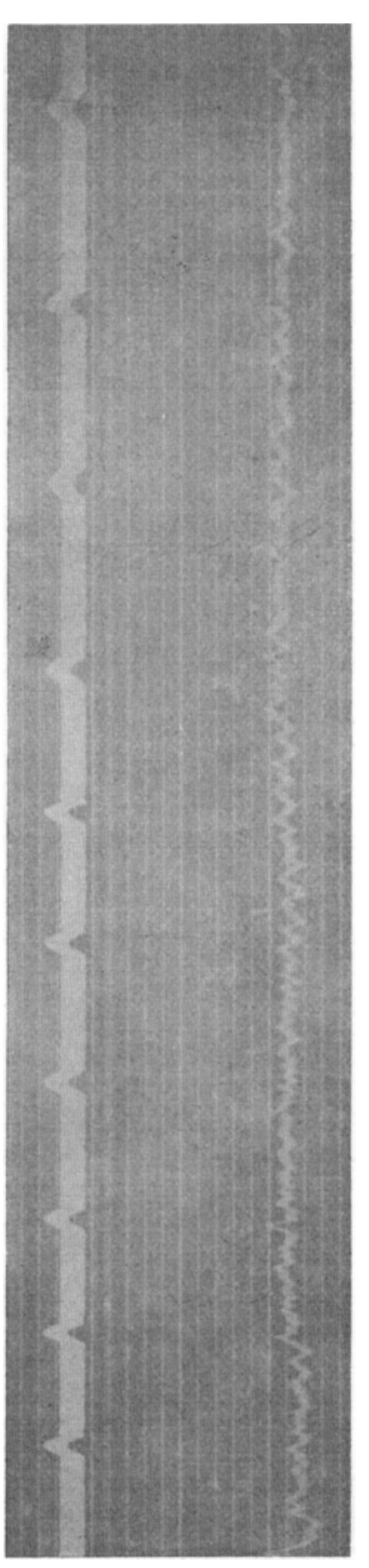


vation nicht begleitet. Doch stellt sich diese ein, wenn bei teilweiser Utberwindung des Widerstandes der Beuger die Insertionspunkte des Quadriceps einander genähert werden, und zwar auch dann, wenn die Beuger noch kräftig innerviert sind. Ähnliche Verhältnisse zeigten sich am Oberarm. Die Willküraktion der Beuger der gesunden Seite entsprach der Norm (vgl. Fig. 43-53).

Fall XIX. L. R., O 45 Jahre. Krank seit etwa vier Jahren. Beginn mit Schwäche des linken Armes und Beines, seit anderthalb bis zwei Jahren auch das rechte Bein schwächer, der rechte Arm beginne in seiner Kraft nachzulassen. Bei der Aufnahme am 21. Okt. innere Organe o. B. Wasser-

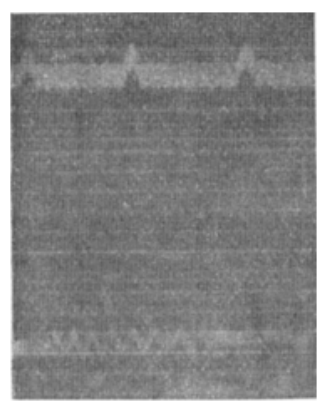

Fig. 54. Fall XIX. Multiple Sklerose. Gegenspannung des (spastischen) Musculus quadriceps. Geringe Impulsfrequenz. mann im Blut negativ. Zunge zittert leicht, weicht nach rechts ab, Nystagmus horizontalis nach beiden Seiten, motorische Hirnnerven im übrigen $\mathbf{0}$. B. Korneal, Conjunctivalreflexe 0 . B., beiderseits temporale Abblassung der Papillen. Der linke Arm in seiner Beweglichkeit schwer gestört. Fingerstrecken völlig unmöglich, Tonus schlaff, Intentionstremor angedeutet, der rechte Arm ohne motorische Störungen; an beiden Beinen hochgradige Spasmen, welche im wesentlichen nach dem Prädilektionstypus verteilt sind, aktive $\mathrm{Be}$ wegungen sind im Kniegelenk nur im Sinn der Streckung möglich, der Fuß kann nur in ganz geringem Ausmaße bewegt werden; Bauchmuskeln paretisch; Gang spastisch ataktisch; Sehnenreflexe an den oberen Extremitäten normal, an den unteren stark gesteigert, keine Kloni. Bauchdeckenreflexe fehlen. Bei Bestreichen der Fußsohle kommt es zu einem komplizierten Abwehrreflex: Beugung im Knie- und Hüftgelenk, Dorsalflexion des Fußes, wobei die große Zehe besonders kräftig innerviert wird. Gelegentlich reiner Babinski. Keine Sensibilitätsstörungen. Sprache skandierend.

Diagnose: Multiple Sklerose.

Wir haben bei dieser Patientin eine sehr große Anzahl von Aufnahmen gemacht, zunächst wurde die Willkürinnervation untersucht, wir fanden folgende Werte: $7,6,5,4,8,7, \ldots .7,6$, einen Ruhestrom aufzunehmen gelang nicht, doch war auch im klinischen Befunde auffällig, daß in der Ruhe keine Spasmen nachweisbar waren, daß diese jedoch bei dem geringsten äußeren Reiz sofort eintraten. Wir haben den durch Einwirkung von Kältereizen zustande kommєnden Spasmus untersucht und erhielten deutliche Aktionsstromschwankungen, deren Frequenz etwa der der Ströme bei Willküraktion dieser Patientin entspricht $(5-6)$.

Zahlreiche Versuche haben wir in der Art unternommen, daß wir die Gegenspannung des Quadriceps gegen passive Bewegungen aufgenommen haben. Wir haben hier stets Aktionsstromschwankungen registrieren können. Die Frequenz dieser betrug: machmal nur 3-4 pro Fünftelsekunde, doch wurden meistens höhere Werte (bis gegen 6) erreicht (Fig. 54). 
Das Babinskische Zehenphänomen haben wir gleichfalls aufgenommen, wir konnten stets. mehrere Zuckungen nachweisen (etwa 5), diese nahmen etwas weniger als eine Fünftelsekunde in Anspruch.

Wir haben ferner Aktionsströme an den Plantarflexoren des Fußes während des oben beschriebenen Abwehrreflexes aufgenommen. Wir erwähnten, daß der Fuß dabei dorsalflektiert wird, trotzdem waren in den Beugern Aktionsströme nachweisbar, wir haben uns davon überzeugt, daß diese aktive Innervation der Beuger gleichzeitig mit der sichtbaren Dorsalflexion des Fußes besteht und nicht etwa dieser nachfolgt.

Zusammenfassung: In einem Falle von multipler Sklerose konnten wir also die Willküraktion spastisch gelähmter Muskeln aufnehmen, die Frequenzen der Aktionsströme waren hier auffallend nieder, sehr ähnliche Frequenz zeigten die reflektorische Spannung bei Kälteeinwirkung sowie die Gegenspannung bei passiver Dehnung der Muskulatur (um 30). Die gleiche Frequenz zeigten die während des Auftretens des Babinskischen Phänomens abgeleiteten Aktionsstromschwankungen. Schließlich konnten wir zeigen, daß während des komplizierten Fluchtreflexes bei Bestreichen der Fußsohle Agonisten und Antagonisten gleichzeitig innerviert werden.

Fall XX. A. H., 58 Jahre Q. Mehrfach Aborte, am 21. Mai 1912. Apoplektischer Insult. Vier Wochen später neuerlicher Anfall. Mitte August 1912 Lähmung der rechten Körperhälfte. Allmähliche Verschlechterung der Sprache. Aufnahme am 2. September 1912. Innere Organe o. B. Wassermann - . Typische rechtsseitige Hemiparese mit Spannungen im wesentlichen nach dem WernickeMannschen Typus (soweit Prüfung möglich). Aktive Bewegungen eingeschränkt. Patellarreflex rechts lebhafter als links. Achillessehnenreflexe $r .=1$. Babinski $r .+$, Oppenheim + , Bauchdecken reflex $\mathbf{r}=1$. Motilität der linken Körperhälfte intakt. Keine sensorischen und sensiblen Störungen. Vorwiegend motorische Aphasie. Keine Apraxie. Psychisch: Benommenheit mittleren Grades.

Wir haben hier eine Ruhespannungskurve vom Musculus biceps erhalten, die Werte betrugen: $6,6,4,4,5,6$, 4, 6 usw. und in einer anderen Aufnahme: 5, 4, 4 usw., am gleichen Muskel haben wir für die gleichen Werte erhalten : $5,6,6,5,5,7, \ldots .5, \ldots .5,4,7,4,6,5,5,5$, 5 , 4, eine Reihe weiterer Aufnahmen ergaben identische Resultate (Fig. 55).

Zusammenfassung: Wir fanden also für Frühcontracturen einen deutlichen Ruhestrom und Gegenspannungen, welche in der Sekunden- 
frequenz recht erheblich hinter den normalen Zahlen für Willküraktionen zurückblieben (Fig. 55).

Fall XXI. E. B., 54 Jahre, Schlosser. Lues negiert, vor 13 Jahren Personenverkennung und Aufregungszustände, die sich fast jedes Jahr wiederholten. Seit 1903 Gangstörungen. Bei der Untersuchung in der Klinik prompte Pupillenreaktion, spastischer Gang, Patellar- und Fußklonus beiderseits, Babinski, keine wesentliche Parese an den Beinen, 1912 wegen Gangstörungen, Harn- und Stuhlinkontinenz neuerdings in der Klinik. Innere Organe o. B., die vier Reaktionen positiv (Wassermann im Liquor bei $0.4 \mathrm{ccm}$ ). Beide Pupillen mit träger und unausgiebiger Lichtreaktion, im übrigen Hirnnerven o. B. Die Beweglichkeit der Rumpf- und Nackenmuskulatur sowie der Extremitäten ungestört, die grobe Kraft der Beine ist in allen Muskelgebieten gleichmäßig herabgesetzt. Es besteht kein Prädilektionstypus, der Tonus der Beinmuskulatur ist bei Gegenspannung in sämtlichen Muskeln in etwa gleichem Grade erhöht. Ataxie ist nicht nachweisbar. Beiderseits Patellarund Fußklonus, Babinski und Oppenheim positiv, Bauchdeckenreflexe und Cre-

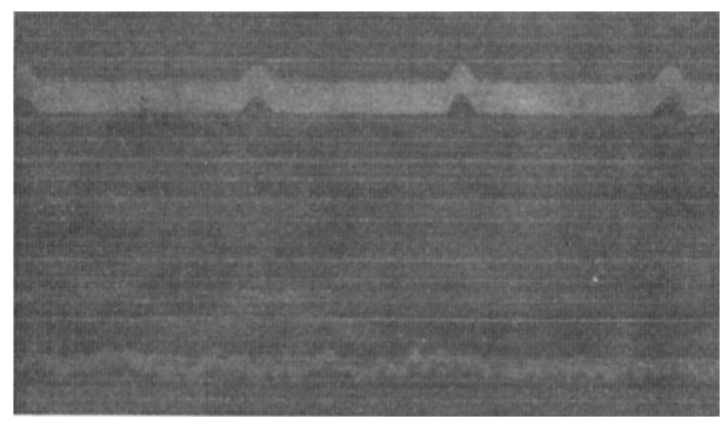

Fig. 56. Fall XXI. Spastische Spinalparalyse. Willküraktion des Musculus quadriceps. Gruppenbildung.

masterreflexe beiderseits schwach. Gang spastisch, Motilität der Arme ungestört. Keine Sensibilitätsstörungen (soweit Prüfung möglich). Inkontinentia urinae et alvi. Psychisch: Euphorie, Geschwätzigkeit.

Diagnose: Spastische Spinal paralyse auf luetischer Basis.

Es wurde die Willküraktion des Musculus quadriceps aufgenommen, die Werte waren folgende: $7,7,9,10,8,11,11, \ldots .9,7,5,7,6,7$, dabei gibt die grobe Zählung nur einen verhältnismäßig ungenauen U̇berblick, da eine auffallende Anordnung insofern besteht, als die Einzelzacken größeren Schwankungen von langsamem Rhythmus wie supperponiert erscheinen. Besonders deutlich treten diese größeren Schwankungen gegen das Ende der Kurve hervor, es kommen etwa zwei solche Schwankungen auf eine Fünftelsekunde, eine genauere Zählung der superponierten Zacken ist dabei recht schwer möglich wegen der Kleinheit derselben. Immerhin seien einige annähernde Werte wiedergegeben: $8,8,6,6,9,7,7$ (vgl. Fig. 56).

Zusammenfassung: Wir fanden also bei der spastischen Spinalparalyse eines Luetikers mit mäßiger Herabsetzung der groben Kraft, die nicht 
nach dem Prädilektionstypus verteilt ist, für die Willküraktion Werte um 40, charakteristisch waren jedoch im weiteren Verlauf der Aktion größere Wellen, über welche die kleineren superponiert erschienen.

Fall XXII. B. B., 28 Jahre, Handlungsgehilfe. 1903 Suicidversuch. Kugel aus dem Kopf nicht entfernt, linksseitige Lähmung. Seither fast ständig in Anstalten, Betrügereien, Unterschlagungen. Bei der Aufnahme vom I. Oktober 1912 ergibt die körperliche Untersuchung: innere Organe o. B., Schädel nicht klopfempfindlich, Facialis in der Ruhe rechts gleich links, beim Sprechen und Lachen, überwiegt der rechte, die Zunge weicht etwas nach rechts ab, im übrigen motorische Hirnnerven o. B. (auch die Augenmuskeln, welche drei Wochen nach dem Suicidversuch beiderseits paretisch gewesen waren). Pupillar-Cornealreflexe + , Konjunktivalreflexe fehlen, beiderseits Optikusatrophie, linksseitige Hemianopsie. Spasmen mäßigen Grades in der gesamten linken Körperhälfte Prädilektionstypus nicht vorhanden, beim Vorstrecken der Hand Krallenhandstellung des zweiten und fünften Fingers (Interosseuslähmung), Beweglichkeit des Daumens stark eingeschränkt, im übrigen gleichmäßige Kraftherabsetzung, beim Gang extreme Extension des Armes im Ellbogengelenk, bei mäßiger Abduktion im Schultergelenk, Gangmitbewegungen fehlen. Auch am Bein kein Prädilektionstypus. Sehnenreflexe beiderseits lebhaft, links etwas lebhafter, links fehlen die Bauchdeckenreflexe, Babinski + , keine wesentlichen Sensibilitätsstörungen. Nach dem Röntgenbefund sitzt die Kugel in der rechten Gehirnhälfte nahe der Mittellinie, knapp hinter dem processus clinoideus posterior (die Einschußstelle in der rechten Schläfengegend). Psychisch: typische alte Dementia praecox.

Diagnose: Mittelhirnverletzung.

Wir haben die Willküraktion des Musculus quadriceps aufgenommen und erhielten folgende Werte: 9, 10, 11, 11, 8, 8, 9, 7, 7, auch hier ist auffällig, daß eine Tendenz zur Bildung kleinerer Gruppen besteht, doch ist sie hier nicht so ausgesprochen, wie in dem vorangehenden Fall, es wird auch hier deutlich, daß sie sich gegen das Ende der Willkürinnervation hin verstärkt.

Zusammenfassung: Auf eine genauere Besprechung des Falles können wir nicht eingehen und erwähnen nur, daß die Läsion in der Mittelhirngegend zu lokalisieren ist. Die geringfügige Parese zeigt im Kurvenbild keine Herabsetzung der Frequenz in der Sekunde (etwa 50), doch ist auch in diesem Falle die Neigung zur Bildung kleiner Gruppen bemerkenswert.

Fall XXIII. E. B., 36 Jahre alt, Maler. Kommt wegen Reißens in den Gliedern, habe früher einen Schlaganfall gehabt mit Krämpfen. Aufgenommen am 20. August, die körperliche Untersuchung ergibt außer einer Kyphoskoliose eine geringfügige Sohwäche des linken Facialis, eine geringe Parese des linken Arms in sämtlichen Muskeln, ebenso am Bein, ohne wesentliche Veränderung des Tonus. Beide Hände zeigen grobschlägigen Tremor, die paretische in viel stärkerem Grade, Romberg angedeutet, sämtliche Sehnenreflexe links stärker als rechts, Bauchdeckenreflexe fehlen links, sind rechts vorhanden. Anscheinend Hypaesthesie links (Angaben des Patienten ungenau).

Diagnose: Schlaffe Hemiplegie.

Wir haben die Willküraktion der Unterarmbeuger untersucht. Wir erhielten vollkommen normale Frequenzzahlen: 10, 9, 10, 10,9 usw. 
Gleichwohl ist die Kurve eigenartig dadurch, daß noch sehr auffallend Gruppenbildung hervortritt (Fig. 57).

Zusammenfassung: Wir fanden also bei einem nicht hypertonischen Hemiplegiker mit Zittererscheinungen normale Sekundenfrequenzen der Aktionsströme, as trat jedoch dic bereits wiederholt erwähnte Gruppenbildung deutlich hervor. Da wir auf diesen Begriff im folgenden noch häufig zurückkommen, seien einige Erläuterungen gegeben. Gruppenbildung von Zacken muß in der Kurve immer dann hervortreten, wenn

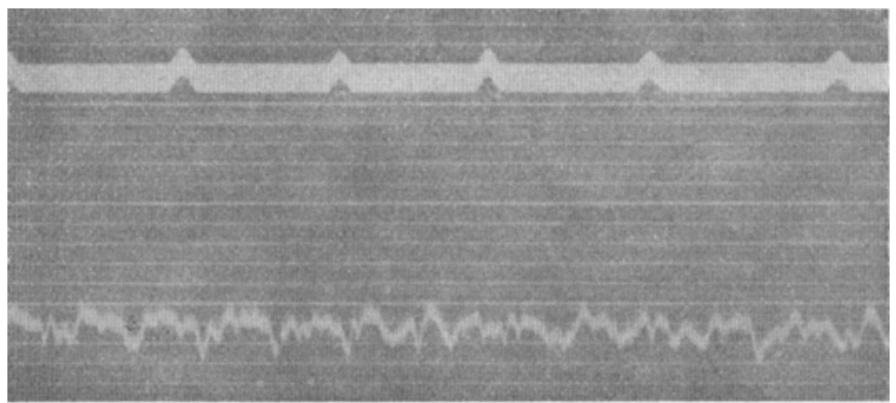

Fig. 57. Fall XXIIr. Hemiplegie. Zittern. Ableitung von den Unterarmbeugern bei Faustschluß. Gruppenbildung.

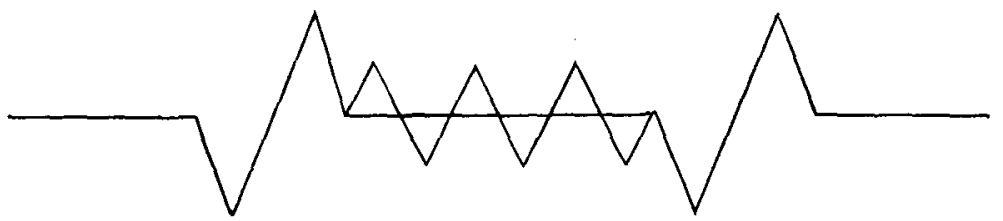

Fig. 58,

zwischen den kräftigeren Aktionsstromschwankungen in regelmäßigen Pausen schwächere auftreten, resp. neben den schwächeren. Die schematische Fig. 58 zeigt, wie wir uns das Zustandekommen der Gruppen vorstellen. Beginnt nun jeder Zitterimpuls mit einer kräftigen Stromschwankung, so ist unsere Gruppenbildung bereits gegeben. Diese Ausführungen sind für die Einschätzung der "Gruppenbildung" stets im Auge zu behalten.

Fall XXIV. F. N., Maler, 47 Jahre, verheiratet, wiederholt Bleivergiftungen. Ende Januar 1908, allmählich einsetzende Lähmung der rechten Körperhälfte, seither allmähliche Verschlechterung; jetzt Klagen über Kopfschmerzen, Angstgefühle, Schwäche der rechten Körperhälfte, Lues negiert. Innere Organe $0 . B$. Wassermann - . Neurologisch: Kopf meist nach rechts gehalten, Schädel nicht empfindlich, Quintuspunkte frei, Zähne quer gerieft, Andeutung einer gespaltenen Oberlippe. Links geringe Facialisschwäche (Schwäche des unteren Astes), Zunge, Masseteren, Gaumensegel, Augenbewegungen o. B. Pupillar-, Konjunktival-, Corneal-, Rachenreflexe o. B. Geruch o, B., Geschmack rechts stark herabgesetzt für sämtliche Qualitäten, im vorderen und hinteren Anteil der Zunge, relative 
Hemianopie nach rechts, insbesondere für Farben, Augenhintergrund o. B., Gehör o. B. (Befund der Ohrenklinik), Sprache, Schlingakt o. B. Hemiplegie rechts, am Arm die grobe Kraft sämtlicher Muskelgruppen in etwa gleich schwerem Maße (Dynamometerdruck etwa $5 \mathrm{~kg}$ ) gestört, die Beweglichkeit ungestört; im Fußgelenk ist die Bewegung nach aufwärts in beträchtlichem Grade, die nach abwärts in geringerem Grade eingeschränkt, die Kraft in den Kniestreckern besser als in den Kniebeugern, Abduktoren, Adduktoren, Außen- und Innenrotatoren der Hüfte in gleichem nicht unerheblichem Grade geschädigt; der Tonus rechts erheblich herabgesetzt, an Arm und Bein leichte Ataxie, Sehnenreflexe rechts stärker als links, keine Kloni, Bauchdeckenreflexe, Skrotalreflex fehlen rechts, Plantarreflex herabgesetzt, Babinski, Oppenheim - . Motilität der linken Körperhälfte intakt, nur ist der linke Patellarreflex auffallend schwach, Gang unter Nachschleifen des rechten Beines, Mitbewegungen nicht auffä]lig. Sensibilität: sämt-

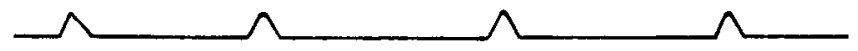

Fig. 59. Fall XXIV. Schlaffe Hemiplegie. Willküraktion des Quadriceps. Normale Frequenz, niedere Zacken.

liche Qualitäten rechts leicht herabgesetzt, am schwersten ist das Lagegefühl gestört (Arm und Bein). Am Rumpf keine Sensibilitätsstörungen, das rechte Bein kühler als das linke.

Diagnose: Schlaffe Hemiplegie.

Die Willküraktion der Kniestrecker der kranken Seite ergab sehr kleine Zacken und wies folgende Werte auf: 8, 10, 11, 9, 10, 10, 9. Es wurde nur einmal in dieser Reihe eine Gruppenbildung beobachtet. Eine weitere Reihe lautet: 9, 8, 9, 11, 11. Keine Gruppenbildung. Eine weitere: $9,11,11, \ldots .10,10$. Keine Gruppenbildung. Die Willküraktion der Unterarmbeuger der gesunden Seite zeigte relativ hohe Werte (bis zu 57 pro Sekunde).

Zusammenfassung: Bei der Willküraktion eines schlaffen Hemiplegikers zeigte sich die Frequenz der Aktionsströme normal. Auch qualitative Abweichungen fanden sich nicht. (Insbesondere war erheblichere Gruppenbildung nicht nachweisbar). Der geringen Kraft entsprechend waren die Wellen in der Kurve sehr nieder (Fig. 59).

Wir glauben auf Grund unseres Materials einen ziemlich vollständigen Ưberblick über die Aktionsströme bei spastischen Lähmungen, bei Contracturen und schlaffen Lähmungen bei Pyramidenbahnläsion geben zu können.

Wir beginnen mit dem Klonus. Außerordentlich häufig entspricht dem mechanischen Einzelstoß des Klonus eine biphasische Stromschwankung, dieses Verhalten gilt sowohl von dem Handklonus als auch von Patellar- und Fußklonus (Fig. 40, 43). Nicht allzu selten jedoch sind es zwei Impulse, durch welche der mechanische Einzelstoß hervorgerufen wird. Wertheim Salomonson hat die entsprechenden Bil- 
der dadurch zu erklären versucht, daß er annahm, daß die zweite Zacke durch Interferenz zustande käme, wenn die beiden Elektroden diesseits und jenseits des nervösen Äquators aufgesetzt würden. Wir haben im Falle XVII und XVIII bei Stellungen der Elektroden, welche eine derartige Interferenz ausschlossen, Bilder erhalten, welche nur so gedeutet werden konnten, daß der mechanische Einzelstoß durch zwei Impulse (ja gelegentlich sogar durch drei Impulse) hervorgerufen werde. In dieser unserer Ansicht werden wir bestärkt durch die Kurven, welche wir vom Fußklonus eines Falles von Paralysis agitans erhalten haben. Hier ist ausnahmslos jeder Schlag des Klonus Resultat von 3-4 Innervationsimpulsen. Wiewohl wir diese Gegensätzlichkeit für theoretisch bedeutsam halten, müssen die UUbergänge beider Formen betont werden.

Aus dem vorangehenden ist es ohne weiteres abzuleiten, daß die Sekundenfrequenzen des Klonus außerordentlich nieder (7-15) sind.

Mit dem Klonus sind zu vergleichen diejenigen Kurven, welche gewonnen wurden, wenn der spastiseh gespannte Muskel in brüsker Weise gedehnt wurde und Gegenspannung jedoch kein Klonus auftrat. Wir erhielten dann vielfach Kurven, welche von denen des Klonus überhaupt nicht zu unterscheiden waren (Fall 17), doch fanden sich (Fall 17 und Fall 18) häufiger Frequenzzahlen, welche diejenigen des Klonus mehr oder minder übertrafen, die Sekundenfrequenz erreichte dann (z. B. am Musculus biceps, Fall XVII Musculus quadriceps, Fall XVIII) 25, 33 (Fig. 41, 44, 54).

Die Resultate für die Gegenspannung waren nicht verschieden, wenn es sich um Gegenspannung bei alten Contracturen handelte (Fall XVII und XVIII), von denen, welche bei Frühcontracturen und Spasmen (Fall XIX, XX und VII) auftraten. Auch hier betrugen die Werte um 25 in der Sekunde. Auch in einem Falle von wächserner Contractur (Fall XII) haben wir ähnliche Resultate erhalten, die Frequenz betrug hier 23 und 25. Auch dieses Resultat verweist darauf, daß ein Stoß des Klonus durch mehrere Impulse hervorgerufen werden kann.

Unsere Untersuchungen über die Gegenspannung beim Normalen sind noch nicht abgeschlossen. Wir können aber bereits jetzt mit Bestimmtheit aussprechen, daß reflektorische Gegenspannung auch beim Normalen durch die Ableitung der Aktionsströme zum Saitengalvanometer nachgewiesen werden kann.

Es erscheint von vornherein wahrscheinlich, daß die Gegenspannung bei verschiedenen Reizen nicht verschieden ausfällt, in der Tat konnten wir im Falle XX konstatieren, daß auf Kältereiz im Musculus quadriceps ähnliche Aktionsstromwellen auftreten, wie nach Dehnung des Muskels.

Untersuchungen Försters und anderer haben uns gelehrt, daß die Spannungszustände des Spasmus und der Contractur von beständigen sensiblen Zuflüssen abhängen. Es handelt sich um eine stete Antwort 
des motorischen Apparates auf zentripetale Zuflüsse. Es liegt also bei den Spannungszuständen (soweit sie nicht auf direkter Reizung beruhen) ein diskontinuierlicher Erregungszustand der Muskeln vor, wobei die Einzelerregung im Prinzip durchaus gleichzusetzen ist der Erregung bei reflektorischer Spannung des Muskels gegen Dehnung und gegen Kältereiz. Schon aus diesen Erwägungen geht hervor, daß auch für den ruhend erscheinenden spastisch gespannten Muskel Aktionsstromwellen gefordert werden müssen, dabei wird jedoch kein kontinuierlicher, sondern ein unregelmäßiger Rhythmus zu erwarten sein. Diesen theoretischen Postulaten entsprechen unsere tatsächlichen Befunde in jeder Hinsicht, wir haben in den Fällen VII und XVI derartige Befunde tatsächlich erhoben (Fig. 17), auch hier war die Frequenz der Aktionsströme pro Sekunde eine geringe im Vergleich zu der der normalen Willküraktion (etwa 25). Daß es nicht in allen Fällen gelingt, derartige Resultate zu erhalten, liegt zum Teil an der wiederholt hervorgehobenen relativen Leistungsfähigkeit des Instrumentariums, zum Teil aber auch daran, daß die Fälle mit deutlich erhöhter Ruhespannung durchaus als selten bezeichnet werden müssen, wofern es sich nicht eben um Reizcontracturen des Frühstadiums und um wächserne Contracturen handelt. Valckenburgh diskutiert in seiner Studie über die Hemiplegie, ob cs überhaupt eine Ruhespannung gebe und kommt im wesentlichen nur deshalb zu einer bejahenden Antwort, weil ihm die Existenz eines Verlustes des Ruhetonus bei der cerebralen Hemiplegie erwiesen scheint (Heilbronner).

Für die Reizcontracturen wird man von vornherein mehr kontinuierliche Aktionsstromwellen fordern müssen, tatsächlich haben wir solche im Falle XX erhalten (Frühcontractur, Fig. 55). Ebenso verzeichneten wir im Falle XII (wächserne Contractur) kontinuierliche Aktionsstromwellen von der bekannten niederen Frequenz (Fig. 37). Für den Rigor der Paralysis agitans haben wir den gleichen Nachweis zunächst nicht erbringen können, doch liegt dies sicher nur an äußeren Umständen, da der einzige uns zur Verfügung stehende Fall dieser Art (Fall X) einen außerordentlich großen Hautwiderstand besaß. Mit Rücksicht auf unsere Befunde im Falle XII wird man auch hier in geeigneten Fällen kontinuierliche Aktionsstromwellen erwarten müssen.

Wir kommen zu der Besprechung der Willküraktion. Wir gehen aus von der Besprechung einer Kurve, welche wir vom Quadriceps des Falles XVIII bei kraftvoller Streckung erhalten haben (Fig. 47). Diese zeigt vollkommen deutlich, daß der willkürlich innervierte spastisch gespannte Muskel eine normale Frequenz der Aktionsströme haben kann. Allerdings tritt schon zu Beginn der Innervation ein zweiter Rhythmus hervor (vgl. auch Fig. 48), es bilden sich kleine Gruppen der Zacken, welche in ihrer Frequenz pro Sekunde annähernd an den Klonus er- 
innern. Dieser langsamere Rhythmus tritt allmählich auf Kosten des rascheren immer mehr hervor, bis schließlich der Rhythmus des Klonus rein erscheint (vgl. die Abbildung) ${ }^{\mathbf{1}}$ ).

Unser gesamtes Material läßt sich nun nach dem Gesichtspunkte der Interferenz einer raschen und einer langsameren Innervationsfolge leicht überblicken. Je schwerer die Lähmung und je hochgradiger der Spasmus ist, desto mehr überwiegt der langsame Rhythmus. So erhielten wir in dem gleichen Falle von den Unterarmbeugern (Fig. 46) Kurven, welche von denen des Klonus nicht zu unterscheiden waren, während an dem von Biceps brachii gewonnenen Kurven (Fig. 49) nur die geringe Frequenz der Innervationsimpulse auffällig erschien. Erst die aufmerksame Betrachtung deckte die Neigung zur Gruppenbildung im oben beschriebenen Sinne auf. Die in den Fällen XXI, XXII (mittelschwere und leichte spastische Lähmungen) aufgenommenen Kurven ergaben als wesentliches Resultat wiederum eine Gruppenbildung der Wellen (Fig. 56). In unserer Auffassung hierin etwas Wesentliches zu sehen, werden wir durch Untersuchungen Buytend $\mathrm{yks}$ und Hoffmanns bestärkt. Jener fand bei der decerebrierten Katze in den Kurven Stellen, wo in der Reihe der Oszillationen von dem normalen 70-90 er Rhythmus größere Wellen (3-4 kleinere Wellen enthaltend) auszuzählen waren, welche eine Frequenz von $20-30$ pro Sekunde aufwiesen. Die gleichzeitig registrierten mechanischen Wellen betrugen 15-20 pro Sekunde. Auch Hoffmann fand bei der Registrierung der Aktionsströme des Sartorius beim epileptischen Anfall des Hundes z wei Rhythmen, einen Zehner- und einen Vierzigerrhythmus. Es scheint uns nach unseren Kurven berechtigt, auch die Gegenspannung als Mischung derartiger Innervationsrhythmen aufzufassen, wobei aber zum Teil ein Alternieren, zum Teil eine Superposition der Rhythmen stattfindet. Wir geben aber zu, daß es uns fraglich erscheint, ob jede Verlangsamung in den einschlägigen Fällen auf Interferenz zweier Erregungsreihen zu beziehen ist. Wir neigen vielmehr zu der Ansicht, daß es Verlangsamungen des Rhythmus gibt, die man auf prinzipiell andere Weise deuten kann (Ataxie, Ermüdung, Entspannung, choreatische Zuckung) und erwähnen auch in diesem Zusammenhang, daß wir in dem Falle XII langsame Rhythmen antrafen, wiewohl die Sehnenreflexe vollkommen fehlten. Weitere theoretische Deutungsversuche scheinen uns derzeit nicht am Platze zu sein.

Es erhebt sich ohne weiteres die Frage, welches denn das Kurvenbild der schlaffen Hemiplegie sei. Leider ist unser Material in dieser Hinsicht sehr gering. In dem untersuchten Falle (Fall XXIV) haben wir jedoch Gruppenbildung nicht angetroffen (Fig. 59). Auch zeigte sich

1) Von der Ermüdungskurve sind diese Kurven, wie ein Blick auf unsere $A b$ bildnngen zeigt, ohne weiteres abzugrenzen. 
auf weite Strecken der normale Rhythmus. Die Wellen waren sehr niedrig. Fall XXIII, der keine Hypertonie zeigte, ist durch Zittern kompliziert, so daß er nicht in bestimmtem Sinne verwertet werden kann. Wir hoffen, durch spätere Untersuchungen unser Material vervollständigen zu können.

Im ersten Teil unserer Untersuchungen haben wir darauf hingewiesen, daß bei Bewegungen von gewöhnlichen Typus die Innervation der Antagonisten nicht ein plötzliches Aufhören der Innervation der Agonisten bedingt, vielmehr werden diese eine ganze Strecke lang gleichzeitig mit den Antagonisten innerviert. Wir schreiben daher dem Hering-Sherringtonschen Gesetze keine allgemeine Gültigkeit zu. Es war nun von besonderem Interesse, die Verhältnisse bei spastischen Lähmungen zu studieren. Lewandowsky baut ja seine Anschauung von der Contractur darauf auf, daß hier der Hering-Sherringtonsche Innervationsmechanismus in pathologischer Ưbertreibung vorliege. Auf Grund klinischer Beobachtungen erscheint diese Annahme bereits wenig wahrscheinlich (vgl. insbesondere Förster und Valckenburgh). Wir konnten im Falle XVIII konstatieren, daß bei kräftiger aktiver Beugung im Kniegelenk auch die Strecker aktiv innerviert werden, und zwar umso kräftiger, je brüsker die aktive Innervation der Antagonisten erfolgt (Fig. 49, 50, 51).

Um den Einwand zu entkräften, daß nur die bei der Contractur gespannten Muskeln in dieser Weise mit innervieren, haben wir am Oberarm des Falles XVIII Strecker und Beuger bei Innervation der Antagonisten untersucht; das Resultat war das gleiche: bei der Beugung werden die Strecker, bei der Streckung die Beuger mit innerviert. Unsere Abbildungen (Fig. 52 und 53) lassen an diesem Sachverhalte keinen Zweifel. Wir gehen nicht darauf ein, daß eine Reihe anderer Theorien (z. B. die von Mann), mit unseren Befunden gleichfalls nicht $\mathrm{zu}$ vereinigen ist.

Im Falle XIX haben wir für eine reflektorische Bewegung gleichfalls gleichzeitige Innervation der Agonisten und Antagonisten nachgewiesen. Schließlich besteht bei der wächsernen Contractur (Fall XII, Fig. 36) das gleiche Verhalten.

Ein Versuch, die mitgeteilten tatsächlichen Befunde zu deuten, muß derzeit notwendig unvollkommen bleiben, da experimentelle Studien über diese Fragen bisher noch ausstehen. Wir werden nur die vorzüglichen Arbeiten Hoffmanns und Buytendyks heranziehen können, doch behandeln beide Untersuchungen nur einen kleinen Teil des Gebietes. Wir hoffen, späterhin durch experimentelle Studien unsere klinischen Untersuchungen vervollständigen zu können. Unter diesen Vorbehalten möchten wir folgende Vorstellungen als den bisher festgestellten Tatsachen am besten genügend hinstellen: Bei der 
spastischen Lähmung lassen sich fast durchgehends zwei Innervationsmechanismen feststellen, die sich in der verschiedensten Art durchkreuzen und ergänzen. Der eine tritt uns am reinsten im Klonus entgegen und ist durch eine außerordentlich geringe Frequenz der Innervationsimpulse in der Sekunde gekennzeichnet. Dieser Mechanismus muß als subcortical angesprochen werden, vielleicht im wesentlichen als spinal (an irgendeinen muskulären Rhytbmus zu denken liegt keine Veranlassung vor). Man wird sich wenigstens schwer entschließen, für den Klonus die Mitwirkung des Cortex anzunehmen. Wir glauben diesen Innervationsmechanismus auch bei der Ruhespannung des spastischen Muskels, bei der Gegenspannung und bei der Willküraktion des Spastikers vorgefunden zu haben. Wir fanden innerhalb dieser Reihe seine Bedeutsamkeit zurücktretend. Wir glauben nicht, daß es sich um einen Mechanismus handelt, der dem Normalen nicht zukommt. Beim Klonus der Hysterischen hat Werthei m-Salo monson Kurvenbilder erhalten, welche uns eine Gruppierung zu zeigen scheinen, welche der der Willküraktion der spastischen Lähmung leichtesten Grades ähnelt. Bei willkürlicher Imitation des Klonus haben wir, wie aus der Figur ersichtlich, gleichfalls Bilder erhalten, die wenigstens eine äußerliche Ähnlichkeit mit denen der Willküraktion der Spastiker zeigten. Haben wir darin den Ausdruck des gleichen Mechanismus wie beim Normalen ? ${ }^{1}$ )

Jedenfalls halten wir diesen Innervationsmechanismus für eiren primitiven im Vergleich zu demjenigen, der in der Willküraktion des Normalen hervortritt. Hoffmann hat am Hunde gezeigt, daß die Großhirnrindenreizung mit einer Reizfrequenz von weniger als 40 auch dann zu einem dem Normalen angenäherten Rhythmus führt, wenn die Reizfrequenz beträchtlich geringer wird. Diese Transformation erfolgt jedoch nur dann, wenn die Reizung nicht zu lange angedauert hat. Bei Reizfrequenzen um 50 wird der Rhythmus in den Aktionsströmen klar wiedergegeben, bei höheren Reizfrequenzen ist die Reizfrequenzwiedergabe eine unvollkommene. Die Untersuchungen Hoffmanns zeigen, daß das Gesamthirn den Fünfzigerrhythmus irgendwie eingeprägt hat, sagen aber nichts darüber aus, welchen Apparaten er zuzuschreiben ist. Bei Tieren muß er nach den Untersuchungen B u ytendyks jedenfalls auch subcortical vertreten sein. Buytendyk fand an der decerebrierten Katze die gleichen Innervationsrhythmen wie bei den normalen. (Daneben fand er allerdings auch ein zeitweises Hervortreten des ,,Klonusrhythmus.") Es ist jedoch zu berücksichtigen, daß die nervösen Funktionen bei der Katze weiter spinalwärts lokalisiert gedacht werden müssen, als beim Menschen. Wir halten es nicht

1) Vgl. die Ausführungen zu Fall XXIII. 
für berechtigt, die verschiedenen Mechanismen als cortical und subcortical einander gegenüberzustellen, sondern ziehen vor, von einem übergeordneten und einem untergeordneten Mechanismus zu sprechen.

Weitere Untersuchungen werden zeigen müssen, ob und in welcher Weise eine Lokalisation möglich ist.

Wir haben schon oben erwähnt, daß es uns nicht wahrscheinlich ist, daß der Langsamkeit der Rhythmen immer die gleiche Genese zugrunde liegt und haben für die langsameren Rhythmen der willkürlichen Entspannung, der Ermüdung, der Ataxie, auch der verschiedenen Zuckungsformen, ja selbst für die der Hemiplegie die Möglichkeit einer anderen Erklärung in Betracht gezogen. Doch ist auch diese Frage eine völlig ungeklärte. Die Ausdrucksfähigkeit der Kurvenbilder ist ja überhaupt eine beschränkte. Wir haben im Verlaufe unserer Untersuchungen nur eine geringe Anzahl von Elementarstörungen in der Kurve vorgefunden : Verlangsamung der Innervationsfolge, Gruppenbildung und ausnahmsweise Verlängerung der Dauer der Stromschwankung ${ }^{1}$ ).

Immerhin glauben wir als wichtig für die Pathophysiologie der Hemiplegie hervorheben zu dürfen, daß wir fast stets beide Mechanismen in der Gegenspannung und in der Spannung des ruhenden Muskels vorgefunden haben. Beachtenswert erscheint ferner, daß der primitivere Mechanismus bei der Willküraktion je nach der Schwere der Störung in verschiedenem Grade hervortritt. Die vorangehenden Zeilen sollen nichts anderes geben als eine vorläufige Zusammenfassung. Für eine wirkliche Theorie $\mathrm{mu} ß$ noch weiteres Material gesammelt werden.

\section{Einige kompliziertere Bewegungsstörungen.}

F all XXV. O. S., Telegraphenarbeiter, 42 Jahre alt. Seit 17 Jahren erkrankt, Beginn mit Zitterbewegungen in der rechten Hand, später auch in der linken. Verlangsamung der Sprache und psychische Störungen (vorwiegend sexuelle Utbererregbarkeit). Gegenwärtig schon seit Jahren unverändert, temporale Abblassung beider Papillen, Nystagmus horizontalis, skandierende Sprache, geringfügiger Intensionstremor beider Hände, Gang leicht spastisch, Sehnenreflexe an den unteren Extremitäten lebhaft, kein Babinski. Bauchdeckenreflexe rechts schwächer als links, aber sämtlich vorhanden.

Diagnose: Multiple Sklerose.

Es wurde die Willküraktion der Unterarmbeuger untersucht. Die Werte waren folgende: $11,9,9,12,12,11,11,14,9,10,7$. Gelegentlich tritt Gruppenbildung ähnlich wie bei den Spastikern auf (Fig. 60).

Wir fanden also an einer Extremität, die Intentionstremor zeigte, nichts Charakteristisches. Wir benutzen die Gelegenheit, darauf zu

1) Die Zahl der Nebenzacken ist nur mit großer Vorsicht zu bewerten. Wir wissen ja, daß sie schon beim Normalen bei geringem Druck (Piper) und bei Ermüdung viel stärker hervortreten. 
verweisen, daß wir uns der Unsicherheit des Kriteriums „Gruppenbildung" sehr wohl bewußt sind. Immerhin gibt ja das Auftreten der Gruppenbildung hier einen gewissen Sinn. Erwähnt sei, daß Sãnger und Bornstein die Einzelbewegung des Intentionstremors in Einzelwellen zerlegt haben.

Fall XXVI. B. G., 14 Jahre alt, Kaufmannslehrling. Im 12. Jahre im Anschlu $B$ an Influenza Augenlähmung. veitstanzähnliche Bewegungen: zwisehen Influenza und nervösen Störungen 6 Wochen. 14 Tage vor der Aufnahme wurde der Gang schlechter, nachdem sich gelegentlich schon früher Schwäche der Beine gezeigt hatte, bisweilen Nachträufeln beim Urinieren, keine Parästhesie, keine Sprachveränderung, kein $Z_{\text {wangslachen. }}$

Bei der Aufnahme am 31. Juli 1912 innere Organe o. B., Wassermann negativ, Pupillen reagieren prompt, Nystagmus beim Blick nach beiden Seiten, sonst Hirnnerven (auch Papille und Gesichtsfeld) o. B. Beim Vorstrecken der Hände sinkt

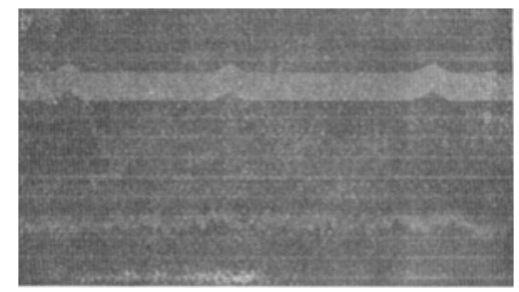

Fig. 60. Fall 25. Multiple Sklerose. Willktiraktion der Unterarmbeuger. (Intentionstremor.) Gruppenbildung.

die rechte allmählich abwärts, Finger rechts in den Grundphalangen überstreckt, Handgelenk gebeugt, beide vorgestreckte Arme schwanken, der rechte stärker. Beweglichkeit der Arme ungestört, Kraft rechts leicht herabgesetzt, Tonus herabgesetzt, am rechten Arm Adiadochokinese angedeutet. An den Beinen Herabsetzung der Kraft, links stärker, an beiden Beinen reichliche Mitbewegungen, Strü m pell sche Phänomen, links stärker als rechts. Ruhetonus beiderseits schlaff, bei Bewegungen initiale.Spasmen beiderseits, nur das linke Peronealgebiet, das eine besonders hochgradige Parese zeigt, keine initialen Spasmen. Ataxie beiderseits. Gang spastisch ataktisch, der linke Fuß schleift nach, er ist der Peroneuslähmung entsprechend, supiniert. Patellarreflexe beiderseits lebhaft mit angedeutetem Klonus, rechts organischer Fußklonus, links fehlt der Achillessehnenreflex, links Babinski und Oppenheim positiv, Armreflexe vorhanden, die oberen Bauchdeckenreflexe sind schwach, die unteren fehlen. Rechts Fußsohle und ein handbreiter Streifen oberhalb des änßeren Knöchels für sämtliche Qualitäten hypästhetisch, Lagegefühl für die Endglieder beiderseits gestört. Während der Beobachtung in der Klinik zeitweise Doppelsehen, auch sonst schwanken die Erscheinungen, Bauchdeckenreflexe zeitweise vorhanden. Bei der Entlassung keine Kloni, Sensibilitätsstörungen verschwunden, am 9. Nov. 1912 Zunahme der Spasmen und Paresen an beiden Beinen.

Diagnose: Multiple Sklerose.

Die Willküraktion der rechten Unterarmbeuger wurde zu einer Zeit untersucht, wo der Aufnahmestatus gültig war: die Zahlen lauteten: $7,8, \ldots 8, \ldots 7,6,6, \ldots 8,5,5$. Also recht niedere Werte. 
Worauf diese Herabsetzung der Werte zu beziehen ist, auf die Parese oder auf die Koordinationsstörungen, bleibe dahingestellt.

Fall XXVII. P. N., Schlosser, 41 Jahre alt. Seit 2 Jahren Sprache gestört, Mai 1911 Schlaganfall mit Lähmung der rechten Seite, seither Lähmungsanfälle 3-4 mal täglich. Jetzt arbeitsunfähig, keine Kinder.

Aufgenommen am 26. Aug. 1912. Innere Organe o. B., Pupillen weit, beide träge reagierend, die rechte träger, Facialis beiderseits schlaff. Äußerste Ungeschicklichkeit bei sämtlichen Bewegungen, die Bewegungen eckig, insbesondere rechts, reichliche Mitbewegungen und Zittererscheinungen, ebenfalls rechts stärker. Ataxie angedeutet, Gang plump, unbehilflich, kein Romberg, sämtliche Sehnenreflexe lebhaft. Rechts Fußklonus angedeutet. Schwere paralytische Sprach. störung. Schrift schwer gestört. Psychisch, dement euphorisches Wesen, schwere Störungen der Merkfähigkeit, und Orientierung. Keine aphasischen Störungen, nur die Wortfindung leicht gestört. Beim Sprechen zuckende (choreiforme) Mitbewegungen der Arme und Beine. Keine motorische und ideatorische Apraxie.

Diagnose: Progressive Paralyse.

Die Aufnahme der Aktionsströme der Unterarmbeuger ergab: 4, 4, $6,6, \ldots 8,8,11,5,7,7,7,3,9,7$. Es zeigte sich dabei eine auffallende Unregelmäßigkeit der Zacken.

Die Bewegungsstörung, die hier vorliegt, scheint uns die engste Verwandtschaft mit der Kleistschen innervatorischen Apraxie zu besitzen, wie man ja überhaupt nicht fehlgehen wird, wenn man in der Mehrzahl der Fälle von paralytischer Ungeschicklichkeit herdförmige Schädigungen annimmt. Der mit dem Saitengalvanometer erhobene Befund ist geeignet, die Annahme einer ,organischen“ Ungeschicklichkeit zu stützen.

Fall XXVIII. F. G., 57 Jahre alt, Maurer. 1910 verlor er plötzlich die Sprache, 1911 linksseitige Lähmung neuerliche Verstärkung einen Monat später, gleichzeitig auch Schmerzen im linken Arm, konnte nicht sprechen, Suicidideen.

Aufnahme am 20. Mai 1912. Mäßige Arteriosklerose, Wassermann im Blut negativ, Z Zunge zittert etwas, Facialis links spurweise schlaffer als rechts, im übrigen motorische Hirnnerven o. B., ebenso die sensorischen. Corneal-, Conjunctival-, Pupillenreflexe positiv, rechts gleich links. Muskeltonus an den Extremitäten leicht erhöht, es überwiegt der Tonus der Arm- und Handbeuger links. Kraft, Koordination, Beweglichkeit o. B., Gang von ausgesprochen hemiplegischem Typus, linker Arm im Schultergelenk in Mittelstellung im Hand- und Ellbogengelenk gebeugt, linkes Bein wird circumduziert, Sehnenreflexe lebhaft, sämtlich vorhanden, Tricepsreflexe links stärker als rechts, Hautreflexe normal, leichte Herabsetzung der Sensibilität (nicht exakt zu prüfen). Es besteht außerdem typische, rein motorische Aphasie mit schweren Störungen des Lesens und der Schrift. Links besteht eine Verarmung der Spontanbewegungen und geringfügige Apraxie, ideokinetische Eigenleistungen dabei intakt, gegen den Körper gerichtete Bewegungen abgeändert, greift $\mathrm{z}$. B. als er nach der Nase greifen will, zunächst nach dem linken Ohr. Drohen kann er mit der linken Hand nicht, beim Langenasemachen Steifheit der Bewegungen, Objekthantierungen auch links gut, rechts sind die Bewegungen nur etwas steif, aber sonst nicht abgeändert. Psychisch meist etwas ablehnend und unwillig.

Bis November 1912 nur insofern Veränderung, als die linksseitigen apraktischen Erscheinungen noch verschwommener werden.

Diagnose: Motorische A phasie, linksseitige geringfügige A praxie. 
Vom rechten Unterarm wurde mit dem folgenden Resultat abgeleitet: $10,11,11,8,9,7,11,9,10$. Vom linken mit folgendem: 9, 8, $10,6,8,9,10$ (zum Teil scheint ein Klonusrhythmus daneben angedeutet zu sein).

Die Herabsetzung der Aktionsstromfrequenzen links ist eine sehr geringe. Dazu kommt, daß geringfügige spastische Erscheinungen nachweisbar waren. Diese für die Herabsetzung heranzuziehen, liegt um so näher, als auch die Form der Kurve Annäherungen an die der Spastiker zeigte. Die Apraxie hat sich im Kurvenbild nicht bemerkbar gemacht.

Von den hier kurz erwähnten Bewegungsstörungen hat nur die corticale Apraxie einigermaßen umschriebene Befunde gegeben. $\mathrm{Ob}$ andere Apraxieformen sich im Kurvenbild gleichfalls irgendwie bemerkbar machen, werden spätere Untersuchungen zeigen müssen.

\section{Psychosen.}

Fall XXVIII. B. H., Kontorist, 31 Jahre alt. Familienanamnese belanglos, sehr begabt; 6 Wochen vor der Aufnahme in Hamburg erkrankt, schwermütig, saß still, starrte vor sich hin, ,man mußte ihm jedes Wort abkaufen“", aß schlecht, war schon vorher $1 / 4 \mathrm{Jahr}$ im Krankenhaus. Im übrigen keine manisch-depressiven Züge nachweisbar, außerhalb der Attacken munter und aufgeräumt.

Somatisch keine pathologischen Befunde. Liegt stumpf und ruhig im Bette, die Vorgänge der Umgebung, nicht beachtend, spricht spontan nicht, iBt schlecht, erwidert den Gruß des Arztes, örtlich und zeitlich orientiert, fühlt sich krank, Interessen habe er nicht, traurig ruhiger Gesichtsausdruck und entsprechende Haltung, Ausdrucksbewegungen in abgeschwächtem Grade vorhanden. Auf Frage ,ich bin jetzt verändert, ich bin ruhiger geworden“, könne sich nicht so freuen wie früher, ,ich weiß nicht, es ist mir nicht so gegeben“. Fühlt sich jetzt arbeitsfähig, fühlt sich im Denken nicht gehemmt. Selbstvorwürfe fehlen, Aufforderungen werden prompt befolgt.

Der Zustand bessert sich rasch, am 6. Sept. besteht weder subjektive noch objektive Hemmung, ist ruhig, eher heiter, kann entlassen werden.

Diagnose: Manisch-depressives Irresein.

Die Aktionsströme, die vom Quadriceps abgeleitet wurden, ergaben folgende Frequenzen: 9, 11, 9, 10, 10, 9, 8, 8, 9, 11, 9, 9, 7, 10 usw., die vom Unterarm: 9, 9, 8, 10, 11, 10, 10, 9, 9. Auch sonst nichts Auffälliges.

Wie zu erwarten war, waren die Aktionsströme in einem Falle leichter Depression normal. Bemerkenswert ist nur, daß im Gegensatz zu den Resultaten Pipers die Werte eher für den Quadriceps höher sind als für den Unterarm. Nun haben wir das fest gestreckte Bein durch Druck zu beugen gesucht, Piper ließ ein Gewicht heben. Nach den Resultaten, die wir an Normalen gewonnen haben, scheint es uns durchaus möglich, daß die Differenz hierin eine Erklärung findet. Damit wäre auch die Aufgabe gegeben, die Aktionsstromrhythmen der einzelnen Muskelgruppen unter Berücksichtigung dieser Verhältnisse zu vergleichen. 
Fall XXIX. E. F., Techniker, 29 Jahre alt. Aufgenommen am 20. Okt. 1908. Familienanamnese belanglos. Hat schlecht gelernt, trank immer reichlich, insbesondere in letzter Zeit, richtete einem Mädchen eine Weinkneipe ein, bekam Verfolgungsideen, zerschlug Scheiben, prügelte Leute auf der Straße, hatte viel Angst, konnte schließlich nicht mehr arbeiten, wollte das Mädchen erschießen; in die Klinik aufgenommen am 2. Okt. 1908. Somatisch nichts Besonderes.

Bei der Aufnahme still, bisweilen zwangmäßiges Lachen, auffallend gleichmütig, am 22. Okt. ängstlich gehemmt, in den Antworten unsicher; am 25. Okt. Halluzinationen, hört Hilferufen, äußert Angst vor der Zukunft; am 27. Okt. äußert er, es sei ihm, als ob er in Äther schwebe, seit einigen Tagen kein Zwangslachen; am 30. Okt. behauptet er, in der Nacht am Magen operiert worden zu sein, ist nicht davon abzubringen. Am l. Nov. das Gefühl, er atme Blut ein, äußert Lebensüberdruß. Am 15. Dez. geordnet, drängt binaus, Stimmung suggestiv stark beeinflußbar. Am 13. Jan. 1909 relativ geordnet, macht genaue Angaben über sein Vorleben; im weiteren Verlauf spielt er anderen Patienten häufig Possen, schlägt z. B. auf den Tisch, wenn sie Karten spielen, legt sich tags angezogen ins Bett, lacht unmotiviert, raucht zeitweilig unmäßig, ist gelegentlich sehr ablehnend; im Mai schlägt er Fenster ein, schreibt an den Staatsanwalt wegen Freiheitsberaubung, wird ruhig, als er isoliert wird. Gegen Ende des Jahres zu ist er nicht mehr aus dem Bett herauszubekommen, ist einsilbig, apathisch, äußert oft unmotiviert und ohne entsprechenden Affekt, läppische Größenideen, schlägt eine Fensterscheibe ein, ,, weil ich ein Mensch bin“. Ende Soptember fällt die gebundene Haltung auf, ist mutazistisch, negativistisch, zeitweise stark ausgesprochene Katalepsie; onaniert stark.

Dieser Zustand bleibt im wesentlichen die folgende Zeit unverändert. Zur Zeit unserer Untersuchungen bietet er folgendes Bild (4. Mai 1912): Stets steife, gebundene Haltung, ausgesprochener Ausfall an Spontaneität, Verarmung an mimischen und automatischen Bewegungen, bisweilen grimassierend, insbesondere Stirnrunzeln, Kopf häufig zur Seite gedreht, ausgesprochene Ruhespannungen, sitzt wie kontrakt da, sämtliche Bewegungen steif und behindert, starke Gegenspannungen (ohne Zurückschnellen, wenn die Anspannung plötzlich unterbrochen wird), hochgradige Flexibilitas cerea, am stärksten die Nackenspannung und die Spannungen in den Masseteren. Lidschlag und Augenbewegungen selten, die Abwehrbewegungen ungeschickt, weicht vor der stechenden Nadel, die gegen sein Gesicht gerichtet ist, mit dem Kopfe zurück, Mimik der Unlust, keine Abwehrbewegungen der Hände.

Geringe spontane Aufmerksamkeit, antwortet auf Fragen (wie heißt das Haus hier) (würgt, zahlreiche Mitbewegungen, dann langsam:) "Mittelpunkt". (Welches Haus ist hier?) ,das ist ein Haus dritter Klasse" (zahlreiche steife Mitbewegungen). (Was machen Sie hier?) (kneift das linke Auge zu, zieht die Schultern hoch, legt die Stirne in Querfalten, sagt schließlich:) ,Zur Unterhaltung“". (Kennen Sie mich?) (Nickt, grimassiert heftig, zieht die Schultern hoch, macht Mundbewegungen, schließlich Lächeln.) (Sind Sie verrückt?) Die gleichen Mitbewegungen wie bei den übrigen Fragen, keine Affektreaktion, plötzlich erfolgt konvulsivisches Lachen. Aufforderungen befolgt er gegen Schluß der Unterredung hin nicht mehr, während er zu Beginn der Untersuchungen die Aufforderung, zu den Referenten zu kommen und sich zu setzen, nach mehrfacher Wiederholung der Aufforderung befolgt hatte. Der motorische Befund seither völlig unverändert.

Diagnose: Dementia praecox. Katatones Zustandsbild mit Spannungen.

Der Versuch, bei diesen Patienten die Aktionsströme aufzunehmen, stieß auf große Schwierigkeiten, es gelang uns nicht, von den kontra- 
hierten Muskeln Ruheströme abzuleiten, wiewohl die Faust wiederholt ganz nach Art der hemiplegischen geballt erschien. Hingegen haben wir wiederholt die Willküraktion von Muskeln, welche diese katatronische Contractur zeigten, aufnehmen können, am besten gelang der Versuch in der A'rt, daß wir den Patienten Gegenstände in die Hand gaben und sie ihm dann wegzunehmen suchten, er hielt diese Gegenstände dann krampfhaft fest, wir geben die Zahlenreihen von vier derartigen Versuchen wieder (die Schwingungsfrequenz pro Fünftelsekunde): 4, 3,

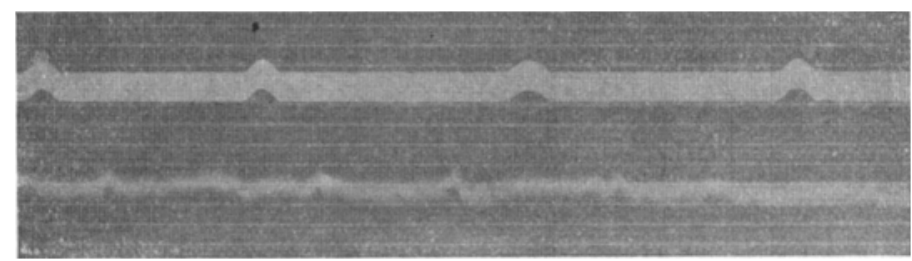

Fig. 61. Fall XXIX. Katatonie mit Spannungen. Willküraktion der Unterarmbeuger, während ein Gegenstand krampfhaft festgehalten wird. Geringe Frequenz der Aktionsströme. Häufige Pausen.

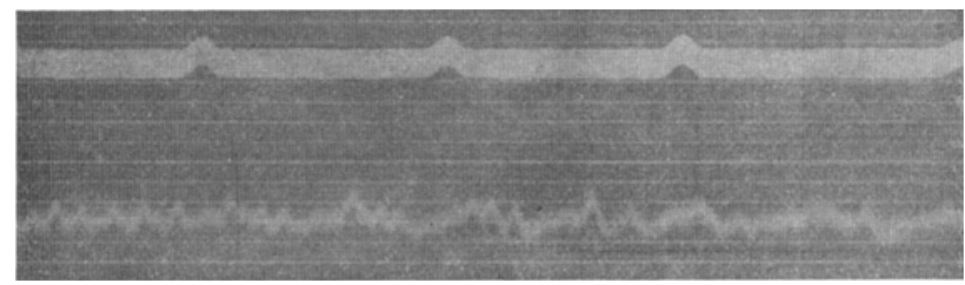

Fig. 62. Fall XXIX. Katatonie. Krampfhaftes Festhalten. Geringe Frequenz der Aktionsstromschwankungen. Pausen.

$3,2,2,4,4,4,2,2,9,3,9,3,3,3,3,9,2, \ldots 1,9,3,3,2,2,1,4,4$, $2,3,2,4,4,3,5,3,3,4,3, \ldots 4,5,5,4,3,1,5,4,3,3,5,4,3,5,3$, $\ldots 8,7,6,5,6,5,5,3,3,6,3^{1} / 2,7,6,6,9,3,9,3,6,9$ (Fig. 61 und 62 ).

Da es doch möglich schien, daß die besondere Art der geforderten Innervation schuld trüge an den abnorm niederen Frequenzzahlen, haben wir die Aktionsströme eines gesunden unter den gleichen Bedingungen (Entwinden von Gegenständen aus der Hand) aufgenommen. Wir erhielten folgende Reihen: $8,7,6,6,6,6,9,5,5,5, \ldots 5,5,5,5,4,5$, $6,4,5,4,9,6$. Es sind also diese Zahlen, welche von derjenigen Versuchsperson stammen, welche die geringsten Frequenzzahlen unter den normalen hatte, beträchtlich höher als die Zahlen, welche von den Katatoniker gewonnen wurden.

Bei der willkürlichen Innervation (Faustschluß) wurden gelegentlich viel höhere Werte erhalten, so erhielten wir folgende Reihe: 11, 14, 11, 
$13,9,11,11,12, \ldots 11,12$. Doch wurden zu einer Zeit, wo an Ermüdung nicht zu denken war, häufig außerordentlich niedere Werte gefunden, z. B. 10, 4, 4, 3 (vgl. Fig. 63).

Zusammenfassung: Die Diagnose des Falles als Katatonie mit ausgeprägten Spannungszuständen braucht nicht weiter diskutiert zu werden.

Wir haben also in einem Falle von Katatonie einen Befund erhoben, welchen wir willkürlich zu erzielen nicht imstande waren, die Herabsetzung der Frequenzzahlen war eine so beträchtliche, wie wir sie beim Normalen niemals beobachtet haben. Es muß jedoch ausdrücklich hervorgehoben werden, daß wir diese niederen Frequenzzahlen nicht konstant bei unserem Patienten vorgefunden haben. Wir zählten,

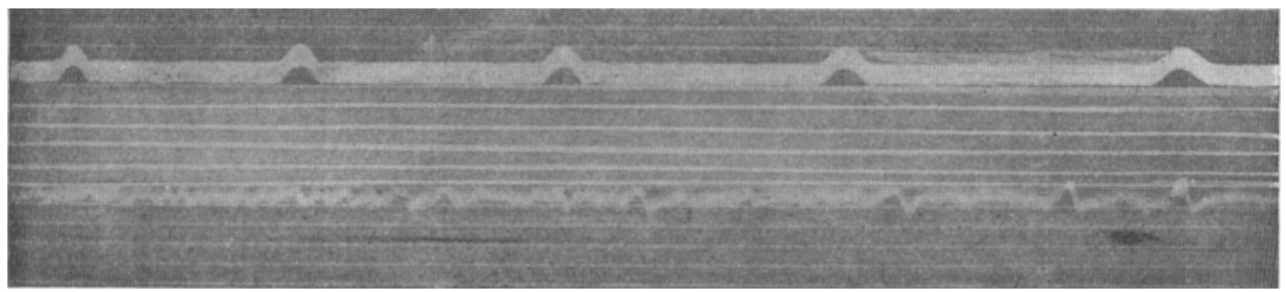

Fig. 63. Fall XXIX. Katatonie mit Spannungen. Freiwillig geleisteter Druck. Unterarmbeuger. Langsame Rhythmen.

allerdings nur für vereinzelte Fünftelsekunden 13, die Höchstzahl, die wir in einer Sekunde erhielten, betrug 58, dem steht gegenüber, daß wir bisweilen nur 20 Impulse pro Sekunde nachweisen konnten. Wie aus der Beschreibung hervorgeht, handelt es sich um einen Katatoniefall mit sehr ausgesprochenen und schweren Spannungen, welche wir schon nach ihrer klinischen Erscheinungsform als organiseh bedingt ansprachen (vgl. zu diesen Fragen Kle ist). Die Untersuchung der Aktionsströme ergab also außerordentlich schwere Veränderungen, welche sehr erinnern an die Veränderungen, welche wir bei spastischen Lähmungen antrafen. Es scheint also der Befund geeignet zu sein, die Annahme jener Autoren zu stützen, welche, wenigstens für einen Teil der Spannungen, bei Katatonie einen organischen Ursprung vermuten, $d$. h. eine lokalisierbare Schädigung motorischer Apparate. Es ist dies die Anschauung Kahlbaums, welche später insbesondere von Wernicke und seinen Schülern vertreten wurde.

Mehr als ein Wahrscheinlichkeitsmoment bringen jedoch unsere Untersuchungen nicht. Wir konnten zeigen, daß einen bestimmten Bewegungstypus ein bestimmtes elektromuskuläres Geschehen entspricht. Je nach der Dauer der Bewegung, je nach der Art der geforderten Leistung konnten wir verschiedene Bilder der mittels des Saitengal- 
vanometers gewonnenen Kurve feststellen. Es wäre immerhin denkbar, daß bei der Katatonie ein vom Normalen so völlig verschiedener Bewegungsentwurf vorläge, daß auch das Kurvenbild ein völlig verzerrtes wird. Wir hätten es dann mit dem unmittelbaren Ausdruck einer Fehlanlage des Bewegungsentwurfes zu tun. Es muß betont werden, daß keineswegs das elektromuskuläre Bild nur das Abbild der klinisch beobachteten Tatsache wiedergebe, da $\beta$ die einzelne Bewegung absatzweise erfolgt. Dazu sind die Pausen, welche zwischen den einzelnen Innervationsstößen auftreten zu klein (stets weniger als eine Zehntelsekunde). Es zeigt uns vielmehr das elektromuskuläre Bild Vorgänge an, welche mit einer anderen Methode überhaupt nicht feststellbar sind.

Graphische Untersuchungen bei der Katatonie liegen bisher nur außerordentlich wenige vor. Ermes hat sich darauf beschränkt, die Haltungskurven der Katatoniker aufzunehmen, wir gehen auf diese Untersuchung nicht näher ein, da sie nur das zeigt, was man ohne Apparate auch sehen kann. Wichtiger sind Untersuchungen von Pfahl, Isserlin und Lotmar. Diese Autoren haben für die Katatonie übereinstimmend festgestellt, daß es zu eigenartigen, ganz kurzdauernden Stillständen in der Bewegung kommt. Isserlin und Lotmar verzeichnen Pausen von ${ }^{4} / 100-5 / 100$ Sekunde. Es muß betont werden, daß diese Pausen, die Pfahl, Isserlin und Lot mar -ob mit Recht, bleibe dahingestellt - als psychogen bedingt ansehen, mit den von uns im Kurvenbild des Saitengalvanometers beobachteten wahrscheinlich nicht identisch sind. In unserem Falle waren die Pausen in dem Ablauf der Aktionsströme nur ausnahmsweise so groß, es fanden sich zwischen den Pausen von $1 / 25$ Sekunde bis zu der kontinuierlichen Folge von Aktionsstromschwankungen alle Übergänge.

Besonders bemerkenswert ist ferner, daß gar nicht selten eine einzelne oder zwei biphasische Schwankungen von derartigen Pausen eingerahmt werden, ein Verhalten, daß eine willkürliche oder psychogen bedingte Pausenbildung deswegen unwahrscheinlich macht, weil wir Willküraktion von $1-2$ Aktionsstromschwankungen nicht beobachtet haben.

Fall XXX. R. E., 29 Jahre alt, Kaufmann. Familienanamnese belanglos. Seit 7 Wochen verändert, Willenlosigkeit, Mutlosigkeit und Starrsinn, äußerte Lebensüberdruß, Pupillen angeblich schon seit mehr als $10 \mathrm{Jahren}$ verändert. Im Sanatorium wegen positiven Wassermanns mit Quecksilber und Salvarsan behandelt.

Bei der Aufnahme am 20. Juli 1912 innere Organe o. B. Wassermann im Blut positiv, im Liquor bei $0,2 \mathrm{ccm}$, die Zellenzahl im Liquor $10 \mathrm{im} \mathrm{cmm}$, Phase 1 stark positiv. Neurologisch: Die rechte Pupille weiter als die linke und etwas entrundet, beide reagieren ausgesprochen träge und unausgiebig auf Licht, die rechte fast starr, Konvergenzreaktion ist beiderseits etwas besser, der somatische Befund im übrigen negativ. Psychisch: Liegt völlig unbewegt mit starrer Mimik im Bett, spricht nicht. Aufforderungen werden nicht befolgt, spontane Aufmerksamkeit 
nicht zu bemerken. Bei der Pupillenuntersuchung Zusammenkneifen der Lider, gegen Stiche unzweckmäßige Abwehrbewegungen: träges und langsames Rückbeugen des Gesichtes. Er ißt nicht, Speisen behält er im Mund, sträubt sich gegen Füttern und Lumbalpunktion. Passiv gegebene Stellungen behält er bei, leichte initiale Gegenspannung, Ruhespannung nur in der Nacken- und Kiefermuskulatur, die linke Hand zeigt Andeutungen einer Contracturstellung: Finger eng aneinander geschlossen, Hand leicht gebeugt, Daumen adduziert. Haltungen werden allmählich aufgegeben. Aus dem Bette geholt, bleibt er dort stehen, wo er hingestellt wird, Haltung steif, in den nächsten Tagen keine Änderung, wird aber allmählich etwas belebter, macht gelegentlich Spontanbewegungen. Am 27. Juli werden Aufforderungen befolgt, bei der Aufforderung, den Hammer zu nehmen, ruckweise Bewegungen der Hand, die Bewegung steif und sehr langsam, auch sonst zeigen die Bewegungen Steifigkeit, Eckigkeit, sie erfolgen langsam und mit häufigen Absätzen, die motorischen Erscheinungen bestehen fort bis Ende deq

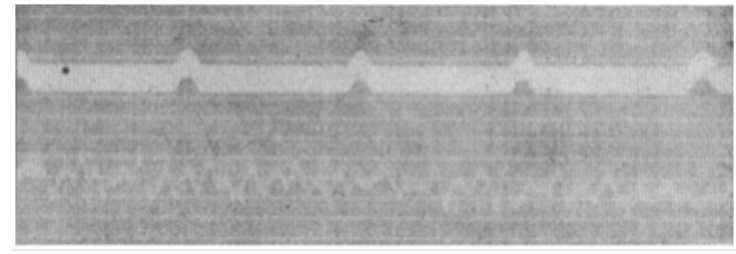

Fig. 64. Fall XXX. Progressive Paralyse. Katatones Zustandsbild. Händedruck. Langsame Rhythmen.

Monats. Ist häufig unrein, wird allmählich etwas freier, spricht mit der Frau (nicht mit dem Arzt). Die motorischen Erscheinungen stark abgeschwächt, am 2. Sept. folgendes Gespräch mit dem Arzt: (Wie gehts?) „Schlecht.“ (Warum?) „Weil mich die Leute quälen." (Sie müssen doch essen!) „Ich habe es nicht verlangt." (Wo sind Sie hier?) „Hier.“ (Kennen Sie mich?। „Nein.“

Am 21. Sept. unverändert entlassen.

Diagnose: Progressive Paralyse. Katatones Zustandsbild.

Die Aufnahme der Willküraktion der Unterarmbeuger ergab auffallend geringe Werte: $7,7,6,7,7,6,6,7,6,3,5,4,7,6,7,7,5,5$, 4, 6, 4, 6, 6, 4, 6 (Fig. 64).

Zusammenfassung: Es liegt eine Paralyse vor mit katatonem Zustandsbild. Wir sehen in der auffälligen Verminderung der Sekundenfrequenzen eine Bestätigung der an dem vorangehenden Fall gewonnenen Resultate, geben jedoch $\mathrm{zu}$, daß für die theoretische Verwertung derselben das komplizierte klinische Bild nicht günstig ist.

In den beiden folgenden Fällen von Dementia praecox haben wir trotz ausgeprägter motorischer Erscheinungen charakteristische $\mathrm{Ab}$ änderungen des Kurvenbildes vermißt.

Fall XXXI. M. N., 38 Jahre alt, Beamter. Vetter in einer Irrenanstalt gestorben. Im Winter 1911 halluzinierte er sehr heftig, glaubte die Leute sprächen über ihn, hörte Sticheleien. Am 17. März 1912 glaubte er, daß die Leute, denen er auf der Straße begegnete, geschickt seien, um ihn zu beobachten. Weinte grundlos, behauptete, seine Frau gäbe ihm Gift, lief im Hemd auf die Straße. Bei der ersten Aufnahme am 18. März 1912 halluzinierte er lehhaft, hört Stimmen, er solle noch 
heute hingerichtet werden, zeitweise starker depressiver Affekt, in Haltung und Mimik starke Gebundenheit, Flexibilitas cerea und Katalepsie. Dieser Zustand dauerte etwa 14 Tage, dann vollkommen ruhig und geordnet, wird am 3. Mai nach Hause entlassen. Arbeitete dann als Bureaubeamter bis zum 28. Sept., dann trat Gefühl der unüberwindlichen Abneigung gegen die Frau auf, es würde ihm in allem entgegengearbeitet. Schlug die Frau, ,es hätten sich Gegensätze aneinander gerieben", er machte diese Angaben (deren objektiver Tatbestand von der Frau bestätigt wird) selbst. Pathetische abstruse Ausdrucksweise in allen Außerungen, den Unterschied zwischen Kind und Zwerg erklärt er folgendermaßen: „Das Kind hat nach den Naturgesetzen eine bestimmte Größe, während der Zwerg ein Gedanke ist, der auf unnormalem Boden geht", dichtet in ähnlichem Stile, aber formal ziemlich gewandt. Die Antworten erfolgen im allgemeinen ziemlich prompt, er spricht jedoch mit monotoner Stimme, der Gesichtsausdruck ist einförmig und unbewegt, es besteht eine deutliche Verarmung der Spontanbewegungen, Aufforderungen und $Z$ weckhandlungen werden rasch und prompt vollzogen. Passiv gegebene Stellungen werden ebenso wie aktiv eingenommene beibehalten, dabei werden passiv gegebene Stellungen leicht abgeändert, die Haltung wird auch dann beibehalten, wenn Kraftleistung hierzu erforderlich ist. Der Arm bleibt gestreckt, auch wenn man einen Stuhl auf ihn hängt. Das Bein bleibt in der Hüfte gebeugt und im Kniegelenk gestreckt, auch wenn ein Gegenzug von $4 \mathrm{~kg}$ angewendet wird, Auf die Frage, weshalb er dies täte, sagte er, ,weil der Herr Doktor es angeordnet hat". Er nimmt auch eine passiv gegebene Stellung, welche ihm (anläBlich der graphischen Aufnahme) wiederholt gegeben wird, schließlich spontan ein. Bisweilen werden vorgemachte Gesten nachgemacht.

Diagnose: Dementia praecox, katatone Form.

Es wurden von Musculus quadriceps die Aktionsströme abgeleitet, nachdem ihm die oben beschriebene Beinstellung gegeben war. Die Aktionsströme zeigten keine deutliche Abweichung von der Norm: $9,8,10,8,8,10,9$ usw.

Es wurde die Ermüdung abgewartet, es traten dann Zittererscheinungen auf, die sich auch in der Kurve als Gruppierung bemerkbar machten, im übrigen auch hier normale Kurvenbilder mit folgenden Frequenzen: 5, 7, 6, 5 usw.

Wenn der Gegenzug von $4 \mathrm{~kg}$ ausgeübt wurde, waren die Kurvenbilder, wenn man davon absieht, daß die einzelnen Zacken höher waren, die gleichen. Auch die Ermüdung zeigte nichts Auffälliges.

Zusammenfassung: Bei einem Katatoniker mit kataleptischen Erscheinungen haben wir Haltungskurven aufgenommen, welche der Norm entsprechen. Es ist bemerkenswert, daß es sich, um eine Katalepsieform handelt, welche nicht mit abnormen Spannungen einhergeht und welche mit einem leichten Grad von Echopraxie verbunden ist. Der Kranke selbst gibt als Ursache des Festhaltens den supponierten Wunsch des Arztes an. Trotz allem möchten wir über die Frage der organischen oder nichtorganischen Natur dieser Katalepsieform nicht entscheiden.

Fall XXXII. P. S., 20 Jahre alt, Maurerlehrling. Bruder der Mutter in Irrenanstalt. Schwester der Mutter gestorben an Gehirnschlag mit 28 Jahren. Schon als Kind auffällig. Eigensinnig, leicht erregbar. In der letzten Zeit Stimmen. Nahm absonderiiche Haltungen ein. 
Aufgenommen am 3. Juni 1912. Er grimassiert sehr lebhaft. Liegt ruhig zu Bett, bewegt in den großen Gelenken nur wenig. Rhythmisches Zucken im rechten Quadriceps, ,das geht von den Gedanken aus". Parakinetische manierierte Gesten. Manieriertes Atmen. Eigenartige seitliche Einstellung der Augen häufig. Biegt häufig den Rücken stark ein. Zeitweise kurze schlagende Bewegungen mit den Fingern. Hypotonie in allen Gelenken. Passiv gegebene Stellungen werden ebenso wie aktiv eingenommene beibehalten. Nur erfolgen in den kleinen Gelenken meist choreiforme und athetoide Bewegungen. Sämtliche AuBerungen abstrus manieriert. ,Jede Bewegung, die ich mache, das ist der Gedanke." Somatisch im übrigen o. B. Im Verlauf der Beobachtung erheblicher Rückgang sämtlicher Erscheinungen.

Diagnose: Dementia praecox, katatone Form. Spannungen nicht a usgeprägt.

Die Aufnahme der Aktionsstromschwankungen der Unterarmbeuger ergab normale Werte: 50 pro Sekunde. Auch sonst zeigten die Kurven nichts Auffälliges.

Zusammenfassung: In einem Falle von Dementia praecox mit ausgeprägten motorischen Erscheinungen, jedoch ohne Spannungen (es bestand Hypotonie) fanden sich normale Kurvenbilder. Daß aus negativen Befunden keine Schlüsse auf lokalisierbare oder nicht lokalisierbare Schädigung gezogen werden können, zeigen unsere (negativen) Befunde bei Chorea minor und bei leichteren Graden der tabischen Ataxie.

Es zeigen unsere. Befunde, daß die Untersuchung der Aktionsströme mit dem Saitengalvanometer geeignet ist, unsere Kenntnisse von der Muskelinnervation unter pathologischen Bedingungen zu erweitern. Wir glauben, daß ein weiterer Ausbau dann möglich sein wird, wenn gesicherte experimentelle Grundlagen vorhanden sind. Jedenfalls hat die Klinik bestimmte Fragestellungen in dieser Richtung ergeben.

\section{Literaturverzeichnis.}

Nur die im Obigen erwähnten Arbeiten sind zitiert, weitere Literatur bei Piper (l. c.) und Frankfurther, Zeitschr. f. d. ges. Neur. u. Psych. Ref. Erg. 6, H. 3 (Sammelreferat).

Babinski, Sur le rôle du cervelet dans les actes volitionelles necessitant une succession rapide des mouvements (Diadoccocinésie). Rev. neurol. 10, 1013. 1902.

Bisehoff, Ein Fall von Chorea senilis. Archiv f, klin. Medizin 69, 404. 1901. Bornstein u. Sänger, Diskussionsbemerkung zu unserem Vortrag in Hamburg. Deutsche Zeitschr. f. Nervenheilk. 1912. VI. Versamml. deutsch. Nervenärzte.

Bruns, Utber einige besondere Punkte der Pathogenese der Chorea minor. Neur. Centralbl. 24, 537. 1905.

- Zur Symptomatologie der Paralysis agitans. Neurol. Zentralbl. 23, 978. 1904.

Buytendyk, Úber die elektrischen Erscheinungen bei der reflektorischen Innervation der Skelettmuskulatur des Säugetiers. Zeitschr. f. Biol. 59, 36. 1912.

Dittler, R., Utber die Innervation des Zwerchfells als Beispiel einer tonischen Innervation. Archiv f. d. ges. Physiol. 130, 400, 1909.

Ermes, Über die Natur der bei Katatonie zu beobachtenden Muskelzustände. Inaug.-Diss. Gießen 1901. 
Eulenburg, Realencyclopädie.

Fischer, Ein geheilter Fall von Polioencephalitis haemorrhag. superior usw. Zeitschr. f. d. ges. Neur. u. Psych. 8, 475. 1912.

Förster, Die Contracturen bei Erkrankungen der Pyramidenbahn. 1906.

- Die Koordination. 1902.

Forster, Paralysis agitans. Handbuch der Neurologie 3.

Gilles de la Tourette u. Charcot, Le syndrôme de Benedikt. La semaine méd. 1900, S. 127; zit. nach Halban u. Infeld.

Gregor u. Hänsel, Beiträge zur Kenntnis der Störung außerer Willenshandlungen. 2. Mitt. Monatsschr. f. Neur. u. Psych. 26, 87. 1909.

Halban u. Infeld, Zur Pathologie der Hirnschenkelhaube. Obersteiners Arbeiten 9, 329. 1902.

Heilbronner, Zur Symptomatologie der Hemiplegie. Deutsche Zeitschr. f. Nervenheilkunde 28, 1. 1905.

Hering, E. H., Beitrag zur Frage der gleichzeitigen Tätigkeit antagonistisch wirkender Muskeln. Zeitschr. f. Heilk. 16. 1895.

- Beitrag zur experimentellen Analyse koordinierter Bewegungen. Archiv f. d. ges. Physiol. 70. 559. 1898.

Hering u. Sherrington, Über Hemmung der Kontraktion willkürlicher Muskeln bei elektrischer Reizung der Großhirnrinde. Archiv f. d. ges. Physiol. 68. 1897.

Hoffmann, Ưber die Innervation der reflektorisch ausgelösten Kontraktionen beim normalen und strychninvergifteten Frosch. Archiv f. Anat. u. Physiol., physiol. Abt. 1911, s. 233. Jahrg. 1910, Supplementband.

- Utber die Innervation des Muskels bei Großhirnreizung. Ebendaselbst S. 286.

Isserlin, M., Über den Ablauf einfacher willkürlicher Bewegungen. Kraepelins psycholog. Arbeiten 6, 1. 1910.

- u. F. Lotmar, Ưber den Ablauf einfacher willkürlicher Bewegungen bei einigen Nerven- und Geisteskranken. Vorläuf. Mitteil. Zeitschr. f. d. ges. Neur. u. Psych. 10, 198. 1912.

Janischewsky, Un cas de maladie de Parkinson avec syndrôme pseudobulbaire et pseudoophtalmoplegique. Quelques considerations sur la pathogénie de cette maladie. Revue neurol. 17, No. 13. 1909.

Kahlbaum, Die Katatonie. 1874.

Kleist, Untersuchungen an Geisteskranken mit psychomotorischen Störungen. Leipzig 1908.

- Weitere Untersuchungen an Geisteskranken mit psychomotorischen Störungen. Leipzig 1909.

- Über nachdauernde Muskelkontraktion. Journal f. Neur. u. Psych. 10, 95. 1908.

- Utber corticale Apraxie. Jahrb. f. Psych. 28, 46. 1907.

Kö nig, Zur Psychopathologie der Paralysis agitans. Archiv f. Psych. 50, 285. 1912.

Lewandowsky, Bemerkungen über die hemiplegische Contractur. Deutsche Zeitschr. f. Nervenheilk. 29, 208. 1905.

- Über die Bewegungsstörung der infantilen cerebralen Hemiplegie und die Athétose double. Deutsche Zeitschr. f. Nervenheilk. 29, 339. 1905.

- Handbuch der Neurologie 1 (2). 1910.

Mann, Utber das Wesen und die Entstehung der hemiplegischen Contractur. Monatsschr. f. Neur. u. Psych. 4. 45, 123, 1898.

Marcuse, Benediktsches Syndrom und seltene Tumoren des Hirnstammes. Zeitschr. f. d. ges. Neur. u. Psych. 12, 281. 1912.

Muratow, Ưber die protrahierten corticalen Krämpfe bei der allgemeinen Paralyse. Neur. Centralbl. 16, 194. 1897. 
Oppenheim, Lehrbuch der Nervenkrankheiten. 1908.

- Kleine Beiträge zur Neuropathie. Journal f. Psych. 1, 129. 1902/3.

Pfahl, Die genauere Untersuchung der verschiedensten Bewegungsvorgänge, namentlich der willkürlichen Vorgänge mittels graphischer Methoden. Klinik f. psych. u. neuro. Krankh. v. Sommer 6, H. 1 u. 2.

Piper, Elektrophysiologie menschlicher Muskeln. Berlin 1912.

Schilder, Ưber Chorea und Athetose. II. u. III. Mitt. Zeitschr. f. d. ges. Neur u. Psych. 11, 26 u. 47. 1912.

Simons u. Hoffmann, Crampi bei amyotrophischer Lateralsklerose. Zeitschr. f. d. gesamte Neurol. u. Psych. V, 23. 1911.

Valckenburg, Beitrag zur Analyse der cerebralen Hemiplegie. Archiv f. Psych. 43, 899. 1908.

Wernicke, Lehrbuch der Psychiatrie, 2. Aufl. 1905.

Wertheim Salomonson, Clonus of organic and functional origin. Folia neurobiol. 4, 1. 1910.

Zingerle, Utber Paralysis agitans. Journ. f. Neur. u. Psych. 14, 80. 1909. 